\title{
Timescales and settings for alteration of chondritic meteorites
}

A. N. Krot, I. D. Hutcheon, A. J. Brearley, O. V. Pravdivtseva, M. I. Petaev, C. M. Hohenberg

November 21, 2005

Meteorites and the Early Solar System II 
This document was prepared as an account of work sponsored by an agency of the United States Government. Neither the United States Government nor the University of California nor any of their employees, makes any warranty, express or implied, or assumes any legal liability or responsibility for the accuracy, completeness, or usefulness of any information, apparatus, product, or process disclosed, or represents that its use would not infringe privately owned rights. Reference herein to any specific commercial product, process, or service by trade name, trademark, manufacturer, or otherwise, does not necessarily constitute or imply its endorsement, recommendation, or favoring by the United States Government or the University of California. The views and opinions of authors expressed herein do not necessarily state or reflect those of the United States Government or the University of California, and shall not be used for advertising or product endorsement purposes.

This work was performed under the auspices of the U.S. Department of Energy by University of California, Lawrence Livermore National Laboratory under Contract W-7405-Eng-48. 


\title{
Timescales and Settings for Alteration of Chondritic Meteorites
}

\author{
Alexander N. Krot \\ University of Hawai'i at Manoa \\ Ian D. Hutcheon \\ Lawrence Livermore National Laboratory \\ Adrian J. Brearley \\ University of New Mexico \\ Olga V. Pravdivtseva \\ Washington University \\ Michael I. Petaev \\ Harvard University \\ Charles M. Hohenberg \\ Washington University
}

\begin{abstract}
Most groups of chondritic meteorites experienced diverse styles of secondary alteration to various degrees that resulted in formation of hydrous and anhydrous minerals (e.g., phyllosilicates, magnetite, carbonates, ferrous olivine, hedenbergite, wollastonite, grossular, andradite, nepheline, sodalite, Fe,Ni-carbides, pentlandite, pyrrhotite, Ni-rich metal). Mineralogical, petrographic, and isotopic observations suggest that the alteration occurred in the presence of aqueous solutions under variable conditions (temperature, water/rock ratio, redox conditions, and fluid compositions) in an asteroidal setting, and, in many cases, was multistage. Although some alteration predated agglomeration of the final chondrite asteroidal bodies (i.e. was pre-accretionary), it seems highly unlikely that the alteration occurred in the solar nebula, nor in planetesimals of earlier generations. Short-lived isotope chronologies $\left({ }^{26} \mathrm{Al}-{ }^{26} \mathrm{Mg},{ }^{53} \mathrm{Mn}-{ }^{53} \mathrm{Cr},{ }^{129} \mathrm{I}-{ }^{129} \mathrm{Xe}\right)$ of the secondary minerals indicate that the alteration started within 1-2 Ma after formation of the Ca,Al-rich inclusions and lasted up to $15 \mathrm{Ma}$. These observations suggest that chondrite parent bodies must have accreted within the first 1-2 Ma after collapse of the protosolar molecular cloud and provide strong evidence for an early onset of aqueous activity on these bodies.
\end{abstract}




\section{INTRODUCTION}

In this chapter, we review the mineralogy, petrology, and time-scales for secondary alteration of type 1-3 carbonaceous (CI, CM, CR, CV, and ungrouped carbonaceous chondrite MAC88107), enstatite and ordinary chondrites that resulted in the formation of hydrous and anhydrous minerals (e.g., phyllosilicates, carbonates, magnetite, Ni-bearing sulfides, fayalite, ferrous olivine, andradite, hedenbergite, wollastonite, grossular, nepheline, sodalite). Although thermal and shock metamorphism are also among the secondary processes which affected most chondritic meteorites and resulted in some mineralogical modifications, the ages of these processes are not discussed here.

Chondrites consist of four major components: chondrules, Fe,Ni-metal grains and/or metaltroilite aggregates, refractory inclusions [Ca,Al-rich inclusions (CAIs) and amoeboid olivine aggregates (AOAs)], and fine-grained matrix material. The only exception is CI chondrites which lack chondrules, refractory inclusions, and Fe,Ni-metal grains. In addition, some chondrites contain foreign lithic clasts. It is generally believed that the refractory inclusions, chondrules, and Fe,Ni-metal formed in the solar nebula by high temperature processes that included evaporation and condensation. Many CAIs and most chondrules and Fe,Ni-metal were subsequently melted during multiple brief heating episodes. The refractory inclusions are considered to be the oldest solids formed in the solar nebula 4567.2 \pm 0.6 Ma ago (Amelin et al., 2002). Chondrule formation appears to have started less than $1 \mathrm{Myr}$ after CAIs and lasted for at least 4 Myr (Amelin et al., 2004; Bizzarro et al., 2004). Chondrules and matrices in a primitive chondrite are chemically complementary (Bland, pers. comm., 2004), suggesting that most of the

matrix materials could have been thermally processed during chondrule formation (Scott and Krot, 2004). 
Most chondrite groups show evidence for relatively low temperature alteration that affected all their chondritic components (Brearley and Jones, 1998). The nature of this alteration remains controversial and has been attributed to nebular (or pre-accretionary) and/or asteroidal processing (e.g., Brearley, 2003). Timing of the alteration using short-lived chronology such as ${ }^{26} \mathrm{Al}-{ }^{26} \mathrm{Mg},{ }^{53} \mathrm{Mn}-{ }^{53} \mathrm{Cr}$, and ${ }^{129} \mathrm{I}-{ }^{129} \mathrm{Xe}$, can potentially resolve this controversy and constrain ages of chondrule formation and time of accretion of the chondrite parent asteroids. We note that because the life time of the solar nebula is poorly constrained (Podosek and Cassen, 1994), dating of secondary alteration alone typically cannot distinguish between nebular and asteroidal settings of alteration, which should be based on mineralogical and isotopic (e.g., oxygen) observations, thermodynamic analysis, and petrologic experiments. At the same time, the prolonged duration of alteration and similar ages of alteration to other asteroidal processes, such as thermal metamorphism and igneous differentiation, favor asteroidal settings of alteration. Since the environment of alteration (nebular vs. asteroidal) remains controversial, in each section we briefly summarize the mineralogical, petrologic and isotopic (oxygen isotopic compositions) arguments supporting nebular or asteroidal settings for the alteration of a chondrite group (see also Brearley, 2003, 2005).

\section{SHORT-LIVED ISOTOPE CHRONOLOGY OF SECONDARY ALTERATION OF CHONDRITIC METEORITES}

\section{1. ${ }^{26} \mathrm{Al}-{ }^{26} \mathrm{Mg}$ Ages}

${ }^{26} \mathrm{Al}$ is a short-lived radionuclide that $\beta$-decays to ${ }^{26} \mathrm{Mg}$ with a half-life of $\sim 0.73 \mathrm{Ma}$. Excess ${ }^{26} \mathrm{Mg}\left({ }^{26} \mathrm{Mg}^{*}\right)$ can be detected by secondary ionization mass spectrometry (SIMS) or by other mass spectrometric techniques in bulk samples or mineral fractions [e.g., thermal 
ionization mass spectrometry (TIMS) and inductively coupled plasma mass spectrometry (ICPMS)]. If ${ }^{26} \mathrm{Mg}^{*}$ is derived from in situ decay of ${ }^{26} \mathrm{Al}$, then the data points plotted as $\delta^{26} \mathrm{Mg}$ [permil (\%) deviation from the terrestrial ${ }^{26} \mathrm{Mg} /{ }^{24} \mathrm{Mg}$ ratio of 0.13932 ] against the ${ }^{27} \mathrm{Al} /{ }^{24} \mathrm{Mg}$ ratio will define a straight line (Al-Mg isochron) with the slope proportional to ${ }^{26} \mathrm{Al} /{ }^{27} \mathrm{Al}$ at the time of $\mathrm{Al}-\mathrm{Mg}$ isotope system closure. Based on the measured abundances of ${ }^{26} \mathrm{Mg} *$ in numerous CAIs, the solar system initial ${ }^{26} \mathrm{Al} /{ }^{27} \mathrm{Al}$ ratio, called "canonical", is estimated to be $\sim 5 \times 10^{-5}$ (e.g., MacPherson et al., 1995; Bizzarro et al., 2004). The difference in the initial ${ }^{26} \mathrm{Al} /{ }^{27} \mathrm{Al}$ ratios between the unknown sample and the canonical ${ }^{26} \mathrm{Al} /{ }^{27} \mathrm{Al}$ ratio in CAIs corresponds to their relative formation age:

$$
\Delta t_{\text {sample-CAI }}(\mathrm{Ma})=1 / \lambda \times \ln \left[\left({ }^{26} \mathrm{Al} /{ }^{27} \mathrm{Al}\right)_{\mathrm{CAI}} /\left({ }^{26} \mathrm{Al} /{ }^{27} \mathrm{Al}\right)_{\text {sample }}\right],
$$

where $\lambda=\ln 2 / 0.73$ is the ${ }^{26} \mathrm{Al}$ decay constant; negative/positive values correspond to older/younger ages than CAIs with a canonical ${ }^{26} \mathrm{Al} /{ }^{27} \mathrm{Al}$ ratio.

\section{2. ${ }^{53} \mathrm{Mn}-{ }^{53} \mathrm{Cr}$ Ages}

${ }^{53} \mathrm{Mn}$ is a short-lived radionuclide that $\beta$-decays to ${ }^{53} \mathrm{Cr}$ with a half-life of $\sim 3.7 \mathrm{Ma}$ (Lugmair and Shukolyukov, 1998). This half-life and the fact that $\mathrm{Mn}$ and $\mathrm{Cr}$ are reasonably abundant elements that experienced extensive fractionation during aqueous alteration, make the ${ }^{53} \mathrm{Mn}-{ }^{53} \mathrm{Cr}$ chronometer very useful for dating aqueous activity on chondrite parent asteroids (e.g., formation of carbonates and fayalite).

The excess of ${ }^{53} \mathrm{Cr}\left({ }^{53} \mathrm{Cr} *\right.$ relative to the terrestrial ${ }^{53} \mathrm{Cr} /{ }^{52} \mathrm{Cr}$ ratio of 0.113458 (Papanastassiou, 1986) can be detected by SIMS in individual minerals having high $(>100)$ $\mathrm{Mn} / \mathrm{Cr}$ ratios, which can yield a high concentration of radiogenic ${ }^{53} \mathrm{Cr}$, with minimal interference from non-radiogenic Cr. If ${ }^{53} \mathrm{Cr}^{*}$ is derived from in situ decay of ${ }^{53} \mathrm{Mn}$, then the data points 
plotted as $\delta^{53} \mathrm{Cr}$ (\%o deviation from the terrestrial ${ }^{53} \mathrm{Cr} /{ }^{52} \mathrm{Cr}$ ratio) against ${ }^{55} \mathrm{Mn} /{ }^{52} \mathrm{Cr}$ ratio will define a straight line (Mn-Cr isochron) with the slope proportional to ${ }^{53} \mathrm{Mn} /{ }^{55} \mathrm{Mn}$ ratio at the time of the isotope closure of $\mathrm{Mn}-\mathrm{Cr}$ system. The relative ages of two samples, 1 and 2, are then calculated from their ${ }^{53} \mathrm{Mn} /{ }^{55} \mathrm{Mn}$ ratios:

$$
\Delta t_{1-2}(\mathrm{Ma})=1 / \lambda \times \ln \left[\left({ }^{53} \mathrm{Mn} /{ }^{55} \mathrm{Mn}\right)_{2} /\left({ }^{53} \mathrm{Mn} /{ }^{55} \mathrm{Mn}\right)_{1}\right],
$$

where $\lambda=\ln 2 / 3.7$ is the ${ }^{53} \mathrm{Mn}$ decay constant. Due to the uncertainty in the solar system initial abundance of ${ }^{53} \mathrm{Mn}$ [estimates range from $0.84 \times 10^{-5}$ (Lugmair and Shukolyukov, 1998) to $1.4 \times 10^{-}$ ${ }^{5}$ (Lugmair and Shukolyukov, 2001) to $(2.8 \pm 0.3) \times 10^{-5}$ (Nyquist et al., 2001) to $4.4 \times 10^{-5}$ (Birck and Allègre, 1988; Birck et al, 1999)], the Mn-Cr ages discussed below are given relative to the $\left({ }^{53} \mathrm{Mn} /{ }^{55} \mathrm{Mn}\right)_{0}$ ratio of $(1.25 \pm 0.07) \times 10^{-6}$ for the angrite Lewis Cliff (LEW) $86010\left(\Delta \mathrm{t}_{\mathrm{LEW}}\right)$ that has the absolute age determined by $\mathrm{Pb} / \mathrm{Pb}$ of $4557.8 \pm 0.5 \mathrm{Ma}$ (Lugmair and Shukolyukov, 1998).

\section{3. ${ }^{129} \mathrm{I}-{ }^{129}$ Xe Ages}

The incorporation of live ${ }^{129}$ I into solid matter in the early solar system and subsequent $\beta$ decay resulted in production of its stable ${ }^{129} \mathrm{Xe}$ daughter $\left({ }^{129 *} \mathrm{Xe}\right)$ at iodine-bearing sites. Isotopic closure, achieved when I and Xe migration ceased, preserved a parent-daughter record that is observable today in whole-rock samples or mineral separates in many meteorites. If no Xe losses have occurred, the ratio of radiogenic ${ }^{129 *} \mathrm{Xe}$ to stable ${ }^{127} \mathrm{I}$ equals the value for the initial iodine $\left({ }^{129} \mathrm{I} /{ }^{127} \mathrm{I}\right)$ at the time of isotopic closure. Due to the 15.7 Ma half-life of ${ }^{129} \mathrm{I},{ }^{129} \mathrm{I} /{ }^{127} \mathrm{I}$ evolved rapidly in the early solar system. Differences in this initial iodine among meteoritic samples form the basis of I-Xe dating (Reynolds, 1960). The analytical technique of I-Xe dating involves neutron irradiation in a reactor, which converts a fraction of ${ }^{127} \mathrm{I}$ to ${ }^{128^{*}} \mathrm{Xe}\left[{ }^{127} \mathrm{I}(n, \gamma \beta) \rightarrow{ }^{128^{*}} \mathrm{Xe}\right]$. Correlated quantities of two iodine derived Xe isotopes $\left({ }^{129 *} \mathrm{Xe}\right.$ and $\left.{ }^{128^{*}} \mathrm{Xe}\right)$ released in stepwise 
pyrolysis and measured by ion counting mass spectrometry (Hohenberg, 1980). The simplicity of this technique is enhanced by including in the irradiation a meteorite standard of known age (Nichols et al., 1994) with the relative I-Xe age then given by the relative slopes of the isochrons. Typically, the ratio of ${ }^{129} \mathrm{Xe}$ to some Xe isotope not produced in the irradiation, such as ${ }^{130} \mathrm{Xe}$ or ${ }^{132} \mathrm{Xe}$, is plotted against the ratio of ${ }^{128} \mathrm{Xe}$ to that same isotope. The choice of ${ }^{130} \mathrm{Xe}$ or ${ }^{132} \mathrm{Xe}$ normalization is usually determined by the relative correction (if any) for spallation or fission effects, respectively, at these isotopes. If the ${ }^{128^{*}} \mathrm{Xe}$ and ${ }^{129 *} \mathrm{Xe}$ are both derived from iodine of uniform isotopic composition, then the data points will define a straight line (I-Xe isochron), with the slope proportional to the ${ }^{129} \mathrm{I} /{ }^{127} \mathrm{I}$ ratio at the last time Xe isotopes were in equilibrium (Swindle and Podosek, 1988). The I-Xe isochron is thus a two-component mixture of trapped and I-derived Xe. The trapped Xe component is confined to lie at the lower end of this isochron and typically of "planetary" composition (Lavielle and Marti, 1992). Therefore, I-Xe ages are calculated directly from the differences in isochron slopes $\left({ }^{129 *} \mathrm{Xe} /{ }^{128^{*}} \mathrm{Xe}\right)_{\text {sample }}$ with that of the standard $\left({ }^{129 *} \mathrm{Xe} /{ }^{128 *} \mathrm{Xe}\right)_{\text {standard }}$ (Shallowater aubrite or Bjurböle L4 ordinary chondrite; Bjurböle predates Shallowater by 460,000 yrs, Brazzle et al., 1999):

(3) $\Delta t_{\text {sample-Shallowater }}(\mathrm{Ma})=1 / \lambda \times \ln \left[\left({ }^{129} \mathrm{I} /{ }^{127} \mathrm{I}\right)_{\text {Shallowater }} /\left({ }^{129} \mathrm{I} /{ }^{127} \mathrm{I}\right)\right.$ sample $]$,

where $\lambda=\ln 2 / 15.7$ is the ${ }^{129} \mathrm{I}$ decay constant; negative/positive values correspond to older/younger ages than Shallowater. Based on the comparison of I-Xe and Mn-Cr systems with the absolute $\mathrm{Pb}-\mathrm{Pb}$ chronometer for samples analysed by mulitple systems, Gilmour et al. (work in progress) concluded that the I-Xe system closed in Shallowater aubrite 5.7 \pm 1.1 Ma earlier than the Mn-Cr system closed in LEW86010 angrite, at 4563.5 \pm 1.0 Ma before the present. Use of St. Severin as internal standard during the early measurements (e.g., Zaikowski, 1980), which was later shown to be inhomogeneous (Hohenberg et al., 1981), makes these measurements difficult 
to compare with recent results, although the relative ages should be meaningful (Pravdivtseva et al., 2003a).

Because iodine is a mobile element, the I-Xe chronometry has been shown to be a promising technique for dating secondary alteration processes, that is capable of resolving age differences of a few hundred thousand years between closure times of different mineral phases from the same meteorite (e.g., Swindle, 1998; Brazzle et al., 1999; Pravdivtseva and Hohenberg, 2001; Pravdivtseva et al., 2001, 2003a-c; Hohenberg et al., 2004). Special attention, however, must be paid to proper selection and preparation of the samples for I-Xe dating, and to its interpretation (what mineral phases or process are being dated), which should be based on detailed mineralogical study (e.g., Krot et al., 1999). If samples contain more than one iodine-bearing phase and if the different mineralogical sites degas with different time-temperature profiles, stepwise pyrolysis can simulate mineral separation (Swindle, 1998). Whole-rock samples occasionally produce well-defined isochrons, but the results cannot be adequately interpreted if the major iodine carrier phase is unknown (e.g., Kennedy et al., 1988). On the other hand, some chondritic components such as chondrules, CAIs, lithic chondritic clasts (often called "dark inclusions"), although representing mixtures of several mineral phases, can often be studied as simple objects if the major iodine carrier can be identified (e.g., Kirschbaum, 1988).

\section{TIMESCALES AND SETTINGS FOR SECONDARY ALTERATION OF CHONDRITIC METEORITES}

\subsection{Timescale of Aqueous Alteration of CI Chondrites}

Although CI chondrites are chemically the most primitive meteorites in that they provide the best compositional match to the solar photosphere (Anders and Grevesse, 1989; Palme and 
Jones, 2003), their primary mineralogy and petrography were erased by extensive aqueous alteration at $\sim 50-150^{\circ} \mathrm{C}$ on their parent body (e.g., Richardson, 1978; McSween, 1979; Kerridge et al., 1979a,b; Bunch and Chang, 1980; Clayton and Mayeda, 1984; Zolensky et al., 1989; Endress and Bischoff, 1996; Endress et al., 1996; Leshin et al., 1997). Subsequently, some CI chondrites experienced thermal metamorphism (e.g., Tonui et al., 2003). All known CI chondrites are regolith breccias consisting of various types (lithologies) of heavily-hydrated lithic fragments composed of a fine-grained phyllosilicate-rich matrix containing magnetite, sulfides, sulfates, and carbonates. The fragments are cemented by networks of secondary Ca- and Mg-sulfate veins which could be of terrestrial origin (Gounelle and Zolensky, 2001).

Four chemically distinct types of carbonates are found in CI chondrites: dolomite [CaMg$\left.\left(\mathrm{CO}_{3}\right)_{2}\right]$, breunnerite $\left[\mathrm{Mg}(\mathrm{Fe}, \mathrm{Mn})\left(\mathrm{CO}_{3}\right)_{2}\right]$, calcite $\left(\mathrm{CaCO}_{3}\right)$ and Mg,Ca-bearing siderite $\left(\mathrm{FeCO}_{3}\right)$, with dolomite being the dominant phase (Richardson, 1978; Fredriksson and Kerridge, 1988; Johnson and Prinz, 1993; Riciputi et al., 1994; Endress and Bischoff, 1996). Mineralogical and isotopic (oxygen, carbon) observations suggest that the carbonates precipitated from aqueous solutions circulating on the CI parent body (e.g., Clayton and Mayeda, 1984; Grady et al., 1988; Endress and Bischoff, 1996; Leshin et al., 2001). Carbonates are commonly intergrown with magnetite of different textural types (platelet, framboidal, spherulitic), phosphates, and sulfides, suggesting a related paragenesis (Endress and Bischoff, 1996). Based on the chemical differences among dolomites within and among CI chondrites and petrographic observations of dissolution textures, composite grains etc., Endress et al. (1996) concluded that several episodes of aqueous alteration occurred on the CI parent body. In spite of such complexity, there have been no attempts yet to combine petrographic observations with isotopic measurements to date the different episodes of aqueous activity of the CI parent body. 


\subsubsection{Strontium isotope dating of CI carbonates}

Strontium isotope measurements of carbonate separates from the CI chondrite Orgueil reveal that dolomite and breunnerite formed within $50 \mathrm{Myr}$ after accretion of its parent body (Macdougal et al., 1984; Macdougal and Lugmair, 1989). Relatively large variations of ${ }^{87} \mathrm{Sr} /{ }^{86} \mathrm{Sr}$ ratios (0.699-0.702) observed among different carbonates suggest different formation times for different types of CI carbonates (Macdougal et al., 1984).

\subsubsection{Chromium isotope dating of CI carbonates}

Scatena-Wachel et al. (1984) reported ${ }^{53} \mathrm{Cr}^{*}$ corresponding to an upper limit for the ${ }^{53} \mathrm{Mn} /{ }^{55} \mathrm{Mn}$ ratio of $3.8 \times 10^{-7}$ in a breunnerite grain from Orgueil, but did not draw any conclusion about the timescale of aqueous activity. Subsequently Endress et al. (1996) measured Cr-isotope compositions of five dolomite fragments from the CI chondrites Orgueil and Ivuna. These fragments occur between lithic clasts and are not genetically related to lithological units; they may represent debris of former carbonate veins, which were subsequently destroyed and distributed during impact-induced regolith gardening (Endress and Bischoff, 1996). All five fragments show ${ }^{53} \mathrm{Cr} *$ linearly correlated with the ${ }^{55} \mathrm{Mn} /{ }^{52} \mathrm{Cr}$ ratios, indicative of in situ decay of ${ }^{53} \mathrm{Mn}$ (Figs. 1a,b). The data points for two fragments from Orgueil and for an Ivuna fragment plot along a line corresponding to the initial ${ }^{53} \mathrm{Mn} /{ }^{55} \mathrm{Mn}$ ratio of $(1.99 \pm 0.16) \times 10^{-6}$; the data points for two other fragments from Orgueil define a line with slope $(1.42 \pm 0.16) \times 10^{-6}$. The difference between the lines, if significant, corresponds to a time difference of 1.8 Ma. Alternatively, all five carbonates formed contemporaneously, but some of the Orgueil carbonates experienced partial isotopic equilibration of the Mn-Cr system (Endress et al., 1996).

Subsequently, evidence for live ${ }^{53} \mathrm{Mn}$ in isolated carbonate grains from Orgueil (Fig. 1c; see also Fig. 1 in Hoppe et al., 2004) and a CI-like clast from the Supuhee (H6) chondrite breccia 
(Fig. 1d) have been reported by Hutcheon and Phinney (1996), Hutcheon et al. (1997), and Hoppe et al. (2001). Chromium isotope measurements in Orgueil carbonates imply ${ }^{53} \mathrm{Mn} /{ }^{55} \mathrm{Mn}$ ratio ranging from $(1.77 \pm 0.15) \times 10^{-6}$ to $(3.88 \pm 0.39) \times 10^{-6}$ at the time of formation of these grains. This difference in slope was interpreted as (i) it may indicate isotopic disequilibrium among carbonates subjected to several alteration events reflecting either the growth of carbonates from isotopically disparate fluids or partial $\mathrm{Cr}$ isotopic reequilibration, or (ii) it may have chronological significance, corresponding to an interval of $\sim 4$ Myr between episodes of aqueous activity. The latter is consistent with the variation in the times of formation of dolomites and breunnerites suggested from Sr isotope studies (Macdoudal and Lugmair, 1989). Chromium isotope measurements of carbonates in Supuhee define a correlation line with a slope corresponding to $\left({ }^{53} \mathrm{Mn} /{ }^{55} \mathrm{Mn}\right)_{0}$ ratio of $(8 \pm 4) \times 10^{-6}$, suggesting that the aqueous activity on the CI-like parent body started earlier than recorded by the Orgueil carbonates (Hutcheon et al., 1997).

The observed range in the initial ${ }^{53} \mathrm{Mn} /{ }^{55} \mathrm{Mn}$ ratios in CI carbonates [from $(1.42 \pm 0.16) \times 10^{-6}$ to $\left.(8 \pm 4) \times 10^{-6}\right]$ corresponds to an age difference of $\sim 9$ Ma and may represent the duration of aqueous activity of the CI parent body that started $\sim 10 \pm 3$ Ma prior to differentiation of the angrite parent body.

\subsubsection{Iodine-xenon isotope dating of CI magnetites}

Jeffery and Anders (1970) showed that the trapped Xe resided mostly in phyllosilicates and the radiogenic ${ }^{129}$ Xe in magnetite of Orgueil. Later, Herzog et al. (1973) and Lewis and Anders (1975) reported the apparent I-Xe age of the Orgueil magnetites as being 7 Myr older than Shallowater and interpreted this age as the condensation time of the solar nebula. These results and interpretation are clearly inconsistent with petrographic evidence for asteroidal formation of 
magnetite (e.g., Kerridge et al., 1979a) and with relatively young ${ }^{53} \mathrm{Mn}-{ }^{53} \mathrm{Cr}$ and ${ }^{87} \mathrm{Sr} /{ }^{86} \mathrm{Sr}$ ages of carbonates described above. Recent reexamination of the anomalous ${ }^{129} \mathrm{I}-{ }^{129} \mathrm{Xe}$ age of Orgueil magnetite (fraction containing $>90 \%$ magnetite) showed much later closing time of the I-Xe

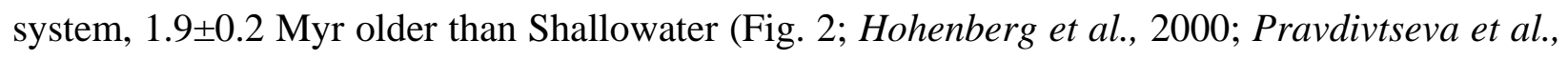
2003b). The differences between the two studies are probably due to difficulties with the irradiation monitors in the early studies (Hohenberg et al., 2000).

For a highly magnetic fraction (composed of $\sim 14 \%$ magnetite and $\sim 86 \%$ hydrated carbonaceous material) separated from Orgueil with a hand magnet, the I-Xe ages are 3.0 \pm 0.4 Myr (Hohenberg et al., 2000) and 1.5 \pm 0.3 Myr (Pravdivtseva et al., 2003b) younger than Shallowater, suggesting that the magnetic fraction may contain several iodine carriers recording different stages of aqueous activity on the CI parent body. This is consistent with oxygen isotopic compositions of separated components from CI chondrites (Fig. 3). In each CI chondrite, magnetite ( $\Delta^{17} \mathrm{O}=1.3 \%$ o to $1.8 \%$ ) is out of oxygen isotopic equilibrium with the phyllosilicates $\left(\Delta^{17} \mathrm{O}=-0.3 \%\right.$ to $0.3 \%$ ), suggesting that phyllosilicates continued to equilibrate with water as anhydrous silicates are progressively altered to phyllosilicates, whereas isotope exchange between magnetite and fluid was kinetically slow (Rowe et al., 1994). Carbonates $\left(\Delta^{17} \mathrm{O}=0.3 \%\right.$ to $0.5 \%$ ) are in isotopic equilibrium with phyllosilicates (Leshin et al., 2001), suggesting precipitation from a fluid of similar oxygen isotopic composition.

\subsection{Timescale of Aqueous Alteration of the Polymict Chondrite Breccia Kaidun: Evidence from Chromium Isotope Compositions of Carbonates}

Kaidun is a polymict chondrite breccia containing lithic clasts of the C1, CM-like, CR-like, CV, R, EH, and EL chondrites (Clayton and Mayeda, 1999; Zolensky and Ivanov, 2003). Most 
clasts have been extensively altered at $\sim 250-450^{\circ} \mathrm{C}$ by hydrothermal fluids that resulted in formation of phyllosilicates, and carbonate- and phyllosilicate-filled veins (Johnson and Prinz, 1993; Weisberg et al., 1994; Zolensky et al., 1996). All lithic clasts contain carbonates, with calcite being the dominant phase; dolomite is less abundant (Johnson and Prinz, 1993; Weisberg et al., 1994). Calcite occurs within altered chondrules, CAIs and mineral fragments, and as fragments dispersed throughout the matrix and in veins. The veins occur along the boundaries between lithic clasts, suggesting some calcite formed after agglomeration of the Kaidun breccia.

Chromium isotopic compositions of five calcite and one dolomite grain from three different lithologies (CR-like, CM1, and C1) measured by Hutcheon et al. (1999) are plotted in Figure 4a. The slope of the correlation line on a ${ }^{53} \mathrm{Mn}-{ }^{53} \mathrm{Cr}$ evolution diagram corresponds to an initial ${ }^{53} \mathrm{Mn} /{ }^{55} \mathrm{Mn}$ ratio of $(9.4 \pm 1.6) \times 10^{-6}$, suggesting nearly contemporaneous formation of carbonates in the lithologies studied $\left(\Delta \mathrm{t}_{\mathrm{LEW}} \sim 10.8 \pm 1 \mathrm{Myr}\right)$.

\subsection{Timescale of Aqueous Alteration of CM chondrites}

The CM carbonaceous chondrites are a diverse group of petrologic type 1-2 meteorites that experienced low-temperature $\left(\sim 0-25^{\circ} \mathrm{C}\right)$ aqueous alteration to various degrees in an asteroidal setting that resulted in formation of a variety of secondary phases, including phyllosilicates, magnetite, Fe,Ni-sulfides, and carbonates (e.g., Kerridge and Bunch, 1979; Zolensky and McSween, 1988; Zolensky et al., 1993; Brearley and Jones, 1998). Some CM chondrites [e.g., Begica-7904, Yamato (Y) 86720] subsequently experienced thermal metamorphism and partial dehydration (e.g., Tomeoka et al., 1989; Tomeoka, 1990; Ikeda, 1992; Clayton and Mayeda, 1999). 
Detailed mineralogical and isotopic studies of CM carbonates revealed their complex formation history, involving periods of dissolution and reprecipitation due to interactions with fluids of different compositions (e.g., Zolensky et al., 1989; Johnson and Prinz, 1993; Riciputi et al., 1994; Brearley et al., 1999, 2001; Brearley and Hutcheon, 2000, 2002; Benedix et al., 2003). Carbonates occur in fine-grained rims around chondrules and mineral fragments and within altered CAIs (e.g., Bunch and Chang, 1980). There is no common association of carbonates with other phases in CM chondrites, although textural observations suggest that carbonates must have coprecipitated with phyllosilicates, magnetite, and tochilinite (e.g., Kerridge and Bunch, 1979; Bunch and Chang, 1980; Barber, 1981; Mackinnon et al., 1984; Johnson and Prinz, 1993). However, oxygen isotope compositions of carbonates (Clayton and Mayeda, 1984; Brearley et al., 1999; Benedix et al., 2003), magnetite (Rowe et al., 1994), and phyllosilicate-rich matrix (Clayton and Mayeda, 1984) in the CM chondrite Murchison (Fig. 3) indicate that the phyllosilicates are not in isotope equilibrium with carbonates and magnetite. It is suggested that carbonates and magnetites precipitated from an isotopically evolving water reservoir, prior to formation of phyllosilicates (Rowe et al., 1994; Brearley et al., 1999; Benedix et al., 2003). Timing of aqueous activity on the CM parent body remains poorly constrained and is largely based on a limited number of chromium isotope measurements in carbonates (Brearley and Hutcheon, 2000; Brearley et al., 2002).

\subsubsection{Chromium isotope dating of CM carbonate formation}

In the relatively weakly-altered and virtually unbrecciated CM chondrite Y791198 calcite is the only carbonate present. Calcite grains show complex zoning indicating periods of dissolution and reprecipitation (Brearley et al., 2001). Three out of six calcite grains analyzed for Cr isotopic

compositions showed the presence of ${ }^{53} \mathrm{Cr}^{*}$ correlated with the respective ${ }^{55} \mathrm{Mn} /{ }^{52} \mathrm{Cr}$ ratios, 
indicating in situ decay of ${ }^{53} \mathrm{Mn}$. The slope of the correlation line on a ${ }^{53} \mathrm{Mn}-{ }^{53} \mathrm{Cr}$ evolution diagram corresponds to an initial ${ }^{53} \mathrm{Mn} /{ }^{55} \mathrm{Mn}$ ratio of $(8.7 \pm 1.5) \times 10^{-6}$ (Fig. 4b).

In the heavily-altered CM1 chondrite Allan Hills (ALH) 84034 both calcite and dolomite are present; calcite is much less abundant (Brearley and Hutcheon, 2000). The two phases always occur separately, except within altered CAIs where they can coexist. Dolomites are commonly intergrown with serpentines and pentlandite; calcites are inclusion-free. One of the dolomite grains exhibits resolvable ${ }^{53} \mathrm{Cr} *$ corresponding to an initial ${ }^{53} \mathrm{Mn} /{ }^{55} \mathrm{Mn}$ ratio of $(5.0 \pm 1.5) \times 10^{-6}$ (Fig. 4c).

The observed range in the initial ${ }^{53} \mathrm{Mn} /{ }^{55} \mathrm{Mn}$ ratios in CM carbonates [from $(1.3 \pm 0.6) \times 10^{-5}$ to $\left.(5.0 \pm 1.5) \times 10^{-6}\right]$ corresponds to an age difference of $\sim 5 \mathrm{Ma}$ and may represent duration of aqueous activity of the CM parent body that started $\sim 12.5 \pm 2.5$ Ma prior to differentiation of the angrite parent body (Lugmair and Shukolyukov, 1998).

\subsection{Timescale of in situ Aqueous Alteration of the Ungrouped Carbonaceous Chondrite MAC88107: Evidence from Petrographic Observations and Chromium Isotope Compositions of Secondary Fayalite}

The ungrouped carbonaceous chondrite MacAlpine Hills (MAC) 88107 has a bulk chemical composition intermediate between $\mathrm{CO}$ and $\mathrm{CM}$ chondrites, and O-isotopic composition similar to CO-CV-CK chondrites (Clayton and Mayeda, 1999). In contrast to CK and most CO chondrites, MAC88107 shows no evidence for thermal metamorphism; its thermoluminescence properties (Sears et al., 1991) suggest low petrographic type (3.0-3.1). Chondrules and CAIs are surrounded by continuous fine-grained, accretionary rims, indicating that the meteorite largely escaped post-accretional brecciation (Krot et al., 2000a). 
The meteorite experienced a small degree of in situ alteration that resulted in formation of saponite, serpentine, magnetite, pentlandite, fayalite, and hedenbergite (Krot et al., 2000a). We emphasize that similar secondary phases are observed in the Bali-like oxidized CV chondrites, where their origin remains controversial (see below). Because, MAC88107 may provide a clue for understanding the origin of secondary mineralization in CV chondrites, it is discussed in detail in this chapter. Fayalite $\left(\mathrm{Fa}_{90-100}\right)$ and hedenbergite $\left(\sim \mathrm{Fs}_{50} \mathrm{Wo}_{50}\right)$ occur as veins, which start at the opaque nodules in the chondrule peripheries, crosscut fine-grained rims and either terminate at the boundaries with the neighboring fine-grained rims or continue as layers between these rims (Fig. 5a,b). Fayalite also overgrows isolated forsteritic $\left(\mathrm{Fa}_{1-5}\right)$ and fayalitic $\left(\mathrm{Fa}_{20-40}\right)$ olivine grains without any evidence for Fe-Mg interdiffusion (Fig. 5c), and replaces magnetitesulfide grains (Fig. 5d). All textural varieties of fayalite are compositionally similar and characterized by high $\mathrm{MnO}$ content (0.4-0.85 wt\%) and nearly complete absence of $\mathrm{Cr}_{2} \mathrm{O}_{3}$.

Based on the petrographic observations and thermodynamic analysis of phase relations in the Si-Fe-Ca-O-H system, Krot et al. (2000a) concluded that phyllosilicates, magnetite, pentlandite, fayalite, and hedenbergite in MAC88107 formed during low-temperature ( 150$200^{\circ} \mathrm{C}$ ) alteration in the presence of aqueous solution capable of transporting $\mathrm{Si}, \mathrm{Fe}, \mathrm{Ca}, \mathrm{Mn}$, and Mg. Because most fayalite grains in MAC88107 are too small $(<10 \mu \mathrm{m})$ for Mn-Cr-isotope study by an ion microprobe, the $\mathrm{Cr}$ isotope compositions were measured only for a coarse-grained fayalite replacing a magnetite-sulfide nodule (Fig. 5d) and adjacent matrix. Both analyses of the fayalite grain show large ${ }^{53} \mathrm{Cr} *$ correlated with the respective ${ }^{55} \mathrm{Mn} /{ }^{52} \mathrm{Cr}$ ratios, indicative for the in situ decay ${ }^{53} \mathrm{Mn}$ (Fig. 6a). The slope of the correlation line fitted to the data, passing through the normal $\mathrm{Cr}$ isotope composition of matrix $\left(\delta^{53} \mathrm{Cr}=0\right)$ at $\mathrm{Mn} / \mathrm{Cr} \cong 1$, corresponds to the initial ${ }^{53} \mathrm{Mn} /{ }^{55} \mathrm{Mn}$ ratio of $(1.58 \pm 0.26) \times 10^{-6}$ at the time the fayalites formed $\left(\Delta \mathrm{t}_{\mathrm{LEW}}=-1.25 \pm 0.83 \mathrm{Ma}\right)$. 


\subsection{Chondrites and Settings of Their Alteration}

The CV carbonaceous chondrites are currently subdivided into the reduced $\left(\mathrm{CV}_{\text {red }}\right)$ and two oxidized subgroups, Allende-like ( $\left.\mathrm{CV}_{\text {oxA }}\right)$ and Bali-like $\left(\mathrm{CV}_{\text {oxB }}\right)(M c S w e e n, 1977$; Weisberg and Prinz, 1998), which largely reflect their complex alteration history and may represent different lithological varieties of the same asteroidal body (Krot et al., 1998a).

The $\mathrm{CV}_{\text {oxB }}$ chondrites (e.g., Kaba, Bali) experienced aqueous alteration resulting in replacement of primary minerals in chondrules, CAIs, and AOAs by secondary phyllosilicates, magnetite, Fe,Ni-sulfides, Fe,Ni-carbides, fayalite, salite-hedenbergite pyroxenes $\left(\mathrm{Fs}_{10-50} \mathrm{Wo}_{45-}\right.$ 50), and andradite. Their matrices largely consist of the secondary minerals, including concentrically-zoned nodules of Ca,Fe-pyroxene and andradite, coarse (>10 $\mu \mathrm{m})$ grains of nearly pure fayalite $\left(>\mathrm{Fa}_{90}\right)$, abundant phyllosilicates, and very fine-grained $(<1-2 \mu \mathrm{m})$ ferrous olivine $\left(\sim \mathrm{Fa}_{50}\right)$ (Fig. 7a).

The $\mathrm{CV}_{\text {oxA }}$ chondrites (e.g., Allende, ALH84128) are more extensively altered than the $\mathrm{CV}_{\text {oxB }}$, but contain very minor phyllosilicates (this alteration is often referred as iron-alkali metasomatism). Chondrules and refractory inclusions in the $\mathrm{CV}_{\text {oxA }}$ chondrites contain secondary nepheline, sodalite, Ca,Fe-pyroxenes, andradite, Fe,Ni-sulfides, magnetite, Ni-rich metal, and ferrous olivine. Their matrices are coarser-grained than those in the $\mathrm{CV}_{\text {oxB }}$ and largely consist of Ca,Fe-pyroxene \pm andradite nodules, lath-shaped ferrous olivine ( $\left.\sim \mathrm{Fa}_{50}\right)$, and nepheline (Fig. 7c).

The CV chondrite Mokoia is a complex breccia containing clasts of the $\mathrm{CV}_{\text {oxA }}$ and $\mathrm{CV}_{\text {oxB }}$ lithologies and heavily-metamorphosed oxidized chondritic clasts (Krot et al., 1998a). The $\mathrm{CV}_{\text {oxA }}$ clasts experienced aqueous alteration that overprints "anhydrous" Allende-like alteration (Kimura and Ikeda, 1998). Some oxidized CVs (e.g., MET00430) are mineralogically intermediate between the $\mathrm{CV}_{\text {охв }}$ and $\mathrm{CV}_{\text {oxA }}$ chondrites (Fig. 7b; Krot et al., 2004a). 
The $\mathrm{CV}_{\text {red }}$ chondrites Efremovka and Leoville experienced alteration similar to that of $\mathrm{CV}_{\text {oxA }}$, but to a smaller degree. The reduced $\mathrm{CV}$ chondrite breccia Vigarano contains clasts of the $\mathrm{CV}_{\mathrm{oxB}}$ and $\mathrm{CV}_{\text {oxA }}$ materials (Krot et al., 2000b); the reduced portion experienced aqueous alteration resulting in formation of phyllosilicates and magnetite.

In addition to the oxidized and reduced CV subgroups, CV chondrites contain dark inclusions which are chemically and petrographically similar to their host meteorites (Fig. 7d), but appear to have experienced more extensive alteration (e.g., Fruland et al., 1978; Kurat et al., 1989; Johnson et al., 1990; Buchanan et al., 1997; Krot et al., 1997a, 1998a, 1999, 2001).

\subsubsection{Nebular vs. Asteroidal alteration of CV chondrites}

The origin of secondary mineralization in CV chondrites remains controversial; nebular and asteroidal settings have been proposed. According to the nebular models (Palme and Wark, 1988; Weisberg and Prinz, 1998), chondrules and refractory inclusions in the $\mathrm{CV}_{\text {oxA }}$ were exposed to a highly oxidized nebular gas resulting in their alteration; matrix minerals directly condensed from this gas. This model is, however, inconsistent with (a) the presence of poorlygraphitized carbon (PGC) and pentlandite inclusions in matrix olivine (Brearley, 1999), (b) the lack of volatility-controlled rare earth element (REE) patterns in matrix Ca,Fe-pyroxenes and andradite (Brearley and Shearer, 2000), (c) the large mass-dependent fractionation of oxygen isotopes $\left(\delta^{18} \mathrm{O} \sim 20 \%\right.$ ) in secondary fayalite, magnetite, Ca,Fe-rich pyroxenes, and andradite (Krot et al., 2000c; Choi et al., 2000; Cosarinsky et al., 2003), and (d) the thermodynamic analysis of condensation of ferrous olivine (Grossman and Fedkin, 2003).

According to the asteroidal models (Krot et al., 1995, 1997, 1998a,b, 2004a; Kojima and Tomeoka, 1996), CV chondrites experienced fluid-assisted thermal metamorphism to various degrees, which resulted in mobilization of $\mathrm{Ca}, \mathrm{Si}, \mathrm{Fe}, \mathrm{Mg}, \mathrm{Mn}, \mathrm{Na}$, and $\mathrm{S}$, and replacement of 
primary phases in chondrules, CAIs and matrices by secondary minerals. It was originally suggested that secondary ferrous olivine in CV chondrites formed by dehydration of phyllosilicates during thermal metamorphism (Kojima and Tomeoka, 1996; Krot et al., 1995, 1997a). This mechanism, however, appears to be inconsistent with the lack of mass-dependent fractionation of oxygen isotopes in bulk CV chondrites (Clayton and Mayeda, 1999), which is expected for extensively aqueously-altered and dehydrated meteorites (e.g., metamorphosed CI/CM). Recently, Krot et al. (2004a) concluded that ferrous olivine in CV chondrites formed by several mechanisms during fluid-assisted metamorphism, including replacement of opaque nodules, magnesian olivine and pyroxene, direct precipitation from a supersaturated fluid, and, possibly by dehydration of phyllosilicates.

\subsubsection{Settings and timescale of secondary alteration of the $C V_{\text {oxB }}$ chondrites}

There are several lines of evidence suggesting that the secondary minerals in the $\mathrm{CV}_{\mathrm{oxB}}$ formed during relatively low-temperature aqueous alteration of the CV asteroidal body, rather than by high-temperature gas-solid reactions in the solar nebula. (a) The secondary minerals occur in all $\mathrm{CV}_{\text {oxB }}$ chondritic components, including chondrules, CAIs, AOAs, and matrices. (b) Fine-grained rims around chondrules are commonly crosscut by fayalite-bearing veins that start at the opaque nodules in the chondrule peripheries (Figs. 8a,b). (c) Fayalite replacing magnetitesulfide nodules in type I chondrules (Figs. 8c,d) show large mass-dependent fractionation of oxygen isotopes and contain sulfide inclusions (Fig. 9a), suggesting low-temperature formation. (d) Euhedral fayalite grains of variable compositions overgrow forsterite grains of AOAs without any evidence for Fe-Mg interdiffusion in the neighboring forsterite grains, suggesting precipitation from a low-temperature fluid of variable chemical composition (Fig. 8e). Occasionally, ferrous olivine pseudomorphs chondrule phenocrysts (Fig. 8d) supporting the 
presence of aqueous solutions during the alteration. (e) Low Al contents in secondary Ca,Fepyroxenes, indicating large $\mathrm{Ca} / \mathrm{Al}$ fractionation during their formation, is inconsistent with their high-temperature condensation origin (both $\mathrm{Ca}$ and $\mathrm{Al}$ are refractory lithophile elements of similar volatility and are not expected to be fractionated from each other during condensation). These observations and thermodynamic analysis of phase relations in the Si-Fe-Ca-O-H system (Krot et al., 1998a) suggest that secondary minerals in $\mathrm{CV}_{\text {oxB }}$ chondrites in the presence of aqueous solutions capable of transporting $\mathrm{Si}, \mathrm{Fe}, \mathrm{Ca}, \mathrm{Mn}$, and $\mathrm{Mg}$.

Petrographic observations of type I chondrules (Hua and Buseck, 1995; Krot and Todd, 1998; Krot et al., 1998a,b) suggest the following sequence of secondary mineral formation. Magnetite and Fe,Ni-sulfides replacing Fe,Ni-nodules formed first. Phyllosilicates replacing chondrule mesostases and phenocrysts formed either subsequently or contemporaneously with magnetite. Fayalite, Ca,Fe-pyroxenes and andradite replace magnetite and coexist with phyllosilicates, possibly indicating contemporaneous formation of these phases; occasionally, fayalite is corroded by Ca,Fe-pyroxenes.

\subsubsection{Manganese-chromium isotope dating of secondary fayalite in Kaba and Mokoia}

High $\mathrm{MnO}$ contents (up to $1.5 \mathrm{wt} \%$ ) in secondary fayalite and nearly complete absence of chromium ( $\mathrm{Mn} / \mathrm{Cr}$ ratios range up to $2 \times 10^{6}$ ) favor chromium isotope measurements of fayalite to constrain its crystallization time (Hutcheon et al., 1998; Hua et al., 2003, 2004). Hutcheon et al. (1998) measured $\mathrm{Cr}$ isotope compositions of six fayalite grains replacing magnetite-sulfide nodules within type I chondrules from Mokoia. Hua et al. (2002, 2004) analyzed Cr isotope compositions of twelve fayalite grains associated with magnetite and sulfides in Kaba matrix. Fayalite grains in both textural occurrences have large ${ }^{53} \mathrm{Cr}^{*}$ correlated with ${ }^{55} \mathrm{Mn} /{ }^{52} \mathrm{Cr}$ ratios, indicative for in situ decay of ${ }^{53} \mathrm{Mn}$, which define similar initial ${ }^{53} \mathrm{Mn} /{ }^{55} \mathrm{Mn}$ ratios of 
$(2.32 \pm 0.18) \times 10^{-6}$ and $(2.28 \pm 0.37) \times 10^{-6}$, respectively $\left(\Delta_{\mathrm{tLEW}}=\sim 3.0 \pm 0.7 \mathrm{Myr}\right)$ respectively (Figs. $6 b, c)$.

\subsubsection{Iodine-xenon dating of magnetite and phyllosilicates formation in Kaba and Bali}

Pravdivtseva and Hohenberg (2001) measured Xe isotope compositions of magnetic fractions separated with a hand magnet from fine-crushed Kaba, Bali, and Mokoia. The ${ }^{128} \mathrm{Xe}$ and ${ }^{129} \mathrm{Xe}$ release profiles in Kaba and Bali suggest one major iodine carrier in magnetic separates that yield well-defined isochrons in temperature ranges of $1400-1750^{\circ} \mathrm{C}$ and 1450 $1950^{\circ} \mathrm{C}$, respectively (Figs. 10a,d). The isochrons correspond to closure time of the I-Xe system in the Kaba and Bali magnetite of $4.2 \pm 0.3 \mathrm{Ma}$ and $7.9 \pm 0.2 \mathrm{Ma}$ relative to the Shallowater internal reference standard, respectively.

The ${ }^{128} \mathrm{Xe}$ and ${ }^{129} \mathrm{Xe}$ release profiles at $1400-1900^{\circ} \mathrm{C}$ of the Mokoia magnetic fraction suggest multiple iodine carrier; no isochron was obtained. These results are consistent with the complex brecciated nature and multistage alteration history of this meteorite (Krot et al., 1998a; Kimura and Ikeda, 1998).

Two non-magnetic fractions hand picked from coarsely crushed samples of Kaba and Bali and tentatively identified (using EDS) as enstatite and a mixture of plagioclase-rich mesostasis and Al-rich phyllosilicates were measured for Xe isotope compositions (Pravdivtseva et al., 2001). Considering very fine scale of primary and secondary mineral intergrowths in the $\mathrm{CV}_{\mathrm{oxB}}$ chondrules, it is difficult to expect good mineral separation, and the results should be treated cautiously. The enstatite separates define precise high-temperature isochrons from $\sim 1400^{\circ} \mathrm{C}$ to $\sim 1800^{\circ} \mathrm{C}$ with similar I-Xe ages: $-2.0 \pm 0.8$ Ma for Kaba and $-2.1 \pm 0.7$ Ma for Bali, relative to Shallowater internal standard (Figs. 10b,e). The mixture of plagioclase-rich mesostasis and Alrich phyllosilicates yield lower temperature isochrons corresponding to I-Xe ages of $8.9 \pm 0.7 \mathrm{Ma}$ 
and 9.0 $\pm 0.8 \mathrm{Ma}$, for Kaba and Bali, respectively (Figs. 10c,f). These ages are systematically younger than the corresponding magnetite ages and may suggest that either magnetite formation predates formation of phyllosilicates or that I-Xe isotope closure in magnetite occurred prior to that in phyllosilicates. The overall I-Xe data suggest that the aqueous alteration on the $\mathrm{CV}_{\text {oxB }}$ parent body lasted for at least $10 \mathrm{Ma}$.

\subsubsection{Settings and timescale of alteration of the $C V_{o x A}$ chondrites}

There are several lines of evidence suggesting that iron-alkali metasomatic alteration of the $\mathrm{CV}_{\text {oxA }}$ chondrites resulted from fluid-assisted thermal metamorphism of the $\mathrm{CV}$ asteroidal body (e.g., Krot et al., 1998a), rather than from high-temperature gas-solid reactions in the solar nebula (e.g., Palme and Wark, 1988). (a) The secondary minerals occur in all $\mathrm{CV}_{\text {oxA }}$ chondritic components, including chondrules, CAIs, AOAs, and matrices (e.g., Hashimoto and Grossman, 1987; MacPherson et al., 1988; Krot et al., 1995) and show evidence for in situ formation (e.g., veins, rims, chondrule pseudomorphs; Fig. 11) (Krot et al., 1997a, 1998a,b, 2001; MacPherson and Krot, 2002). (b) Oxygen isotope compositions of the secondary Ca,Fe-pyroxenes, andradite, and wollastonite in matrix and rims around CAIs plot parallel to terrestrial fractionation line at $\Delta^{17} \mathrm{O} \sim-2.5 \%$ with a large range in $\delta^{18} \mathrm{O}$ ( 20\%) (Fig. 9b), comparable to the range reported for the secondary magnetites and fayalites in the $\mathrm{CV}_{\text {oxB }}$ chondrites (Fig. 9a), suggesting lowtemperature formation. This mechanism is also consistent with the presence of sulfide inclusions (Fig. 11b) and lack of volatility-controlled REE patterns in Ca,Fe-pyroxenes and andradite in the Allende matrix (Brearley and Shearer, 2000). (c) Secondary ferrous olivine replacing low-Ca pyroxene phenocrysts in type I chondrules coexists with talc and amphibole (Brearley, 1999), suggesting that Fe was transported by low-temperature aqueous solutions (Krot et al., 2004a), rather than by high-temperature gas phase (Dohmen et al., 1998). 
Although there are many textural and mineralogical similarities in secondary alteration of the $\mathrm{CV}_{\text {oxB }}$ and $\mathrm{CV}_{\text {oxA }}$ chondrites (Figs. 8, 11a-d), the latter are more extensively altered and contain secondary ferrous olivine $\left(\mathrm{Fa}_{40-60}\right)$, nepheline and sodalite instead of fayalite ( $\left.\mathrm{Fa}_{90-100}\right)$ and phyllosilicates. There are also some difference in $\Delta^{17} \mathrm{O}$ values of the secondary phases (fayalite, magnetite, and Ca,Fe-rich silicates) in the $\mathrm{CV}_{\text {oxB }}(\sim-0.6 \%)$ and $\mathrm{CV}_{\text {oxA }}$ chondrites (2.6\%) (Figs. 9a,b). Secondary fayalites in the intermediate $\mathrm{CV}_{\text {oxA-B }}$ meteorites (e.g., MET00430) show inverse compositional zoning (Figs. 7b, 11e) and evidence for dissolution of fayalite and precipitation of more forsteritic olivine (Fig. 11f). These observations may indicate that the $\mathrm{CV}_{\text {oxA }}$ experienced alteration at higher temperatures than the $\mathrm{CV}_{\text {oxB }}$.

Petrographic observations on type I chondrules in the $\mathrm{CV}_{\text {oxA }}$ (Figs. 11a-d; Krot et al., 1998a,b) suggest the following sequence of secondary mineral formation. Magnetite and Fe,Nisulfides replacing Fe,Ni-nodules formed first. Ferrous olivine and Ca,Fe-pyroxenes formed later; they preferentially replace magnetite of the nodules and contain abundant inclusions of Fe,Nisulfides (Figs. 11a-c). Ferrous olivine also replaces low-Ca pyroxene phenocrysts and overgrows or replaces forsteritic olivine phenocrysts (Figs. 10c,d; Krot et al., 1997a). Nepheline and sodalite replace chondrule mesostasis and may have formed prior to, contemporaneously or after ferrous olivine (e.g., Kimura and Ikeda, 1995).

In addition to iron- and alkali-rich minerals in the $\mathrm{CV}_{\text {oxA }}$ chondrites, coarse-grained CAIs in Allende contain secondary grossular, monticellite, wollastonite, and forsterite which typically replace melilite-anorthite assemblages (Hutcheon et al., 1978; Hutcheon and Newton, 1981; Wark, 1987; Krot et al., 2004b). Based on petrographic observations and thermodynamic analysis, Hutcheon and Newton (1981) concluded that grossular and monticellite formed during a prolonged heating in the solar nebula at $\sim 950 \mathrm{~K}$ via the closed-system reaction: 


$$
3 \mathrm{Ca}_{2} \mathrm{MgSi}_{2} \mathrm{O}_{7}+\mathrm{Ca}_{2} \mathrm{Al}_{2} \mathrm{SiO}_{7}+\mathrm{CaAl}_{2} \mathrm{Si}_{2} \mathrm{O}_{8}=2 \mathrm{Ca}_{3} \mathrm{Al}_{2} \mathrm{Si}_{3} \mathrm{O}_{12}+3 \mathrm{CaMgSiO}_{4} .
$$

Krot et al. (2004b) concluded instead that other closed-system reactions took place:

$$
3 \mathrm{Ca}_{2} \mathrm{MgS}_{2} \mathrm{O}_{7}+\mathrm{Ca}_{2} \mathrm{Al}_{2} \mathrm{SiO}_{7}+2 \mathrm{CaAl}_{2} \mathrm{Si}_{2} \mathrm{O}_{8}=3 \mathrm{Ca}_{3} \mathrm{Al}_{2} \mathrm{Si}_{3} \mathrm{O}_{12}+\mathrm{CaMgSiO}_{4}+
$$

$\mathrm{Mg}_{2} \mathrm{SiO}_{4}$

and

$$
4 \mathrm{Ca}_{2} \mathrm{MgSi}_{2} \mathrm{O} 7+\mathrm{Ca}_{2} \mathrm{Al}_{2} \mathrm{SiO}_{7}+\mathrm{CaAl}_{2} \mathrm{Si}_{2} \mathrm{O}_{8}=2 \mathrm{Ca}_{3} \mathrm{Al}_{2} \mathrm{Si}_{3} \mathrm{O}_{12}+4 \mathrm{CaMgSiO}_{4}+
$$

$\mathrm{CaSiO}_{3}$

Although under equilibrium conditions these reaction occur below $950 \mathrm{~K}$, the common presence of unaltered melilite-anorthite intergrowths in the Allende Type C CAIs implies the lack of equilibrium (i.e. temperature estimates should be considered with caution).

\subsubsection{Aluminum-magnesium isotope dating of secondary alteration of the CV CAIs}

Secondary minerals (nepheline, sodalite, grossular) in the CV CAIs generally show no

evidence for ${ }^{26} \mathrm{Mg}^{*}$ suggesting that the alteration took place at least several half-lives of ${ }^{26} \mathrm{Al}$ after the formation of the primary phases typically having canonical ${ }^{26} \mathrm{Al} /{ }^{27} \mathrm{Al}$ ratios of $\sim 5 \times 10^{-5}$ (e.g., Hutcheon and Newton, 1981). The only Allende CAI with excesses of ${ }^{26} \mathrm{Mg}$ in secondary nepheline and sodalite is a fine-grained spinel-rich inclusion analyzed by Brigham et al. (1986). The observed ${ }^{26} \mathrm{Mg}^{*}$ corresponds to an initial ${ }^{26} \mathrm{Al} /{ }^{27} \mathrm{Al}$ ratio of (6-7) $\times 10^{-5}$. MacPherson et al. (1995) interpreted these data as evidence for an early, nebular formation of the secondary minerals that continued over an extended (several Ma) period of time. However, taking into account the low ${ }^{27} \mathrm{Al} /{ }^{24} \mathrm{Mg}$ ratios in the analyzed minerals, the anomalously high initial ${ }^{26} \mathrm{Al} /{ }^{27} \mathrm{Al}$ ratio inferred for this CAI, and the clear evidence for metamorphic redistribution of $\mathrm{Mg}$ isotopes in the Allende CAIs (e.g., Yurimoto et al., 2000), it seems more likely that this "isochron" 
resulted from Mg-isotopic exchange between the primary and secondary minerals of the CAI and does not have a chronological meaning (see also Fig. 2 in MacPherson et al., 1995).

\subsubsection{Iodine-xenon dating of secondary alteration of CAIs and chondrules in Allende}

I-Xe isotope data for the coarse-grained and fine-grained CAIs in Allende, which experienced iron-alkali metasomatic alteration, encompass a spread of $\geq 10 \mathrm{Ma}$, supporting an asteroidal setting of alteration (Swindle et al., 1988). The strong correlation of iodine with chlorine in two fine-grained CAIs analyzed by Kirschbaum (1988) together with the fact that sodalite is the only significant chlorine-bearing mineral in these CAIs, verified sodalite as the major iodine-carrier phase.

Recent xenon isotope measurements (Pravdivtseva et al., 2003b) showed that heavilyaltered fine-grained CAIs in Allende define isochrons with ages between $3.1 \pm 0.2$ and $3.7 \pm 0.2$ Ma younger than Shallowater (Figs. 12a-c). The CAIs have nearly identical release profiles for

radiogenic ${ }^{129 *} \mathrm{Xe}$ and ${ }^{128^{*}} \mathrm{Xe}$, suggesting the same iodine carrier for both (probably sodalite; Kirschbaum, 1988).

Although Allende chondrules often contain large fractions of radiogenic Xe, and an I-Xe association suggestive chronometry, they rarely yield isochrons that are well-defined at the level of precision provided by the isotopic data. Among nine chondrules studied by Swindle et al. (1983), eight have a pattern of increasing model age with each incrementally increased temperature step. This was attributed to relatively slow cooling $\left(\sim 10-20^{\circ} \mathrm{C} / \mathrm{Ma}\right.$ using the lower release temperatures $\left(600-1100^{\circ} \mathrm{C}\right)$ or of $50-300^{\circ} \mathrm{C} / \mathrm{Ma}$ using release temperatures above $1300^{\circ} \mathrm{C}$ ) or the monotonic (with release temperature) relaxation of other conditions during thermal metamorphism or alteration (Swindle et al., 1983; Nichols et al., 1990). One chondrule gave a well-defined isochron with an apparent age of 0.53 \pm 0.15 Ma younger than the Bjurböle 
whole rock age standard (Swindle et al., 1983), and the I-Xe ages of four different chondrules gave ages ranging from $-0.37 \pm 0.16$ Ma to $1.54 \pm 0.07$ Ma, relative to Bjurböle (Nichols et al., 1990). Four coarse-grained chondrule rims tended to be slightly older than the interiors, but these rims were separated from a different set of chondrules, and the only chondrule/rim pair combination yielded concordant ages.

\subsubsection{Setting and I-Xe dating of alteration of the CV dark inclusions}

Dark inclusions in Allende experienced similar secondary alteration to their host meteorite, but to a higher degree (Figs. 13a,b). The very heavily-altered dark inclusions consist almost entirely of secondary ferrous olivine, Ca,Fe-pyroxenes, andradite, nepheline, sodalite, and Fe,Nisulfides, and, if not brecciated, are surrounded by continuous, multilayered Ca,Fe-rich rims (Fig. 14) composed of Ca,Fe-pyroxenes, andradite, \pm wollastonite, \pm kirschteinite. The outermost layer of the rims is often intergrown with chondrule fragments and matrix olivine of the Allende host (Fig. 13f in Krot et al., 1998a; Fig. 10 in Krot et al., 2001). Some of the dark inclusions are crosscut by multiple Ca,Fe-rich veins (Fig. 14a), which are mineralogically similar to the Ca,Ferich rims and often connected to them. The outer portions of the rimmed dark inclusions are depleted in Ca, whereas the Allende matrix just outside the rims contain abundant $\mathrm{Ca}, \mathrm{Fe}-\mathrm{rich}$ silicate inclusions (Figs. 14a,b). Oxygen isotope compositions of Ca,Fe-rich silicates within and around dark inclusions in Allende (Fig. 9c) plot parallel to the terrestrial fractionation line at $\Delta^{17} \mathrm{O} \sim-2 \%$ with a large range in $\delta^{18} \mathrm{O}(\sim 30 \%)$, suggesting low temperature formation of these minerals (Krot et al., 2000c).

Based on these observations and thermodynamic analysis of phase relations in the Si-Fe-CaO-H system, Krot et al. (2001) concluded that the rimmed dark inclusions in Allende experienced at least two-stages of alteration in the presence of aqueous solutions. During an 
early stage of the alteration, which took place in an asteroidal setting, but not in the current location of the dark inclusions, chondrule silicates were replaced by secondary ferrous olivine, nepheline, and sodalite. Calcium lost from the chondrules was redeposited as Ca,Fe-pyroxeneandradite veins and nodules in the dark inclusion matrices. The second stage of alteration took place in situ, during the alteration of the Allende host, and resulted in mobilization of Ca from the dark inclusions and its redeposition as Ca,Fe-rich rims around the dark inclusions and as Ca,Fe-rich nodules in the neighboring matrix of Allende.

Xenon isotope compositions were measured in bulk samples of seventeen Allende dark inclusions (Pravdivtseva et al., 2003b). All dark inclusions yielded similar release profiles with two major peaks, suggesting two major iodine carriers (sodalite, and possibly Ca,Fe-pyroxenes or nepheline), and well-defined I-Xe isochrons (Figs. 12d-f) with ages ranging from $0.5 \pm 0.3$ to 2.8 \pm 0.3 Ma older than the Shallowater internal standard (Table 1). In contrast, three heavilyaltered fine-grained CAIs in Allende yielded well-defined isochrons with ages $3.1 \pm 0.2,3.0 \pm 0.2$, and 3.7 \pm 0.2 Ma younger than Shallowater (Pravdivtseva et al., 2003b. The I-Xe ages of the dark inclusions were interpreted as the time of their early alteration prior incorporation into Allende. The younger I-Xe ages of the fine-grained spinel-rich CAIs may reflect hydrothermal alteration of the Allende host, which could have occurred contemporaneously with the second stage of alteration of the Allende dark inclusions. The lack of evidence for the disturbance of I-Xe system in the Allende dark inclusions suggests that fluid responsible for the alteration of the Allende CAIs must have been in equilibrium with the I- and Xe-bearing phases of the dark inclusions, so the latter were not affected by the second stage of alteration.

Dark inclusions in the $\mathrm{CV}_{\text {red }}$ chondrites Efremovka, Leoville, and Vigarano experienced different styles of aqueous alteration to various degrees (Figs. 13c-f) that resulted in formation of 
ferrous olivine, andradite, magnetite, and phyllosilicates (Kracher et al., 1985; Tomeoka and Kojima, 1998; Brearley, 1998; Krot et al., 1999). The presence of aqueous solutions during the alteration is supported by the textural observations (e.g., chondrule pseudomorphs), the presence of minor phyllosilicates (Krot et al., 1999), and bulk oxygen isotope compositions, which on a three oxygen isotope plot deviate to the right from the CCAM line (Clayton and Mayeda, 1999). Xenon isotope compositions were measured in bulk samples of six dark inclusions from the reduced CVs (Swindle et al., 1998; Krot et al., 1999; Pravdivtseva et al., 2003c). The iodine carriers in the dark inclusions have not been identified; phyllosilicates and magnetite are two possible candidates. The I-Xe ages of the dark inclusions range from $-4.9 \pm 1.8$ to $9.5 \pm 2.3 \mathrm{Ma}$ relative to Shallowater and are generally younger than those of the Allende dark inclusions (Table 1). For the Efremovka dark inclusions, there is a correlation between the degree of alteration and I-Xe closure times: E39 and E80 are more altered than E53 and show an apparent closure time $\sim 4$ to $6 \pm 2$ Ma later than E53 (Fig. 15).

In spite of the different degrees and styles of alteration of dark inclusions in the reduced and oxidized CV chondrites, all of them require "sub-planetary" trapped Xe, which has been interpreted as a result of shock or thermal metamorphism that occurred after precipitation of iodine host, while Xe and some I were still in solution (Hohenberg et al., 2003). This interpretation is generally consistent with the aqueous alteration - dehydration model proposed for the dark inclusions (e.g., Kojima and Tomeoka, 1996) and with shock metamorphism features observed in some of the dark inclusions (e.g., lineation of chondrule pseudomorphs; Fig. 1 in Krot et al., 1999). 
To summarize, the I-Xe ages of the CV dark inclusions, which probably represent fragments of the CV asteroidal body, span $~ 14 \mathrm{Ma}$, suggesting a long period of aqueous alteration on the CV parent body.

\subsection{Timescale of Aqueous Alteration of Ordinary Chondrites}

The effects of aqueous alteration are best documented in chondrules and matrices of the type 3 ordinary chondrites Semarkona (LL3.0), Bishunpur (LL3.1), Krymka (LL3.1), Parnallee (LL3.4), Chainpur (LL3.4), and Tieschitz (H/L3.6) (Hutchison et al., 1987, 1998; Alexander et al., 1989a,b; Bridges et al., 1997; Krot et al., 1997b; Keller, 1998; Choi et al., 1998; Grossman et al., 2000, 2002). This alteration must have occurred in an asteroidal setting and resulted in formation of secondary phyllosilicates, magnetite, maghemite, Fe,Ni-carbides, calcite, Nibearing sulfides, ferrous olivine, and alkali-rich secondary phases. Chondrules in some of the altered ordinary chondrites were dated using I-Xe systematics (Swindle et al., 1991a,b; Ash et al., 1995).

In Semarkona, evidence for aqueous alteration in an asteroidal setting include (a) the large range in mass-dependent fractionation of oxygen isotope compositions of magnetite grains $\left(\delta^{18} \mathrm{O}\right.$ $\sim 13 \%$ ), indicative of Rayleigh fractionation as a result of growth in the presence of a limited water reservoir (Choi et al., 1998), (b) the presence of carbide-magnetite-sulfide veins crosscutting fine-grained rims around chondrules (Krot et al., 1997b), (c) the presence of phyllosilicates in the chondrules and matrix (Hutchison et al., 1987; Alexander et al., 1989a,b), (d) the presence of bleached chondrules and evidence for removal of chondrule mesostasis by dissolution, (e) the elevated $\mathrm{D} / \mathrm{H}$ ratios in the bleached chondrules and matrix of Semarkona, suggesting exchange with an isotopically similar reservoir, most likely aqueous solution (Grossman et al., 2000). Swindle et al. (1991a) observed a range of > 10 Ma in apparent I-Xe 
isotope ages (from $-4.4 \pm 2.9$ Ma to $5.4 \pm 0.5 \mathrm{Ma}$, relative to Shallowater) for seventeen chondrules analyzed in Semarkona (Table 2; Fig. 16). The oldest I-Xe ages were attributed to chondrule formation, whereas the younger ages to aqueous alteration. Taking into account the petrographic evidence for multistage aqueous alteration of the Semarkona chondrules (e.g., Grossman et al., 2000) and the possible presence of several iodine carriers (e.g., magnetite, phyllosilicates), we suggest instead that the entire range of I-Xe ages may reflect duration of aqueous alteration on the LL asteroidal body.

The H/L3.6 chondrite Tieschitz contains secondary nepheline, albite, and unidentified hydrous (?) phases that precipitated from a halogen-bearing aqueous fluid in interchondrule voids and replaced chondrule mesostasis leached out by the fluid (Hutchison et al., 1998). Based on the evidence for partial resetting of the Sm-Nd and K-Ar systems at $\sim 2$ Ga (Turner et al., 1978; Krestina et al., 1996), Hutchison et al. (1998) speculated that aqueous activity on the Tieschitz parent body occurred $\sim 2$ Ga ago. However, the I-Xe ages of the Tieschitz chondrules (Nichols et al., 1991) do not support this hypothesis [decoupling of I-Xe chronometer from ArAr chronometer has also been observed for chondrules from the EH3 chondrite Qingzhen, Ash et al. (1997)]. The best isochrons for three chondrules define closure ages of 1.3, 3.6 and 4.9 Ma after Bjurböle (Fig. 17). All of the chondrules display the regular I-Xe structure: the high temperature sites have higher values of ${ }^{129} \mathrm{I} /{ }^{127} \mathrm{I}$ than the low temperature sites, suggesting slow cooling or monotonic relaxation of the conditions during metamorphism (Nichols et al., 1991). Using a non-diffusive, activation energy dependent model, cooling rates corresponding to a few hundred degrees per Ma, for the high temperature sites, down to a few degrees per Ma, for the low temperature sites, are estimated (Nichols et al., 1991). This is the same range of values observed for the Allende CAIs and chondrules (Swindle et al., 1983, 1988). These slow 
"cooling" rates suggest that the post-formational processes in the regolith are likely responsible for the I-Xe fine structure.

Bridges et al. (1997) described a number of chondrules separated from Chainpur (LL3.4) and Parnallee (LL3.6) that contain mesostasis enriched in $\mathrm{Na}$ and $\mathrm{Cl}$ and contain microcrystalline sodalite, nepheline, and scapolite, and attributed these features to a pre-accretionary (which could be nebular or asteroidal) metasomatism. The I-Xe ages of the Parnallee chondrules (Ash et al., 1995), which range from $1.75 \pm 0.16$ Ma to 5.0 \pm 0.70 Ma after Bjurböle chondrule closure (Table 2), favor an asteroidal setting for the alteration. Two chondrules contain ${ }^{128} \mathrm{Xe}$, but no ${ }^{129} \mathrm{Xe}^{*}$, suggesting that they formed after the decay of ${ }^{129} \mathrm{I}$, possibly by impact (Ash et al., 1995). Swindle et al. (1991b) showed that the range of apparent I-Xe ages of Chainpur chondrules is $50 \mathrm{Ma}$ and that the chondrules evolved in a common reservoir with a chondritic I/Xe ratio. Based on these observations, Swindle et al. (199b) concluded that these ages reflect an asteroidal processing in a regolith.

The presence of halite $(\mathrm{NaCl})$ and sylvite $(\mathrm{KCl})$ containing inclusions of aqueous salt solutions in the $\mathrm{H}$ chondrite regolith breccias Monahans (1998) (H5) and Zag (H3-6) indicates that some of the aqueous alteration on the $\mathrm{H}$ chondrite parent body postdated thermal metamorphism (Zolensky et al., 1999). We note, however, that there is no evidence that the halite in Zag and Monahans formed in situ (e.g., Rubin et al., 2002). Based on the presence of secondary fluid inclusions in halite of both meteorites, Zolensky et al. (1999) concluded that aqueous activity occurred at low temperature $\left(<50^{\circ} \mathrm{C}\right)$ and was episodic. A Rb-Sr model age for a halite crystal in Monahans (1998), calculated for an initial ratio of ${ }^{87} \mathrm{Sr} /{ }^{86} \mathrm{Sr}=$ 0.69876 \pm 0.00040 , the average for H-group chondrites, is $4.7 \pm 0.2 \mathrm{Ga}$ (Zolensky et al., 1999). Subsequently, Whitby et al. (2000) reported essentially pure radiogenic ${ }^{129}$ Xe in halite from Zag. 
Correlated release of ${ }^{129} \mathrm{Xe}$ and ${ }^{128} \mathrm{Xe}$ corresponds to an initial $\left({ }^{129} \mathrm{I} /{ }^{127} \mathrm{I}\right)$ ratio of $(1.35 \pm 0.05) \times 10^{-4}$ and an apparent formation time for the halite of $4.8 \pm 0.9$ Ma before the formation of Bjurböle reference chondrite, suggesting an early onset of aqueous activity on the Zag parent body. The retention of a high ${ }^{129} \mathrm{Xe}^{*} /{ }^{127} \mathrm{I}$ ratio implies that halite has not been subjected to substantial dissolution and recrystallization in the $4.5 \mathrm{Ga}$ since its formation, suggesting that the processes that led to aqueous activity on the Zag parent body may have ended quickly after evaporation of water into space (Whitby et al., 2000).

\subsection{Timescale of Alteration of Enstatite Chondrites}

Ash et al. (1997) reported apparent I-Xe ages of chondrules from the EH3 enstatite chondrite Qingzhen. Most chondrules give excellent isochrons with errors $<1 \mathrm{Ma}$; only one of the chondrules shows evidence for a slight isotopic disturbance. The observed range in I-Xe ages, from -1.08 to +1.98 relative to Shallowater (Table 2), is comparable to those in most unequilibrated ordinary chondrites. Based on the apparent lack of evidence for secondary alteration in Qingzhen, these ages were interpreted as primary, corresponding to the ages of chondrule formation. The iodine carrier in enstatite chondrites is unknown, but the presence of sodalite-like mesostases in some type I chondrules in Qingzhen suggests that it could be sodalite. The origin of these mesostases, and the interpretation of I-Xe ages, remain unclear.

\section{SUMMARY AND FUTURE WORK}

Mineralogical, petrographic, and isotopic observations indicate that most groups of chondritic meteorites experienced asteroidal alteration to various degrees, resulting in formation of secondary minerals such as phyllosilicates, magnetite, carbonates, ferrous olivine ( $\left.\mathrm{Fa}_{40-100}\right)$, salite-hedenbergite pyroxenes $\left(\mathrm{Fs}_{10-50} \mathrm{Wo}_{45-50}\right)$, wollastonite, andradite, nepheline, pentlandite, 
pyrrhotite, Fe,Ni-carbides, and Ni-rich metal. The alteration occurred in the presence of aqueous solutions under variable conditions (temperature, water/rock ratio, $\mathrm{fO}_{2}$, and fluid compositions) and in many cases was multistage. Although some alteration predated agglomeration of the final chondrite asteroidal bodies (e.g., dark inclusions in CV chondrites), there is no compelling evidence that the alteration occurred in the solar nebula nor in planetesimals of earlier generations. The ${ }^{26} \mathrm{Al}-{ }^{26} \mathrm{Mg},{ }^{53} \mathrm{Mn}-{ }^{53} \mathrm{Cr}$, and ${ }^{129} \mathrm{I}-{ }^{129} \mathrm{Xe}$ dating of secondary minerals suggests that alteration may have started within 1-2 Ma after formation of the CV CAIs having absolute $\mathrm{Pb}-\mathrm{Pb}$ age of $4567.2 \pm 0.6 \mathrm{Ma}$ and lasted up to $15 \mathrm{Ma}$ (Tables 1-3; Figs. 18, 19). Based on these observations, we infer that the chondrite parent bodies must have accreted within the first 1-2 Ma after collapse of the protosolar molecular cloud.

There are several carbonaceous chondrite groups not discussed in this chapter with clear evidence for secondary alteration; these include $\mathrm{CR}, \mathrm{CH}, \mathrm{CB}$, and $\mathrm{CO}$ chondrites. The $\mathrm{CR}$ chondrites experienced aqueous alteration to various degrees that resulted in formation of phyllosilicates, magnetite, and carbonates (e.g., Krot et al., 2002). The CB and CH chondrites contain heavily aqueously-altered clasts composed of phyllosilicates, framboidal and platelet magnetite, and carbonates (Greshake et al., 2002). The CO chondrites experienced alteration similar to that observed in CV chondrites (see CV chondrites and their alteration). The alteration resulted in formation of nepheline, sodalite, ferrous olivine, magnetite, Fe,Ni-carbides, and Nibearing sulfides (e.g., Jones, 1997a,b; Rubin, 1998; Russell et al., 1998; Chizmadia et al., 2002; Itoh and Tomeoka, 2003). A degree of alteration correlates with petrologic types of the host meteorites, suggesting that it occurred in an asteroidal setting (e.g., Itoh and Tomeoka, 2003). Although the secondary mineralization in the $\mathrm{CR}, \mathrm{CO}, \mathrm{CB}$, and $\mathrm{CH}$ chondrites has been welldocumented, there have yet been no attempts made to date it. 
Future studies of isotope dating of secondary mineralization of chondritic meteorites should also be focused on understanding the multistage alteration histories using combinations of analytical tools, including SEM, EPMA, CL, TEM, SIMS, and ICP-MS. This approach has already been successfully used in dating carbonate formation in CM carbonaceous chondrites (Brearley et al., 1999, 2001; Brearley and Hutcheon, 2000, 2002). Small grain sizes of the secondary minerals suitable for in situ $\mathrm{Mn}-\mathrm{Cr}$ isotope dating (e.g., carbonates, ferrous olivine) will probably require use of NanoSIMS (e.g., Hoppe et al., 2004).

Finally, we would like to emphasize that progress in the chronology of the early solar system processes requires better understanding the origin of short-lived radionuclides [external (injection) vs. internal (irradiation)] and their distribution (homogeneous vs. heterogeneous) in the protoplanetary disk (e.g., Goswami et al., 2000, 2004; Gounelle et al., 2001), and establishing a unified chronology of the early solar system processes using these radionuclides (e.g., Gilmour and Saxton, 2001; Gilmour et al., 2004). These issues remain unresolved.

Acknowledgements: This work was supported by NASA Grants NAG5-10610 and NAG6-57543 (A. Krot, P.I.), NAG5-11591 (K. Keil, P.I.), NAG5-10523 (I. Hutcheon, P.I.), and NAG5-11682 (A. Brearley, P.I.). We thank T. D. Swindle, M. E. Zolensky, and L. A. Leshin for constructive reviews. This is Hawai'i Institute of Geophysics and Planetology Publication No. XXX and School of Ocean and Earth Science and Technology Publication No. YYY. 


\section{REFERENCES}

Alexander C. M. O'D., Barber D. J., and Hutchison R. (1989a) The microstructure of Semarkona and Bischunpur. Geochim. Cosmochim. Acta, 53, 3045-3057.

Alexander C. M. O'D., Hutchison R., and Barber D. J. (1989b) Origin of chondrule rims and interchondrule matrix in unequilibrated ordinary chondrites. Earth Planet. Sci. Lett., 95, 187-207.

Amelin Y., Krot A. N., Hutcheon I. D., and Ulyanov A. A. (2002) Lead isotopic ages of chondrules and calcium-aluminum-rich inclusions. Science, 297, 1678-1683.

Amelin Y., Krot A. N., and Twelker E. (2004) Pb isotopic age of the CB chondrite Gujba, and the duration of the chondrule formation interval. Geochim. Cosmochim. Acta, 68, Abst. E958.

Anders E. and Grevesse N. (1989) Abundances of the elements: meteoritic and solar. Geochim. Cosmochim. Acta, 53, 197-214.

Ash R. D., Gilmour J. D., Whitby J. A., Turner G., Bridges J. C., and Hutchison R. (1995) The history of the Parnallee meteorite as revealed by iodine-xenon dating (abstract). In Meteoritics, 30, 483-484.

Ash R. D., Gilmour J. D., Whitby J., Prinz M., and Turner G. (1997) I-Xe dating of chondrules from the Qingzhen unequilibrated enstatite chondrite (abstract). In Lunar Planet. Sci. XXVIII, Lunar Planet. Inst., Houston, pp. 61-62.

Barber D. J. (1981) Matrix phyllosilicates and associated minerals in C2M carbonaceous chondrites. Geochim. Cosmochim. Acta, 45, 945-970. 
Benedix G. K., Leshin L. A., Farquhar J., Jackson T., and Thiemens M. H. (2003) Carbonates in CM2 chondrites: Constraints on alteration conditions from oxygen isotopic compositions and petrographic observations. Geochim. Cosmochim. Acta, 67, 1577-1589.

Birck J.-L. and Allègre C. J. (1988) Manganese-chromium isotope systematics and the development of the early solar system. Nature, 331, 579-584.

Birck J.-L., Rotaru M., and Allègre C. J. (1999) ${ }^{53} \mathrm{Mn}-{ }^{53} \mathrm{Cr}$ evolution of the early solar system. Geochim. Cosmochim. Acta, 54, 4111-4117.

Bizzarro M., Baker J. A., and Haack H. (2004) Mg isotope evidence for contemporaneous formation of chondrules and refractory inclusions. Nature, 431, 275-278.

Brazzle R. H., Pravdivtseva O. V., Meshik A. M., and Hohenberg C. M. (1999) Verification and interpretation of the I-Xe chronometer. Geochim. Cosmochim. Acta, 63, 739-760.

Brearley A. J. (1997) Disordered biopyriboles, amphibole, and talc in the Allende Meteorite; products of nebular or parent body aqueous alteration? Science, 276, 1103-1105.

Brearley A. J. (1998) Dark inclusions in the Leoville CV3 carbonaceous chondrite (abstract). In Lunar Planet. Sci. XXIX, Lunar Planet. Inst., Houston, CD-ROM \#1245.

Brearley A. J. (1999) Origin of graphitic carbon and pentlandite in matrix olivines in the Allende meteorite. Science, 285, 1380-1382.

Brearley A. J. (2003) Nebular vs. asteroidal processing. In Meteorites, Comets and Planets (ed Davis, A. M.), Vol. 1 of Treatise on Geochemistry (eds Holland H. D. and Turekian K. K.), Elsevier-Pergamon, Oxford, pp. 247-269.

Brearley A. J. (2005) The action of water. In Meteorites and the Early Solar System II (eds. Lauretta D. S., Leshin L. A., and McSween H. Y. Jr.), this volume. Univ. of Arizona, Tucson. 
Brearley A. J. and Jones R. H. (1998) Chondritic meteorites. In Planetary Materials (ed. J. J. Papike), Reviews in Mineralogy, 36, Washington DC, pp. 3-1 to 3-398.

Brearley A. J., Saxton J. M., Lyon I. C., and Turner G. (1999) Carbonates in the Murchsion CM chondrite: CL characteristics and oxygen isotopic compositions (abstract). In Lunar Planet. Sci. XXX, Lunar Planet. Inst., Houston, CD-ROM \#1301.

Brearley A. J. and Shearer C. K. (2000) Origin of calcium-iron-rich pyroxenes in Allende matrix: Clues from rare-earth-element abundances (abstract). In Meteorit. Planet. Sci., 35 (Suppl.), A33.

Brearley A. J. and Hutcheon I. D. (2000) Carbonates in the CM1 chondrite ALH84034: Mineral chemistry, zoning and Mn-Cr systematics (abstract). In Lunar Planet. Sci. XXXI, Lunar Planet. Inst., Houston, CD-ROM \#1407.

Brearley A. J. and Hutcheon I. D. (2002) Carbonates in the Y791918 CM2 chondrite: Zoning and Mn-Cr systematics (abstract). In Meteorit. Planet. Sci., 37 (Suppl.), A23.

Brearley A. J., Hutcheon I. D., and Browning L. (2001) Compositional zoning and Mn-Cr systematics in carbonates from the Y791198 CM2 carbonaceous chondrite (abstract). In Lunar Planet. Sci. XXXII, Lunar Planet. Inst., Houston, CD-ROM \#1458.

Bridges J. C., Alexander C. M. O'D., Hutchison R., Franchi I. A., and Pillinger C. T. (1997) Sodium-, chlorine-rich mesostases in Chainpur (LL3) and Parnallee (LL3) chondrules. Meteorit. Planet. Sci., 32, 555-565.

Brigham C. A., Hutcheon I. D., Papanastassiou D. A., and Wasserburg G. J. (1986) Evidence for ${ }^{26} \mathrm{Al}$ and $\mathrm{Mg}$ isotopic heterogeneity in a fine-grained CAI (abstract). In Lunar Planet. Sci. XVII, Lunar Planet. Inst., Houston, pp. 85-86. 
Buchanan P. C., Zolensky M. E., and Reid A. M. (1997) Petrology of Allende dark inclusions. Geochim. Cosmochim. Acta, 61, 1733-1743.

Bunch T. E. and Chang S. (1980) Carbonaceous chondrites - II. Carbonaceous chondrite phyllosilicates and light element geochemistry as indicators of parent body processes and surface conditions. Geochim. Cosmochim. Acta, 44, 1543-1577.

Chizmadia L. J., Rubin A. E., and Wasson J. T. (2002) Mineralogy and petrology of amoeboid olivine inclusions in $\mathrm{CO} 3$ chondrites; relationship to parent-body aqueous alteration. Meteorit. Planet. Sci., 37, 1781-1796.

Choi B.-G., McKeegan K. D., Krot A. N., and Wasson J. T. (1998) Extreme oxygen-isotope compositions in magnetite from unequilibrated ordinary chondrites. Nature, 392, 577-579.

Choi B.-G., Krot A. N., and Wasson J. T. (2000) Oxygen-isotopes in magnetite and fayalite in CV chondrites Kaba and Mokoia. Meteorit. Planet. Sci., 35, 1239-1249.

Clayton R. N. and Mayeda T. K. (1984) The oxygen isotope record in Murchison and other carbonaceous chondrites. Earth Planet. Sci. Lett., 67, 151-161.

Clayton R. N. and Mayeda T. K. (1999) Oxygen isotope studies of carbonaceous chondrites. Geochim. Cosmochim. Acta, 63, 2089-2104.

Clayton R. N., Mayeda T. K., Ivanov A. V., and MacPherson G. J. (1994) Oxygen isotopes in Kaidun (abstract). In Lunar Planet. Sci. XXV, Lunar Planet. Inst., Houston, pp. 269-270.

Cosarinsky M., Leshin L. A., MacPherson G. J., Krot A. N., and Guan Y. (2003) Oxygen isotope composition of Ca-Fe-rich silicates in and around al Allende Ca-Al-rich inclusion (abstract). In Lunar Planet. Sci. XXXIV, Lunar Planet. Inst., Houston, CD-ROM \#1043. 
Dohmen R., Chakraborty S., Palme H., and Rammensee W. (1998) Solid-solid reactions mediated by a gas phase; an experimental study of reaction progress and the role of surfaces in the system olivine+iron metal. Amer. Mineral., 83, 970-984.

Endress M. and Bischoff A. (1996) Carbonates in CI chondrites: Clues to parent body evolution. Geochim. Cosmochim. Acta, 60, 489-507.

Endress M., Zinner E., and Bischoff A. (1996) Early aqueous activity on primitive meteorite parent bodies. Nature, 379, 701-703.

Fredriksson K. and Kerridge J. F. (1988) Carbonates and sulfates in CI chondrites: Formation by aqueous activity on the parent body. Meteoritics, 23, 35-45.

Fruland R. M., King A. E., and McKay D. S. (1978) Allende dark inclusions. In Proc. Lunar Sci. Conf. $9^{\text {th }}$, pp. $1305-1329$.

Gilmour J. D. and Saxton J. M. (2001) A time-scale of formation of the first solids. Phil. Trans. R. Soc. Lond. A, 359, 2037-2048.

Gilmour J. D., Pravdivtseva O. V., Busfield A., and Hohenberg C. M. (2004) I-Xe and the chronology of the early solar system (abstract). In Workshop on Chondrites and the Protoplanetary Disk, Kauai, November 8-11, 2004, pp. 39-40.

Goswami J. N. and Vanhala H. A. T. (2000) Extinct radionuclides and the origin of the solar system. In Protostars and Planets IV, (eds. Mannings V., Boss A. P., and Russell S. S.), University of Arizona Press, Tucson, pp. 963-995.

Goswami J., Marhas K., Chaussidon M., Gounelle M., and Meyer B. (2004) Origin of short-lived radionuclides in the solar system (abstract). In Workshop on Chondrites and the Protoplanetary Disk, Kauai, November 8-11, 2004, pp. 43-44. 
Gounelle M. and Zolensky M. E. (2001) A terrestrial origin for sulfate veins in CI1 chondrites. Meteorit. Planet. Sci., 36, 1321-1329.

Gounelle M., Shu F. H., Shang H., Glassgold A. E., Rehm K. E., and Lee T. (2001) Extinct radioactivities and protosolar cosmic-rays: Self-shielding and light elements. Astrophys. J., $548,1051-1070$.

Grady M M., Wright I. P., Swart P. K., and Pillinger C. T. (1988) The carbon and oxygen isotopic composition of meteoritic carbonates. Geochim. Cosmochim. Acta, 52, 2855-2866.

Greshake A., Krot A. N., Meibom A., Weisberg M. K., and Keil K. (2002) Heavily-hydrated matrix lumps in the $\mathrm{CH}$ and metal-rich chondrites QUE 94411 and Hammadah al Hamra 237. Meteorit. Planet. Sci., 37, 281-294.

Grossman J. N., Alexander C. M. O'D., Wang J. H., and Brearley A. J. (2000) Bleached chondrules: Evidence for widespread aqueous alteration on the parent asteroids of ordinary chondrites. Meteorit. Planet. Sci., 35, 467-486.

Grossman J. N., Alexander C. M. O'D., Wang J. H., and Brearley A. J. (2002) Zoned chondrules in Semarkona: Evidence for high- and low-temperature processing. Meteorit. Planet. Sci., 37, 49-73.

Grossman L. and Fedkin A. V. (2003) Elemental abundance constraints on condensation of Allende matrix olivine (abstract). In NIPR Symp. Evolution of solar system materials, a new perspective from Antarctic meteorites, Tokyo, Japan, pp. 31-32.

Hashimoto A. and Grossman L. (1987) Alteration of Al-rich inclusions inside amoeboid olivine aggregates in the Allende meteorite. Geochim. Cosmochim. Acta, 51, 1685-1704.

Herzog G. F., Anders E., Alexander E. C. Jr., Davis P. K., and Lewis R. S. (1973) Iodine129/Xenon-129 age of magnetite from the Orgueil meteorite. Science, 180, 489-491. 
Hohenberg C. M. (1980) High sensitivity pulse-counting mass-spectrometer system for noble gas analysis. Rev. Sci. Instrum., 51, 1075-1082.

Hohenberg C. M., Hudson B., Kennedy B. M., and Podosek F. A. (1981) Noble gas retention chronologies for the St Severin meteorite. Geochim. Cosmochim. Acta, 45, 535-546.

Hohenberg C. M., Pravdivtseva O., and Meshik A. (2000) Reexamination of anomalous I-Xe ages: Orqueil and Murchison magnetites and Allegan feldspar. Geochim. Cosmochim. Acta, 64, 4257-4262.

Hohenberg C. M., Pravdivtseva O. V., and Meshik A. P. (2004) Trapped Xe and I-Xe ages in aqueously altered CV3 meteorites. Geochim. Cosmochim. Acta, 68, 4745-4765.

Hoppe P., Macdougal D., and Lugmair G. W. (2004) High spatial resolution ion microprobe measurements refine chronology of Orgueil carbonate formation (abstract). In Lunar Planet. Sci. XXXV, Lunar Planet. Inst., Houston, CD-ROM \#1313.

Hua X. and Buseck P. R. (1995) Fayalite in the Kaba and Mokoia carbonaceous chondrites. Geochim. Cosmochim. Acta, 59, 563-579.

Hua X., Huss G. R., Sharp T. G. (2002) ${ }^{53} \mathrm{Mn}-{ }^{53} \mathrm{Cr}$ dating of fayalite formation in the Kaba CV3 carbonaceous chondrite (abstract). In Lunar Planet. Sci. XXXIII, Lunar Planet. Inst., Houston, CD-ROM \#1660.

Hua X., Huss G. R., Tachibana S., and Sharp T. G. (2003) Oxygen isotopic compositions of fayalite in the Kaba CV3 carbonaceous chondrite (abstract). In Lunar Planet. Sci. XXXIV, Lunar Planet. Inst., Houston, CD-ROM \#1702.

Hua X., Huss G. R., Tachibana S., and Sharp T. G. (2004) Oxygen, Si, and Mn-Cr isotopes of fayalite in the oxidized Kaba CV3 chondrite: Constraints for its formation history. Geochim. Cosmochim. Acta (in preparation). 
Hutcheon I. D. and Newton R. C. (1981) Mg isotopes, mineralogy, and mode of formation of secondary phases in C3 refractory inclusions (abstract). In Lunar. Planet. Sci. XII, Lunar Planet. Inst., Houston, 491-493.

Hutcheon I. D. and Phinney D. L. (1996) Radiogenic ${ }^{53} \mathrm{Cr}^{*}$ in Orgueil carbonates: Chronoly of aqueous activity on the CI parent body (abstract). In Lunar. Planet. Sci. XXVII, Lunar Planet. Inst., Houston, 577-578.

Hutcheon I. D., Steele I. M., Smith J. V., and Clayton R. N. (1981) Ion microprobe, electron microprobe and cathodoluminescence data for Allende inclusions with emphasis on plagioclase chemistry. In Proc. Lunar Planet. Sci. Conf. $9^{\text {th }}$, pp. 1345-1368.

Hutcheon I. D., Phinney D. L., and Hutchison R. (1997) Radiogenic chromium-53 in CI carbonates: New evidence of early aqueous activity (abstract). In Meteorit. Planet. Sci., 32 (Suppl.), A63.

Hutcheon I. D., Krot A. N., Keil K., Phinney D. L., and Scott E. R. D. (1998) ${ }^{53}$ Mn- ${ }^{53}$ Cr dating of fayalite formation in the CV3 chondrite Mokoia: Evidence for asteroidal alteration. Science, 282, 1865-1867.

Hutcheon I. D., Weisberg M. K., Phinney D. L., Zolensky M. E., Prinz M. , and Ivanov A. V. (1999) Radiogenic ${ }^{53} \mathrm{Cr}$ in Kaidun carbonates; evidence for very early aqueous activity (abstract). In Lunar Planet. Sci. XXX, Lunar Planet. Inst., Houston, CD-ROM \#1722.

Hutchison R., Alexander C. M. O'D., and Barber D. J. (1987) The Semarkona meteorite; first recorded occurrence of smectite in an ordinary chondrite, and its implications. Geochim. Cosmochim. Acta, 51, 1875-1882.

Hutchison R., Alexander C. M. O'D., and Bridges J. C. (1998) Elemental redistribution in Tieschitz and the origin of white matrix. Meteorit. Planet. Sci., 33, 1169-1179. 
Ikeda Y. (1992) An overview of the research consortium, "Antarctic carbonaceous chondrites with CI affinities, Yamato-86720, Yamato-82162, and Belgica-7904". In Proc. NIPR Symp. Antarct. Meteorit. $5^{\text {th }}$, pp. 49-73.

Itoh D. and Tomeoka K. (2003) Nepheline formation in chondrules in CO3 chondrites: Relationship to parent-body thermal metamoprhism (abstract). In NIPR Symp. Evolution of solar system materials, a new perspective from Antarctic meteorites, Tokyo, Japan, pp. 4546.

Jeffery P. M. and Anders E. (1970) Primordial noble gases in separated meteoritic minerals, I, Geochim. Cosmochim. Acta, 34, 1175-1198.

Johnson C. A., Prinz M., Weisberg M. K., Clayton R. N. and Mayeda T. K. (1990) Dark inclusions in Allende, Leoville, and Vigarano: Evidence for nebular oxidation of CV3 constituents. Geochim. Cosmochim. Acta, 54, 819-831.

Johnson C. A. and Prinz M. (1993) Carbonate compositions in CM and CI chondrites, and implications for aqueous alteration. Geochim. Cosmochim. Acta, 57, 2843-2852.

Jones R. H. (1997a) Alteration of plagioclase-rich chondrules in CO3 chondrites; evidence for late-stage sodium and iron metasomatism in a nebular environment (abstract). In Workshop on Parent-body and nebular modification of chondritic materials, LPI Technical Report 9702, 30-31, Maui, HI, United States, July 17-19, 1997 (M. E. Zolensky, A. N. Krot, E. R. D. Scott, eds.).

Jones R. H. (1997b) Ubiquitous anorthitic plagioclase in type I chondrules in CO3 chondrites; implications for chondrule formation and parent-body metamorphism (abstract). In Meteorit. Planet. Sci., 32 (Suppl.), pp. 67-68. 
Keller L. P. (1998) A transmission electron microscope study of iron-nickel carbides in the matrix of the Semarkona unequilibrated ordinary chondrite. Meteorit. Planet. Sci., 33, 913919.

Kennedy B. M., Hudson B., Hohenberg C. M., and Podosek F. A. (1988) ${ }^{129} \mathrm{I}-{ }^{127} \mathrm{I}$ variations among enstatite chondrites. Geochim. Cosmochim. Acta, 52, 101-111.

Kerridge J. F. and Bunch T. E. (1979) Aqueous activity on asteroids: Evidence from carbonaceous meteorites. In Asteroids (ed. T. Gehrels), Univ. Arizona Press, pp. 745-764.

Kerridge J. F., Mackay A. L., and Boynton W. V. (1979a) Magnetite in CI carbonaceous meteorites: Origin by aqueous activity on a planetesimal surface. Science, 205, 395-397.

Kerridge J. F., Macdougall J. D., and Marti K. (1979b) Clues to the origin of sulfide minerals in CI chondrites. Earth Planet. Sci. Lett., 43, 359-367.

Kirschbaum C. (1988) Carrier phases for iodine in the Allende meteorite and their associated ${ }^{129} \mathrm{Xe}_{\mathrm{r}} /{ }^{129} \mathrm{I}$ ratios; a laser microprobe study. Geochim. Cosmochim. Acta, 52, 679-699.

Kimura M. and Ikeda Y. (1995) Anhydrous alteration of Allende chondrules in the solar nebula; II, Alkali-Ca exchange reactions and formation of nepheline, sodalite and Ca-rich phases in chondrules. In Proc. NIPR Symp. Antarctic Meteorites, $8^{\text {th }}$, pp. 123-138.

Kimura M. and Ikeda Y. (1998) Hydrous and anhydrous alterations of chondrules in Kaba and Mokoia CV chondrites. Meteorit. Planet. Sci., 33, 1139-1146.

Kojima T. and Tomeoka K. (1996) Indicators of aqueous alteration and thermal metamorphism on the CV3 parent body: Microtextures of a dark inclusion from Allende. Geochim. Cosmochim. Acta, 60, 2651-2666. 
Kracher A., Keil K., Kallemeyn G. W., Wasson J. T., Clayton R. N., and Huss G. R. (1985) The Leoville (CV3) accretionary breccia. In Proc. Lunar Planet. Sci. Conf., 16 ${ }^{\text {th }}$, J. Geophys. Res., B90, Suppl., D123-D135.

Krestina N., Jagoutz E., and Kurat G. (1996) Sm-Nd system in single chondrules from Tieschitz (H3) (abstract). In Lunar Planet. Sci. XXVII, Lunar Planet. Inst., Houston, pp. 701-702.

Krot A. N. and Todd C. S. (1998) Metal-carbide-magnetite-fayalite association in a Bali-like clast in the reduced CV3 chondrite breccia Vigarano (abstract). In Meteorit. Planet. Sci., 34 (Suppl.), A88-A89.

Krot A. N., Scott E. R. D., and Zolensky M. E. (1995) Mineralogic and chemical variations among CV3 chondrites and their components: Nebular and asteroidal processing. Meteoiritics, 30, 748-775.

Krot A. N., Scott E. R. D., and Zolensky M. E. (1997a) Origin of fayalitic olivine rims and platelike matrix olivine in the CV3 chondrite Allende and its dark inclusions. Meteoritics, 32, 3149.

Krot A. N., Zolensky M. E., Wasson J. T., Scott E. R. D., Keil K., and Ohsumi K. (1997b) Carbide-magnetite-bearing type 3 ordinary chondrites. Geochim. Cosmochim. Acta, 61, 219237.

Krot A. N., Petaev M. I., Scott E. R. D., Choi B.-G., Zolensky M. E., and Keil K. (1998a) Progressive alteration in CV3 chondrites: More evidence for asteroidal alteration. Meteorit. Planet. Sci., 33, 1065-1085.

Krot A. N., Zolensky M. E., Keil K., Scott E. R. D., and Nakamura K. (1998b) Secondary Ca-Ferich minerals in the Bali-like and Allende-like oxidized CV3 chondrites and Allende dark inclusions. Meteorit. Planet. Sci., 33, 623-645. 
Krot A. N., Brearley A. J., Ulyanov A. A., Biryukov V. V., Swindle T. D., K. Keil, Mittlefehldt D. W., Scott E. R. D., Clayton R. N., and Mayeda T. K. (1999) Mineralogy, petrography and bulk chemical, I-Xe, and oxygen isotopic compositions of dark inclusions in the reduced CV3 chondrite Efremovka. Meteorit. Planet. Sci., 34, 67-89.

Krot A. N., Brearley A. J., Petaev M. I., Kallemeyn G. W., Sears D. W. G., Benoit P. H., Hutcheon I. D., Zolensky M. E., and Keil K. (2000a) Evidence for in situ growth of fayalite and hedenbergite in MacAlpine Hills 88107, ungrouped carbonaceous chondrite related to CM-CO clan. Meteorit. Planet. Sci., 35, 1365-1387.

Krot A. N., Meibom A., and Keil K. (2000b) A clast of Bali-like oxidized CV3 material in the reduced CV3 chondrite breccia Vigarano. Meteorit. Planet. Sci., 35, 817-827.

Krot A. N., Hiyagon H., Petaev M. I., and Meibom A. (2000c) Oxygen isotopic compositions of secondary Ca-Fe-rich silicates from the Allende dark inclusions: Evidence against hightemperature formation (abstract). In Lunar Planet. Sci. XXXI, Lunar Planet. Inst., Houston, CD ROM \#1463.

Krot A. N., Petaev M. I., Meibom A., and Keil K. (2001) In situ growth of Ca-rich rims around Allende dark inclusions. Geochem. Internation., 36, 351-368.

Krot A. N., Meibom A., Weisberg M. K., and Keil K. (2002) The CR chondrite clan: Implications for early solar system processes. Meteorit. Planet. Sci., 37, 1451-1490.

Krot A. N., Petaev M. I., and Bland P. A. (2004a) Multiple formation mechanisms of ferrous olivine in CV3 carbonaceous chondrites during fluid-assisted metamorphism. Antarctic Meteorite Res., 17, 154-172. 
Krot A. N., Yurimoto H., Petaev M. I., Hutcheon I. D., and Wark D. A. (2004b) Type C CAIs: new insights into the early solar system processes (abstract). In Meteorit. Planet. Sci., 39, A57.

Kurat G., Palme H., Brandstätter F. and Huth J. (1989) Allende xenolith AF: Undisturbed record of condensation and aggregation of matter in the solar nebula. Zeitschr. Naturforsch., 44a, 988-1004.

Lavielle B. and Marti K. (1992) Trapped xenon in ordinary chondrites. J. Geochem. Res., 97, 875-881.

Leshin L. A., Rubin A. E., and McKeegan K. D. (1997) The oxygen isotopic composition of olivine and pyroxene from CI chondrites. Geochim. Cosmochim. Acta, 61, 835-845.

Leshin L. A., Farquhar J., Guan Y., Pizzarello S., Jackson T. L., and Thiemens M. H. (2001) Oxygen isotopic anatomy of Tagish Lake: Relatinship to primary and secondary minerals in CI and CM chondrites (abstract). In Lunar Planet. Sci. XXXII, Lunar Planet. Inst., Houston, CD-ROM \#1843.

Lewis R. S. and Anders E. (1975) Condensation time of the solar nebula from the extinct ${ }^{129}$ I in primitive meteorites. In Proc. Nat. Acad. Sci. USA, $72^{\text {nd }}, 268-273$.

Lugmair G. W. and Shukolyukov A. (1998) Early solar system timescales according to ${ }^{53} \mathrm{Mn}-$ ${ }^{53}$ Mn systematics. Geochim. Cosmochim. Acta, 62, 2863-2886.

Macdougall J. D. and Lugmair G. W. (1989) Chronology of chemical change in the Orgueil CI chondrite based on Sr isotope systematics (abstract). In Meteoritics, 24, 297.

Macdougall J. D., Lugmair G. W., and Kerridge J. F. (1984) Early solar system aqueous activity: Sr isotope evidence from the Orgueil CI meteorite. Science, 307, 249-251.

Mackinnon I. D. R. and Zolensky M. E. (1984) Proposed structures for poorly characterized 
phases in C2M carbonaceous chondrite meteorites. Nature, 309, 240-242.

MacPherson G. J. and Krot A. N. (2002) Distribution of Ca-Fe-silicates in CV3 chondrites: Possible controls by parent body compaction (abstract). In Meteorit. Planet. Sci., 37 (Suppl.), A91.

MacPherson G. J.., Wark D. A., and Armstrong J. T. (1988) Primitive material surviving in chondrites: Refractory inclusions. In Meteorites and the Early Solar System (J. F. Kerridge and M. S. Matthews, eds.), Univ. of Arizona Press, Tucson, pp. 746-807.

MacPherson G. J., Davis A. M., and Zinner E. K. (1995) The distribution of aluminum-26 in the early solar system: A reappraisal. Meteoritics, 30, 365-386.

McSween H. Y., Jr. (1977) Petrographic variations among carbonaceous chondrites of the Vigarano type. Geochim. Cosmochim. Acta, 41, 1777-1790.

McSween H. Y. Jr. (1979) Are carbonaceous chondrites primitive or processed? A review. Rev. Geophys. Space Phys., 17, 1059-1078.

Nichols R. H. Jr., Hohenberg C. M. and Olinger C. T. (1990) Allende chondrules and rims: I-Xe systematics (abstract). In Lunar Planet. Sci. XXI, Lunar Planet. Inst., Houston, pp. 879-880.

Nichols R. H. Jr., Hagee B. E., and Hohenberg C. M. (1991) Tieschitz chondrules; I-Xe systematics (abstract). In Lunar Planet. Sci. XXII, Lunar Planet. Inst., Houston, pp. 975-976.

Nyquist L. E., Reese Y., Wiesman H., Shih C. Y., and Takeda H. (2001) Live ${ }^{53} \mathrm{Mn}$ and ${ }^{26} \mathrm{Al}$ in an unique cumulate eucrite with very calcic feldspar (abstract). In Meteorit. Planet. Sci., 36 (Suppl.), pp. 151-152.

Palme H. and Wark D. A. (1988) CV-chondrites; high temperature gas-solid equilibrium vs. parent body metamorphism (abstract). In Lunar Planet. Sci. XXIX, Lunar Planet. Inst., Houston, pp. 897-898. 
Palme H. and Jones A. (2003) Solar system abundances of the elements. In Meteorites, Comets and Planets (ed Davis, A. M.), Vol. 1 of Treatise on Geochemistry (eds Holland H. D. and Turekian K. K.), Elsevier-Pergamon, Oxford, pp. 41-63.

Papanastassiou D. A. (1986) Chromium isotopic anomalies in the Allende meteorite. Ap. J., 308, L27-L30.

Podosek F. A. and Cassen P. (1994) Theoretical, observational, and isotopic estimates of the lifetime of the solar nebula. Meteoritics, 29, 6-25.

Pravdivtseva O. V. and Hohenberg C. M. (2001) (abstract). The I-Xe system of magnetic fractions from CV3 meteorites (abstract). In Lunar Planet. Sci. XXXII, Lunar Planet. Inst., Houston, CD-ROM \#2176.

Pravdivtseva O. V., Hohenberg C. M., Meshik A. P., and Krot A. N. (2001) I-Xe ages of different mineral fractions from Bali and Kaba (CV3) (abstract). In Meteorit. Planet. Sci., 36 (Suppl.), A168.

Pravdivtseva O. V., Krot A. N., Hohenberg C. M., Meshik A. M., Weisberg M. K., and Keil K. (2003a) The I-Xe record of alteration in the Allende CV chondrite. Geochim. Cosmochim. Acta, 67, 5011-5026.

Pravdivtseva O. V., Hohenberg C. M., and Meshik A. M. (2003b) The I-Xe age of Orgueil magnetite: New results (abstract). In Lunar Planet. Sci. XXXIV, Lunar Planet. Inst., Houston, CD-ROM \#1863.

Pravdivtseva O. V., Hohenberg C. M., Meshik A. M., Krot A. N., and Brearley A. J. (2003c) IXe age of the dark inclusions from the reduced CV3 chondrites Leoville, Efremovka, and Vigarano (abstract). In Meteorit. Planet. Sci., 38 (Suppl.), A140.

Richardson S. M. (1978) Vein formation in the C1 carbonaceous chondrites. Meteoritics, 13, 
141-159.

Riciputi L. R., McSween H. Y., Jr., Johnson C. A., and Prinz M. (1994) Minor and trace element concentrations in carbonates of carbonaceous chondrites, and implications for the compositions of coexisting fluids. Geochim. Cosmochim. Acta, 58, 1343-1351.

Rowe M. W., Clayton R. N., and Mayeda T. K. (1994) Oxygen isotopes in separated components of CI and CM meteorites. Geochim. Cosmochim. Acta, 58, 5341-5347.

Rubin A. E. (1998) Correlated petrologic and geochemical characteristics of CO3 chondrites. Meteorit. Planet. Sci., 33, 385-391.

Rubin A. E., Zolensky M. E., and Bodnar R.J. (2002) The halite-bearing Monahans (1998) and Zag meteorite breccias: Shock metamorphism, thermal metamorphism and aqueous alteration on the H-chondrite parent body. Meteorit. Planet. Sci., 37, 125-142.

Russell S. S., Huss G. R., Fahey A. J., Greenwood R. C., Hutchison R., and Wasserburg G. J. (1998) An isotopic and petrologic study of calcium-aluminum-rich inclusions from CO3 meteorites. Geochim. Cosmochim. Acta, 62, 689-714.

Scatena-Wachel D. E., Hinton R. W., and Davis A. M. (1984) Preliminary ion microprobe study of chromium isotopes in Orgueil (abstract). In Lunar Planet. Sci. XV, Lunar Planet. Inst., Houston, pp. 718-719.

Scott E. R. D. and Krot A. N. (2004) Thermal history of silicate dust in the solar nebula: Clues from primitive chondrite matrices. Astrophys. J. (in revision).

Sears D. W. G., Hasan F. A., Batchelor J. D., and Lu J. (1991) Chemical and physical studies of type 3 chondrites; XI, Metamorphism, pairing, and brecciation of ordinary chondrites. In Proc. Lunar Planet. Sci. Conf. $21^{\text {st }}$, pp. 493-512.

Swindle T. D. (1998) Implications of iodine-xenon studies for the dating and location of 
secondary alteration. Meteorit. Planet. Sci., 33, 1147-1157.

Swindle T. D. and Podosek F. A. (1988) Iodine-xenon dating. In Meteorites and the Early Solar System (eds Kerridge J. F. and Matthews M. S.), Univ. of Arizona Press, Tucson, pp. 11271146.

Swindle T. D., Caffee M. W., Hohenberg C. M., and Lindstrom M. M. (1983) I-Xe studies of individual Allende chondrules. Geochim. Cosmochim. Acta, 47, 2157-2177.

Swindle T. D., Caffee M. W., and Hohenberg C. M. (1988) Iodine-xenon studies of Allende inclusions: EGGs and the Pink Angel. Geochim. Cosmochim. Acta, 52, 2215-2229.

Swindle T. D., Grossman J. N., Olinger C. T., and Garrison D. H. (1991a) Iodine-xenon, chemical, and petrographic studies of Semarkona chondrules: Evidence for the timing of aqueous alteration. Geochim. Cosmochim. Acta, 55, 3723-3734.

Swindle T. D., Caffee M. W., Hohenberg C. M., Lindstrom M. M., and Taylor G. J. (1991b) Iodine-xenon studies of petrographically and chemically characterized Chainpur chondrules. Geochim. Cosmochim. Acta, 55, 861-880.

Swindle T. D., Cohen B., Li B., Olson E., Krot A. N., Birjukov V. V., and Ulyanov A. A. (1998) Iodine - xenon studies of separated components of the Efremovka (CV3) meteorite (abstract). In Lunar Planet. Sci. XXIX, Lunar Planet. Inst., Houston, CD-ROM \#1005.

Tomeoka K. (1990) Mineralogy and petrology of Belgica-7904: A new kind of carbonaceous chondrite from Antarctica. In Proc. NIPR Symp. Antarct. Meteorit. $3^{\text {rd }}$, pp. 40-54.

Tomeoka K. and Kojima T. (1998) Arcuate band texture in a dark inclusion from the Vigarano CV3 chondrite; possible evidence for early sedimentary processes. Meteorit. Planet. Sci., 33, 519-525. 
Tomeoka K., Kojima H., and Yanai K. (1989) Yamato-86720: A CM carbonaceous chondrite having experienced extensive aqueous alteration and thermal metamoprhism. In Proc. NIPR Symp. Antarct. Meteorit. $2^{\text {nd }}$, pp. 55-74.

Tonui E. K., Zolensky M. E., Lipschutz M. L., Wang M.-S., and Nakamura T. (2003) Yamato 86029: Aqueously altered and thermally metamorphosed CI-like chondrite with unusual textures. Meteorit. Planet. Sci., 38, 269-292.

Turner G., Enright M. C., and Cadogan P. H. (1978) The early history of chondrite parent bodies inferred from ${ }^{40} \mathrm{Ar}-{ }^{39} \mathrm{Ar}$ ages. In Proc.Lunar Planet. Sci. Conf. $9^{\text {th }}$, Geochim. Cosmochim. Acta, 9 (Suppl.), pp. 989-1025.

Weisberg M. K. and Prinz M. (1998) Fayalitic olivine in CV3 chondrite matrix and dark inclusions: A nebular origin. Meteorit. Planet. Sci., 33, 1087-1111.

Weisberg M. K., Prinz M., Zolensky M. E., and Ivanov A. V. (1994) Carbonates in Kaidun chondrite (abstract). In Meteoritics, 29, pp. 549-550.

Whitby J. A., Gilmour J. D., Ash R. D., Prinz M., and Turner G. (1997) Iodine-xenon dating of chondrules and matrix from the Qingzhen and Kota-Kota EH3 chondrite (abstract). In Meteorit. Planet. Sci., 32 (Suppl.), A140.

Whitby J., Burgess R., Turner G., Gilmour J., and Bridges J. (2000) Extinct ${ }^{129}$ I in halite from a primitive meteorite: Evidence for evaporite formation in the early solar system. Science, 288, 1819-1821.

Yurimoto H., Koike O., Nagahara H., Morioka M., and Nagasawa H. (2000) Heterogeneous distribution of Mg isotopes in anorthite single crystal from type B CAI in Allende meteorite (abstract). In Lunar Planet. Sci. XXXI, Lunar Planet. Inst., Houston, CD-ROM \#1593.

Zaikowski A. (1980) I-Xe dating of Allende inclusions: Antiquity and fine structure. Earth 
Planet. Sci. Lett., 47, 211-222.

Zolensky M. E. (1995) Cyclical regolith processes on hydrous asteroids (abstract). Meteoritics, 30, 606-607.

Zolensky M. E. and McSween H. Y., Jr (1988) Aqueous alteration. In Meteorites and the Early Solar System (eds. Kerridge J. F. and Matthews M. S.), University of Arizona Press, pp. $114-143$.

Zolensky M. and Ivanov A. V. (2003) The Kaidun microbreccia meteorite: a harvest from the inner and outer asteroid belt. Chem. Erde, 63, 185-246.

Zolensky M. E., Bourcier W. L., and Gooding J. L. (1989) Aqueous alteration on the hydrated asteroids: Results of EQ3/6 computer simulations. Icarus, 78, 411-425.

Zolensky M., Barrett R. and Browning L. (1993) Mineralogy and composition of matrix and chondrule rims in carbonaceous chondrites. Geochim. Cosmochim. Acta, 57, 3123-3148.

Zolensky M. E., Ivanov A. I., Yang S. V., Mittlefehldt D. W., and Ohsumi K. (1996) The Kaidun meteorite: Mineralogy of an unsual CM1 lithology. Meteorit. Planet. Sci., 31, 484-493.

Zolensky M. E., Bodnar R. J., Gibson E. K. Jr., Nyquist L. E., Reese Y., Shih C.-Y., and Wiesmann H. (1999) Asteroidal water within fluid inclusion-bearing halite in an H5 chondrite, Monahans (1998). Science, 185, 1377-1379. 
Table 1. The I-Xe ages of the dark inclusions from the reduced and oxidized CV chondrites relative to the age of Shallowater (4563.5 $\pm 1.0 \mathrm{Ma}$; Gilmour et al., work in progress) internal standard.

\begin{tabular}{|l|l|c|c|}
\hline chondrite/classif. & sample & I-Xe age, Ma & ref. \\
\hline Allende $\mathrm{CV}_{\text {oxA }}$ & $1 \mathrm{a}-1$ & $-2.8 \pm 0.3$ & {$[1]$} \\
& $12 \mathrm{~b}-1$ & $-2.0 \pm 0.3$ & \\
& $4294-1$ & $-1.9 \pm 0.3$ & \\
& $4 \mathrm{a} 1 / \mathrm{b} 1$ & $-1.9 \pm 0.3$ & \\
& IV-1 & $-1.9 \pm 0.2$ & \\
& $14 \mathrm{~b}-1$ & $-1.6 \pm 0.2$ & \\
& $4884-2$ & $-1.5 \pm 0.2$ & \\
& $4301-1$ & $-1.5 \pm 0.1$ & \\
& $4884-1$ & $-1.4 \pm 0.8$ & \\
& $4314-3$ & $-1.1 \pm 0.2$ & \\
& $1-3$ & $-1.1 \pm 0.2$ & \\
& $25 s l-t w 1$ & $-1.1 \pm 0.2$ & \\
& $4320-1$ & $-1.0 \pm 0.3$ & \\
& $4884-6$ & $-1.0 \pm 0.2$ & \\
& IV-2 & $-0.8 \pm 0.3$ & \\
& $4884-5$ & $-0.7 \pm 0.2$ & \\
& $4884-3$ & $-0.5 \pm 0.3$ & \\
\hline Leoville CV red & LV1 & $+3.0 \pm 0.1$ & [4] \\
& LV2 & $+9.5 \pm 2.3$ & \\
\hline Efremovka CV & E53 & $-4.9 \pm 1.8$ & {$[2,3]$} \\
& E39 & $+0.8 \pm 2.0$ & \\
\hline & E80 & $-1.0 \pm 0.5$ & \\
\hline
\end{tabular}

References: [1] Pravdivtseva et al. (2003b); [2] Krot et al. (1999); [3] Swindle et al. (1998); [4] Pravdivtseva et al. (2003c). 
Table 2. The I-Xe ages of chondrules from type 3 ordinary and enstatite chondrites relative to the age of Shallowater (4563.5 $\pm 1.0 \mathrm{Ma}$; Gilmour et al., work in progress) internal standard.

\begin{tabular}{|c|c|c|c|}
\hline chondrite/classif. & chd\# & I-Xe age, Ma & ref. \\
\hline \multirow[t]{19}{*}{ Semarkona, LL3.0 } & CD-159(l) & $+4.9 \pm 0.5$ & \multirow[t]{19}{*}{ [1] } \\
\hline & CD-159(h) & $-4.9 \pm 2.9$ & \\
\hline & CD-92 & $-1.9 \pm 1.1$ & \\
\hline & CD-95 & $+4.1 \pm 1.2$ & \\
\hline & CD-54 & $-0.4 \pm 1.2$ & \\
\hline & CD-79 & $+0.6 \pm 1.7$ & \\
\hline & CD-60 & $-2.4 \pm 1.7$ & \\
\hline & CD-173 & $-1.8 \pm 2.1$ & \\
\hline & CD-160 & $+4.7 \pm 1.1$ & \\
\hline & CD-8(l) & $+0.6 \pm 1.1$ & \\
\hline & CD-8(h) & $-4.5 \pm 2.3$ & \\
\hline & CD-84(l) & $+0.8 \pm 0.3$ & \\
\hline & CD-84(h) & $-2.5 \pm 0.9$ & \\
\hline & CD-129 & $+1.3 \pm 1.0$ & \\
\hline & CD-153 & $-1.8 \pm 2.8$ & \\
\hline & CD-169 & $0 \pm 0.3$ & \\
\hline & CD-139 & $-2.6 \pm 2.5$ & \\
\hline & CD-101 & $-4.2 \pm 0.6$ & \\
\hline & CD-174 & $-1.9 \pm 1.7$ & \\
\hline \multirow[t]{7}{*}{ Parnallee, LL3.4 } & CB1 & $+4.16 \pm 0.44$ & \multirow[t]{7}{*}{ [2] } \\
\hline & CB2 & $+1.29 \pm 0.16$ & \\
\hline & P6 & $+4.54 \pm 0.70$ & \\
\hline & P9 & no ${ }^{129} \mathrm{Xe}^{*}$ & \\
\hline & Feline & +5.05 & \\
\hline & P32 & $+1.94 \pm 0.26$ & \\
\hline & MC1 & no ${ }^{129} \mathrm{Xe}^{*}$ & \\
\hline \multirow[t]{7}{*}{ Qingzhen, EH3 } & QC1 & +1.98 & \multirow[t]{7}{*}{ [3] } \\
\hline & QC3 & +0.44 & \\
\hline & QC4 & -1.08 & \\
\hline & QC5 & +1.41 & \\
\hline & QC6 & +0.10 & \\
\hline & QC7 & +0.64 & \\
\hline & QC8 & +1.70 & \\
\hline
\end{tabular}

References: [1] Swindle et al. (1991a); [2] Ash et al. (1995); [3] Ash et al. (1997). 
Table 3. The initial ${ }^{53} \mathrm{Mn} /{ }^{55} \mathrm{Mn}$ ratios in secondary carbonate and fayalite in carbonaceous

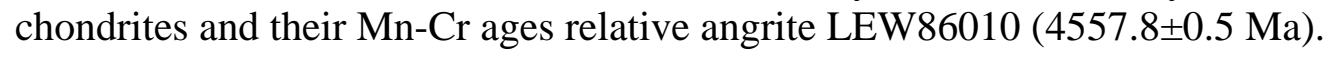

\begin{tabular}{|c|c|c|c|c|c|}
\hline chondrite & classification & $\begin{array}{c}\text { mineral } \\
\text { analyzed }\end{array}$ & $\left({ }^{53} \mathrm{Mn} /{ }^{55} \mathrm{Cr}\right)_{0}$ & $\begin{array}{l}\text { age relative } \\
\text { LEW86010 }\end{array}$ & ref. \\
\hline Orqueil \& Ivuna & CI & dolomite & $(1.99 \pm 0.16) \times 10^{-6}$ & $-2.5 \pm 0.7$ & {$[1]$} \\
\hline Orqueil & $\mathrm{CI}$ & dolomite & $(1.42 \pm 0.16) \times 10^{-6}$ & $-0.7 \pm 0.9$ & {$[1]$} \\
\hline Orqueil & CI & breunnerite & $(1.97 \pm 0.18) \times 10^{-6}$ & $-2.5 \pm 0.8$ & {$[2]$} \\
\hline Orqueil & $\mathrm{CI}$ & breunnerite & $(3.4 \pm 0.4) \times 10^{-6}$ & $-5.3 \pm 0.9$ & {$[2]$} \\
\hline Orqueil & CI & Cr-carbonates & $3.4 \times 10^{-6}$ & -5.3 & {$[3]$} \\
\hline Supuhee, clast & CI-like & $\begin{array}{l}\text { carbonates } \\
\text { calcite, }\end{array}$ & $(8 \pm 4) \times 10^{-6}$ & $-9.9 \pm 2.5$ & {$[3]$} \\
\hline Kaidun* & breccia & dolomite & $(9.4 \pm 1.6) \times 10^{-6}$ & $-10.8 \pm 1.1$ & {$[4]$} \\
\hline ALH84034 & CM1 & dolomite & $(5.0 \pm 1.5) \times 10^{-6}$ & $-7.4 \pm 1.7$ & {$[5]$} \\
\hline Y791198 & CM2 & calcite & $(8.7 \pm 1.5) \times 10^{-6}$ & $-10.3 \pm 2.2$ & {$[6]$} \\
\hline Kaba & $\mathrm{CV}_{\text {oxB }}$ & fayalite & $(2.32 \pm 0.18) \times 10^{-6}$ & $-3.3 \pm 0.7$ & [7] \\
\hline Mokoia & $\mathrm{CV}_{\text {oxB }}$ & fayalite & $(2.28 \pm 0.37) \times 10^{-6}$ & $-3.2 \pm 1.0$ & [8] \\
\hline MAC88107 & ungrouped & fayalite & $(1.58 \pm 0.28) \times 10^{-6}$ & $-1.3 \pm 1.2$ & [9] \\
\hline
\end{tabular}




\section{FIGURE CAPTIONS}

Fig. $1 .{ }^{53} \mathrm{Mn}-{ }^{53} \mathrm{Cr}$ evolution diagrams for carbonates in CI chondrites. a - Dolomite fragments from Orgueil and Ivuna; b - an expanded-scale view of the lower left-hand corner of this plot. The labels a, b and c denore different spots on a given dolomite fragment. The line of slope $1.99 \times 10^{-6}$ is a best-fit line through all data points for Orgueil 5 and normal $\mathrm{Cr}$ (that is, $\delta^{53} \mathrm{Cr}=0$ at ${ }^{55} \mathrm{Mn} /{ }^{52} \mathrm{Cr}=0$ ). The data points for Orqueil 8 and Ivuna 2 fragments are consistent with this line, the data points for the remaining two fragments, Orgueil 1 and 2, fall close to the line of slope $1.42 \times 10^{-6}$ but, compared to the analytical errors, the deviations are not large enough to clearly establish that different carbonates formed at different times (from Endress et al., 1996). c, d - Breunnerite and dolomite in Orgueil (c) and dolomite in Supuhee (d) CI carbonaceous chondrites. Different symbols represent different grains. The lines of slope $(1.97 \pm 0.18) \times 10^{-6}$ and $(8 \pm 4) \times 10^{-6}$ are the best-fit lines through all data points and normal Cr; error bars are $2 \sigma$ (from Hutcheon and Phinney, 1996; Hutcheon et al., 1997).

Fig. $2 .{ }^{129} \mathrm{I}-{ }^{129} \mathrm{Xe}$ evolution diagrams for the Orgueil magnetic separates and Shallowater aubrite. The ${ }^{129} \mathrm{I}-{ }^{129} \mathrm{Xe}$ ages for the nearly pure magnetite fraction containing $>90 \%$ magnetite predate

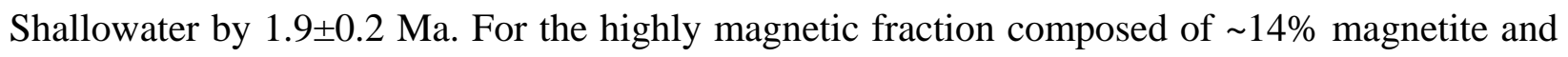

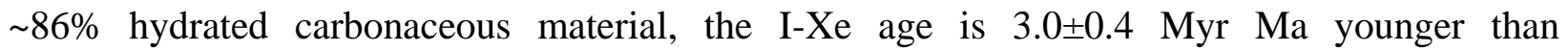
Shallowater (4563.5 $\pm 1 \mathrm{Ma}$; Gilmour et al., work in progress), suggesting that the magnetic fraction may contain several iodine carriers recording different stages of aqueous activity on the CI parent body; error bars are $1 \sigma$ (data from Hohenberg et al., 2000 and Pravdivtseva et al., 2003b).

Fig. 3. Oxygen isotopic compositions of separated components from CI and CM chondrites. Phyllosilicate-rich matrix (phyl) + carbonates and magnetite (mgt) in CI chondrites, as well as 
phyllosilicate-rich matrix and carbonates in CM chondrites are out of isotopic equilibrium. Similar $\Delta^{17} \mathrm{O}$ values for calcite and dolomite fractions from the same splits of the same CM chondrites indicate that both minerals in each split precipitated from a single fluid reservoir. The terrestrial fractionation (TF) line is shown for reference (data from Rowe et al., 1994; Leshin et al., 2001; Benedix et al., 2003).

Fig. 4. ${ }^{53} \mathrm{Mn}-{ }^{53} \mathrm{Cr}$ evolution diagrams for carbonates from (a) Kaidun, and CM carbonaceous chondrites (b) Y791198 and (c) ALH84034. Different symbols represent different grains. The lines of slope $(9.4 \pm 1.6) \times 10^{-6},(8.7 \pm 1.5) \times 10^{-6}$, and $(5.0 \pm 1.5) \times 10^{-6}$ are the best-fit lines through all data points and normal Cr; error bars are $2 \sigma$ (data from Hutcheon et al., 1999; Brearley et al., 2001; Brearley and Hutcheon, 2000).

Fig. 5. Backscattered electron (BSE) images of (a, b) a porphyritic olivine-pyroxene type I chondrule, (c) isolated fayalitic olivine grain and (d) magnetite-sulfide nodule in the ungrouped carbonaceous chondrite MAC88107. a, b - The chondrule is surrounded by a continuous finegrained rim (FGR) crosscut by fayalite (fa) - hedenbergite (hed) - magnetite (mgt) veins. The veins start at the opaque nodules composed of Ni-bearing sulfide and magnetite in the peripheral portion of the chondrule. Chondrule mesostasis $(\mathrm{lm})$ is largely leached out, whereas forsteritic olivine (fo) and low-Ca pyroxene (px) phenocrysts appear to be unaltered. c - Fayalitic olivine (fa ol) is overgrown by fayalite. d - Fayalite preferentially replaces magnetite of the sulfidemagnetite nodule. Low-Ca pyroxene grains at the contact with fayalite and magnetite and forsteritic olivine grain overgrown by fayalite appear to be unaltered (after Krot et al., 2000a).

Fig. $6 .{ }^{53} \mathrm{Mn}-{ }^{53} \mathrm{Cr}$ evolution diagrams for (a) a fayalite grain from the ungrouped carbonaceous chondrite MAC88107, (b) four fayalite grains in three porphyritic olivine-pyroxne type I chondrules from the $\mathrm{CV}_{\text {oxB }}$ chondrite Mokoia, and (c) twelve fayalite grains in matrix of the 
$\mathrm{CV}_{\text {oxB }}$ chondrite. The lines of slope $(1.58 \pm 0.26) \times 10^{-6},(2.32 \pm 0.18) \times 10^{-6}$ and $(2.28 \pm 0.37) \times 10^{-6}$, are the best-fit lines through the data points and normal Cr; error bars are $2 \sigma$ (data from Hutcheon et al., 1998; Krot et al., 2000a; Hua et al., 2002).

Fig. 7. BSE images of matrices in the oxidized CV chondrites (a-b) and Allende dark inclusions (d). All matrices contain $\mathrm{Ca}, \mathrm{Fe}-$ pyroxenes-andradite (hed-andr) nodules. Matrix in the $\mathrm{CV}_{\text {oxB }}$ Kaba contains nearly pure fayalite $\left(\sim \mathrm{Fa}_{100}\right)$ and very fine-grained groundmass largely composed of ferrous olivine $\left(\sim \mathrm{Fa}_{50}\right)$ and phyllosilicates. Matrix in the $\mathrm{CV}_{\text {oxA-B }}$ MET00430 contains fayalite grains showing inverse compositional zoning $\left(\mathrm{Fa}_{80} \mathrm{-50}_{0}\right)$ and coarser grained lath-shaped ferrous olivine $\left(\sim \mathrm{Fa}_{50}\right)$. Matrices in the $\mathrm{CV}_{\text {oxA }}$ ALH81258 and Allende dark inclusion contain relatively coarse-grained, lath-shaped compositionally uniform $\left(\sim \mathrm{Fa}_{50}\right)$ ferrous olivine.

Fig. 8. BSE images of different textural occurrences of secondary fayalite in the $\mathrm{CV}_{\text {oxB }}$ chondrites Kaba and Mokoia. a, b - Porphyritic olivine-pyroxene (POP) type I chondrule surrounded by a continuous fine-grained rim crosscut by fayalite (fa) - magnetite (mgt) veins. The veins start at the opaque nodules composed of Ni-bearing sulfide (sf) and magnetite in the peripheral portion of the chondrule. Region outlined in "a" is shown in detail in "b". c - Opaque nodule in type I chondrule replaced by magnetite, Ni-bearing sulfides, fayalite, and salitehedenbergite pyroxenes (hed). d - Opaque nodule within type I POP chondrule; numbers correspond to fayalite content (in mol\%). Magnetite is replaced by pure fayalite $\left(\mathrm{Fa}_{100}\right)$; forsterite phenocrysts $\left(\mathrm{Fa}_{1}\right)$ are partly pseudomorphed by ferrous olivine $\left(\mathrm{Fa}_{63}\right)$; an outline of one of the grains is indicated by arrows. Fayalite is crosscut by a vein of ferrous olivine ( $\left.\mathrm{Fa}_{87}\right)$, suggesting that forsterite if the source of Mg. e - Amoeboid olivine aggregate composed of forsterite, spinel, Al-diopside, and anorthite. Forsterite grains are overgrown by euhedral ferrous olivines ranging in compositions from $\mathrm{Fa}_{<50}$ to $\mathrm{Fa}_{73}$; some of the fayalite grains contain inclusions of $\mathrm{Fe}, \mathrm{Ni}$ - 
sulfides (sf). f - Fine-grained CAI consisting of concentrically-zoned objects composed of spinel (sp) surrounded by phyllosilicates (phyl) and Al-diopside (di); phyllosilicates probably replace primary anorthite or melilite. Euhedral fayalite grains occur between these bodies; $\mathrm{Ca}, \mathrm{Fe}-$ pyroxenes (hed) overgrow Al-diopside.

Fig. 9. Oxygen isotopic compositions of secondary magnetite (Mgt), fayalite (Fa), Ca,Fe-rich pyroxenes (CaFe-px), andradite (Andr), and wollastonite (Wol), and primary forsteritic olivine (Fo) (a) in type I chondrules in the $\mathrm{CV}_{\text {oxB }}$ chondrites Kaba and Mokoia (data from Choi et al., 2000; Hua et al., 2003), (b) in chondrules, matrix (mx), and in rims around CAIs (data from Choi et al., 2000; Cosarinsky et al., 2003), and (c) in and around Allende dark inclusions (data from Krot et al., 2000c); error bars are $2 \sigma$. The terrestrial fractionation (TF) line and carbonaceous chondrite anhydrous mineral (CCAM) line are shown for reference. (a) In Mokoia, the magnetite and fayalite differ in $\delta^{18} \mathrm{O}$ by $\sim 20 \%$, suggesting formation at low-temperature. In Kaba, the compositions of fayalite and magnetite reported by Choi et al. (2000) are nearly identical, and very close to the intersection of the TF and CCAM lines. The compositions of Kaba fayalites reported by Choi et al. (2000) are inconsistent with those reported by Hua et al. (2003); the latter are similar to those of Mokoia fayalites. We note that compositions of fayalite and magnetite in Kaba reported by Choi et al., 2000) were collected with a 3 month interval and might be in error. Compositions of forsteritic olivine phenocrysts plot along CCAM line and are not in equilibrium with those of the secondary minerals. (b) Oxygen isotope compositions of Ca,Fe-rich pyroxenes and andradite in matrix (mx) and in rims around CAIs are similar and plot parallel to the TF with a range in $\delta^{18} \mathrm{O}$ of $\sim 20 \%$, suggesting formation at low-temperature. Oxygen isotope compositions of magnetite overlap with those of $\mathrm{Ca}, \mathrm{Fe}-\mathrm{pyroxenes}$ and andradite, but plot largely to the left from CCAM line. 
Fig. $10 .{ }^{129} \mathrm{I}-{ }^{129} \mathrm{Xe}$ evolution diagrams for mineral fractions separated from the $\mathrm{CV}_{\text {oxB }}$ chondrites (a-c) Kaba and (d-f) Bali; error bars are $1 \sigma$. The I-Xe ages shown are relative to the Shallowater internal standard (4563.5 \pm 1 Ma; Gilmour et al., work in progress). Numbers next to points represent extraction $\mathrm{W}$-coil temperatures in ${ }^{\circ} \mathrm{C}$ (the sample is probably $150-200^{\circ} \mathrm{C}$ cooler).

Fig. 11. a-d - BSE images of secondary minerals in POP type I chondrules in the $\mathrm{CV}_{\text {oxA }}$ chondrite ALH84028. Magnetite-sulfide nodules are replaced by ferrous olivine (fa) and Ca,Fepyroxenes (CaFe-px); both contain abundant inclusions of sulfides (sf). Low-Ca pyroxene phenocryststs (px) are replaced by ferrous olivine. Chondrule mesostasis is replaced by nepheline (nph). Forsteritic olivine (fo) phenocrysts are largely unaltered, but show enrichment in fayalite contents near the edges and along the fractures. e, f - BSE images of secondary fayalite in the $\mathrm{CV}_{\text {oxA-B }}$ chondrite MET00430. e - Fayalite overgrowing olivine-pyroxene chondrule fragment shows inverse compositional zoning ( $\left.\mathrm{Fa}_{75-50}\right)$. f - Euhedral fayalite grain overgrowing low-Ca pyroxene (px) phenocryst in outer part of a type I chondrule shows complex chemical zoning suggesting dissolution of fayalite and precipitation of more forsteritic olivine from a fluid phase. Numbers correspond to fayalite contents (from Krot et al., 2004a).

Fig. 12. a-c $-{ }^{129} \mathrm{I}-{ }^{129} \mathrm{Xe}$ evolution diagrams for fine-grained CAIs in Allende (from Pravdivtseva et al., 2003b). The contribution from trapped Xe component is within experimental uncertainty consistent with the "planetary" OC-Xe (Lavielle and Marti, 1992). d-f $-{ }^{129} \mathrm{I}^{129}$ Xe evolution diagrams for Allende dark inclusions. Two isochrons plotted for the dark inclusion IV-1 correspond to low- and high-temperature Xe released. All isochrons suggest "sub-planetary" trapped components (Hohenberg et al., 2004). Error bars are $1 \sigma$. I-Xe ages are relative to the Shallowater internal standard (4563.5 \pm 1 Ma; Gilmour et al., work in progress). 
Fig. 13. BSE images of altered chondrules in the dark inclusions (DI) 3529 (a), 4301-2 (b), E53 (c, d), and E39 (e, f) in the oxidized CV chondrite Allende (a, b) and in the reduced CV chondrite Efremovka (c-f). a, b - Chondrules are replaced to various degrees by ferrous olivine, nepheline (nph; black in "d"), and Ca,Fe-pyroxenes (Ca,Fe-px). Chondrule shown in "a" is surrounded by a fine-grained rim composed of lath-shaped ferrous olivine (fa) and nepheline. The rim is crossut by a vein composed of Ca,Fe-pyroxenes and Fe,Ni-sulfides (white). The vein starts at the opaque nodule (outlined) that is replaced by Ca,Fe-pyroxenes and ferrous olivine; sulfide grains (white) are relict. c, d - Chondrules in E53 are pseudomorphed to a various degree by a fine-grained mixture of ferrous olivine (fa) and very minor phyllosilicates (phyl). e, $\mathrm{f}$ Chondrules in E39 are nearly completely replaced by a fine-grained mixture of ferrous olivine, phyllosilicates, and andradite (andr). Forsteritic olivine (fo) and high-Ca pyroxenes (срx) are relict. mes $=$ mesostasis; met $=$ Fe,Ni-metal (from Krot et al., 1998a, 1999).

Fig. 14. Ca Ka X-ray elemental maps of the heavily-altered dark inclusions 4301-2 (a) and IV-1 (b) in the oxidized CV chondrite Allende. The dark inclusions (DI) contain chondrule pseudomorphs (indicated by stars) which are depleted in Ca and consist of the secondary ferrous olivine, nepheline, sodalite, and Fe,Ni-sulides (see Fig. 14b). The dark inclusion 4301-2 is crosscut by multiple veins composed of Ca,Fe-pyroxenes and andradite. Both dark inclusions are surrounded by continuous Ca-rich rims composed of Ca,Fe-pyroxenes, andradite, wollastonite, and kirschteinite. The outer portions of the dark inclusions are depleted in Ca, whereas the neighboring matrix of Allende contains abundant Ca,Fe-rich nodules composed of $\mathrm{Ca}$,Fepyroxenes, andradite, and wollastonite, suggesting that Ca lost from the dark inclusions precipitated as rims and nodules around them (from Krot et al., 2001). 
Fig. 15. ${ }^{129} \mathrm{I}-{ }^{129}$ Xe evolution diagrams for the Efremovka dark inclusions E53, E39 (data from Swindle et al., 1998; Krot et al., 1999), and E80; error bars are $1 \sigma$ (data from Pravdivtseva et al., 2003c). The ages shown are relative to the Shallowater internal standard (4563.5 \pm 1 Ma; Gilmour et al., work in progress). The two apparent isochrons for E80 correspond to different peaks in the release profiles of radiogenic ${ }^{128} \mathrm{Xe}$ and ${ }^{129} \mathrm{Xe}$, suggesting that E80 contains two different iodinecarrying mineral phases with the same closure time but different trapped components. The circled temperature points represent intermediate extraction steps between these two release peaks where radiogenic ${ }^{128} \mathrm{Xe}$ and ${ }^{129} \mathrm{Xe}$ do not correlate.

Fig. 16. Representative three-isotope plots for Xe from irradiated Semarkona chondrules. These include one sample with dual isochrons (CD-159), and samples with single isochrons with apparent old (CD-92 and CD-101) and young (CD-160) I-Xe ages. Diamonds denote points included in high-temperature isochrons and circles are those included in low-temperature (or single) isochrons; erros bars are $1 \sigma$. Numbers next to points represent extraction coil temperatures in ${ }^{\circ} \mathrm{C}$ (the sample is probably $200-300^{\circ} \mathrm{C}$ cooler) (from Swindle et al., 1991a).

Fig. $17 .{ }^{129} \mathrm{I}-{ }^{129}$ Xe evolution diagrams for Tieschitz chondrules. Numbers next to points represent extraction coil temperatures in ${ }^{\circ} \mathrm{C}$ (the sample is probably $200-300^{\circ} \mathrm{C}$ cooler); erros bars are $2 \sigma$ (from Nichols et al., 1991).

Fig. 18. Mn-Cr ages of the secondary carbonates and fayalite in carbonaceous chondrites relative to the LEW86010 angrite; errors are 2 $\sigma$ (data from Endress et al., 1996; Hutcheon and Phinney, 1996; Hutcheon et al., 1997, 1998, 1999; Brearley and Hutcheon, 2000); Brearley et al., 2001; Hua et al., 2002; Krot et al., 2000a). Absolute ages of CAIs from CV chondrites (4567.2 \pm 0.6 Myr; Amelin et al., 2002) and ages calculated based on the initial ${ }^{53} \mathrm{Mn} /{ }^{55} \mathrm{Mn}$ ratios of $1.4 \times 10^{-5}$ 
(Lugmair and Shukolyukov, 2001), $(2.8 \pm 0.3) \times 10^{-5}$ (Nyquist et al., 2001), and $4.4 \times 10^{-5}$ (Birck and Allègre, 1988; Birck et al, 1999) are plotted for reference.

Fig. 19. I-Xe ages of the CV chondritic components (CAIs, chondrules, matrix, dark inclusions) and mineral fractions (magnetite, phyllosilicates) relative to the Shallowater aubrite internal

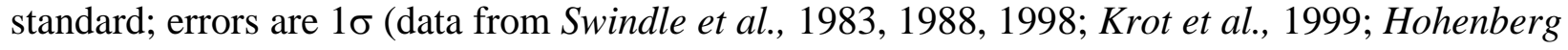
et al., 2001; Pravdivtseva et al., 2003b,c). Based on the comparison of I-Xe and Mn-Cr systems with the absolute $\mathrm{Pb}-\mathrm{Pb}$ chronometer for samples analysed by mulitple isotope systems, Gilmour et al. (work in progress) infer that the I-Xe system closed in Shallowater aubrite at $4563.5 \pm 1.0$ Ma before the present, i.e. 5.7 \pm 1.1 Ma earlier than the Mn-Cr system closed in LEW86010 angrite. 
Fig. 1.
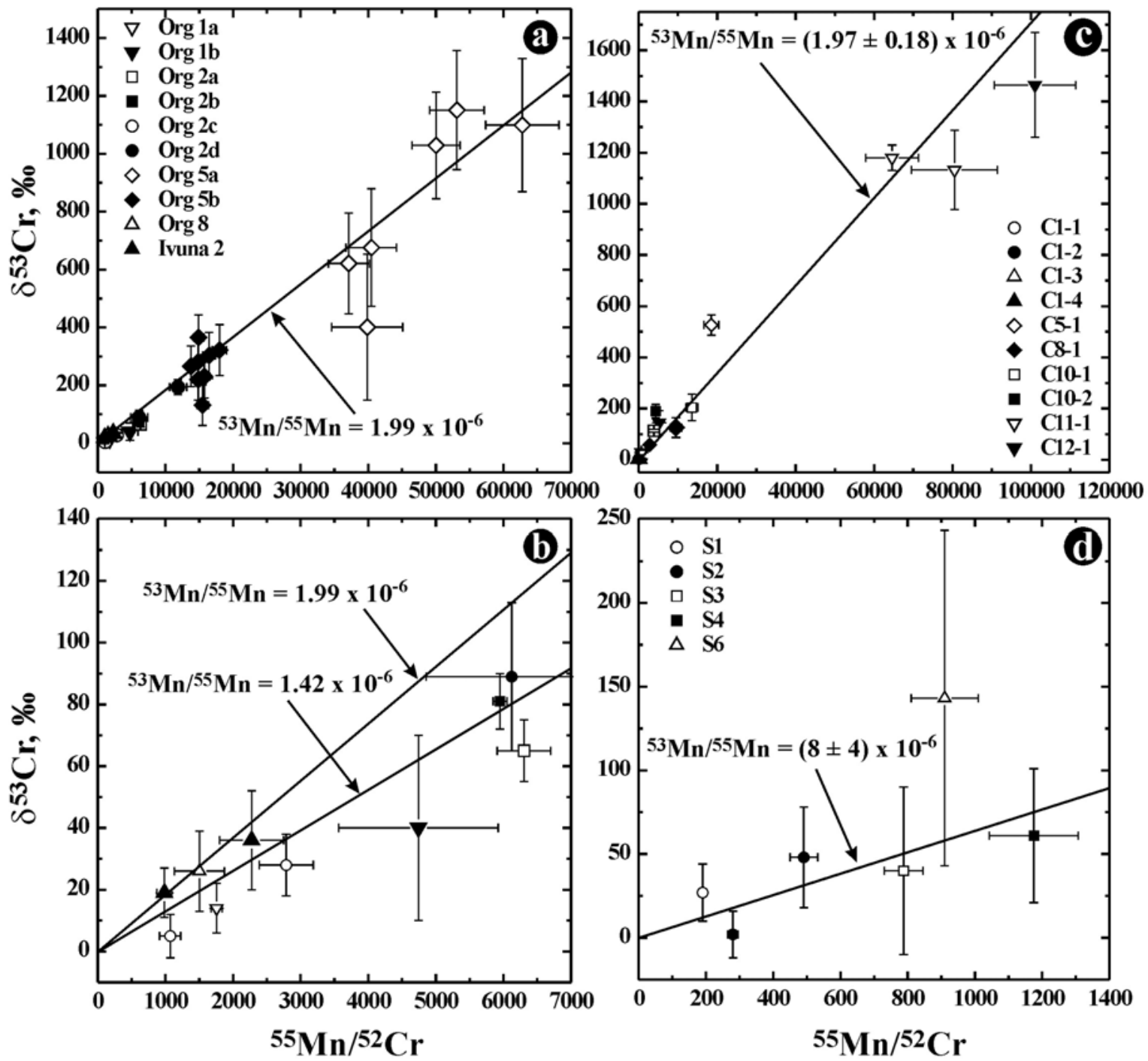
Fig. 2.
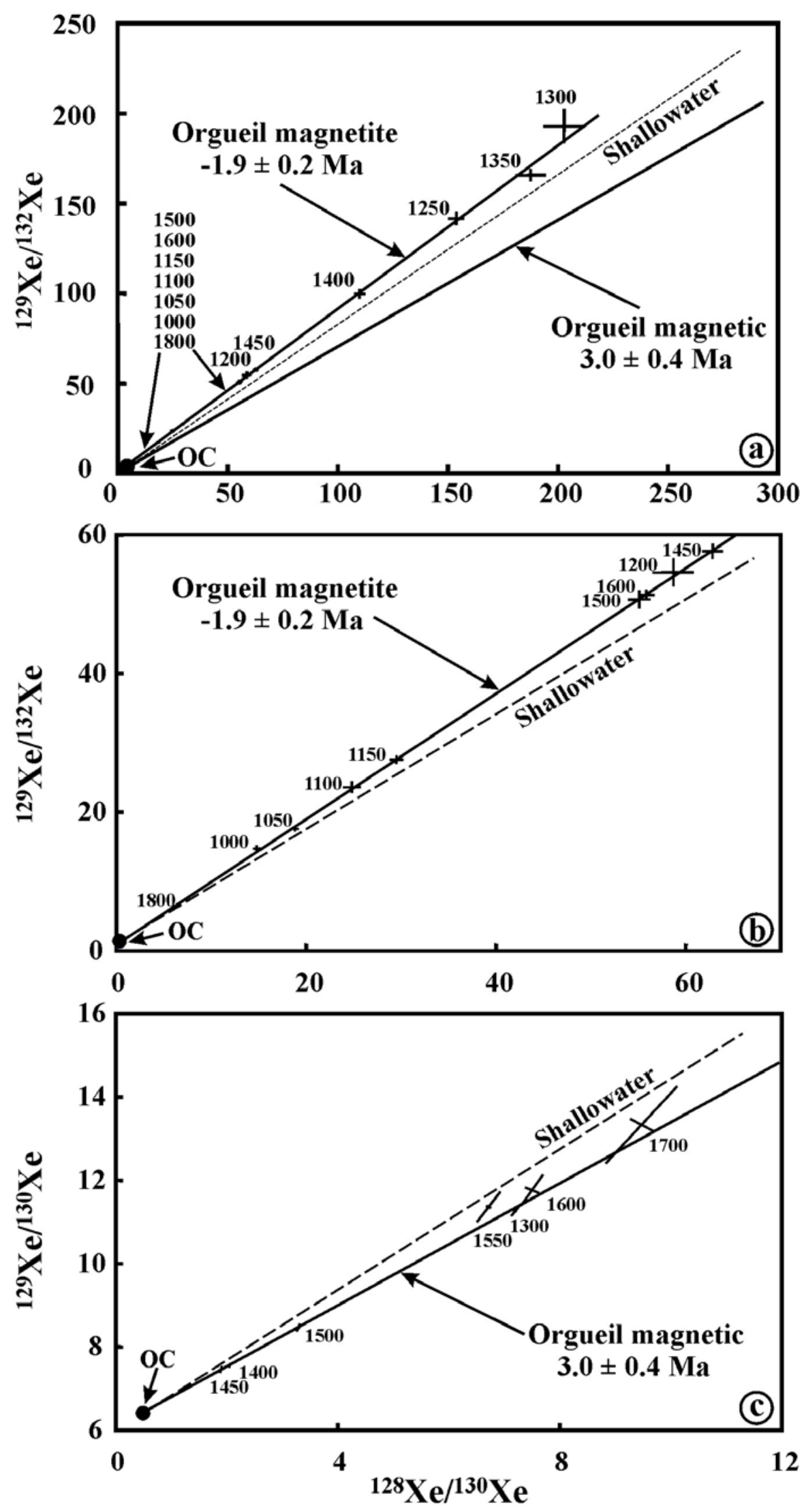
Fig. 3.

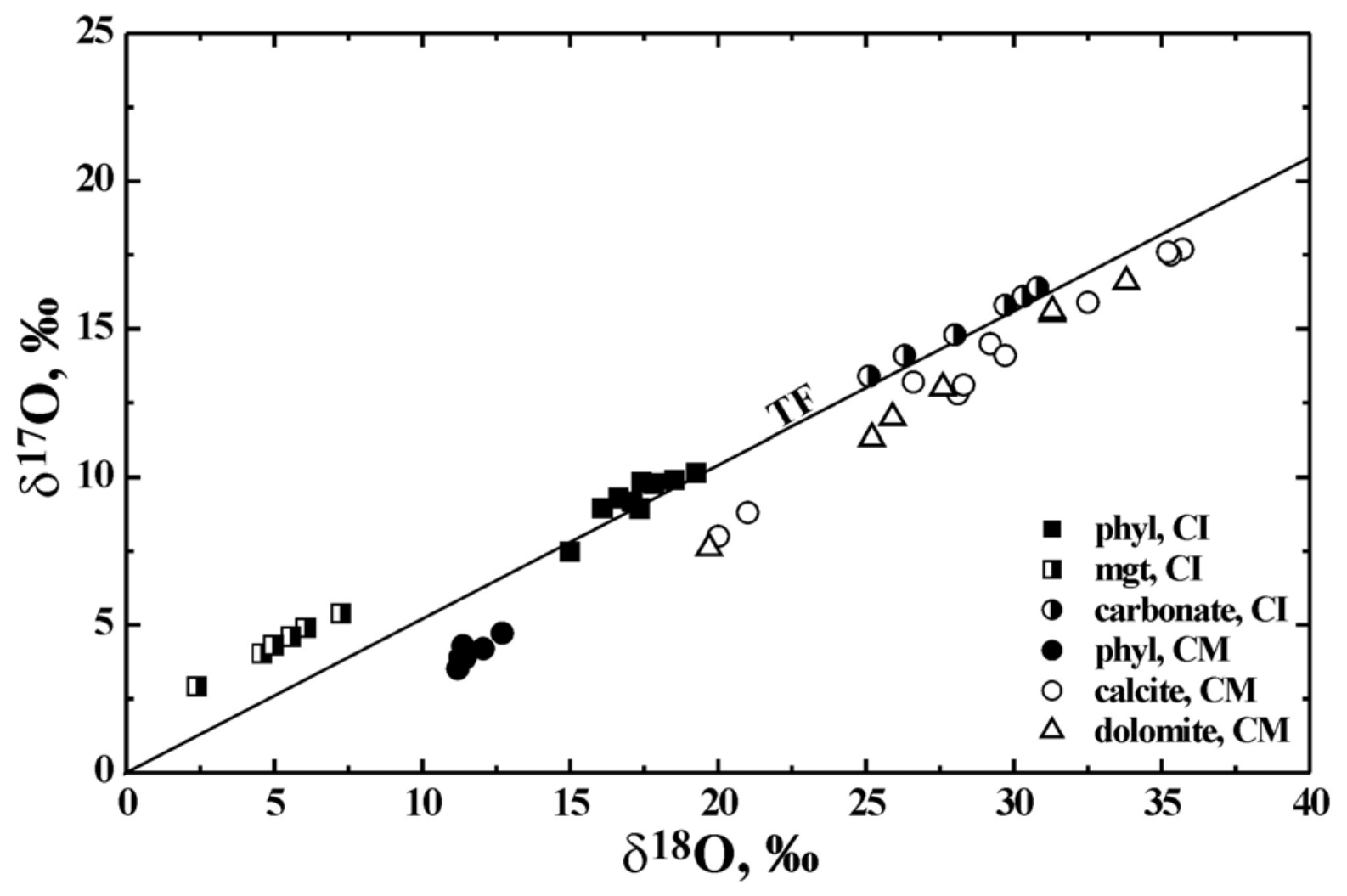


Fig. 4.
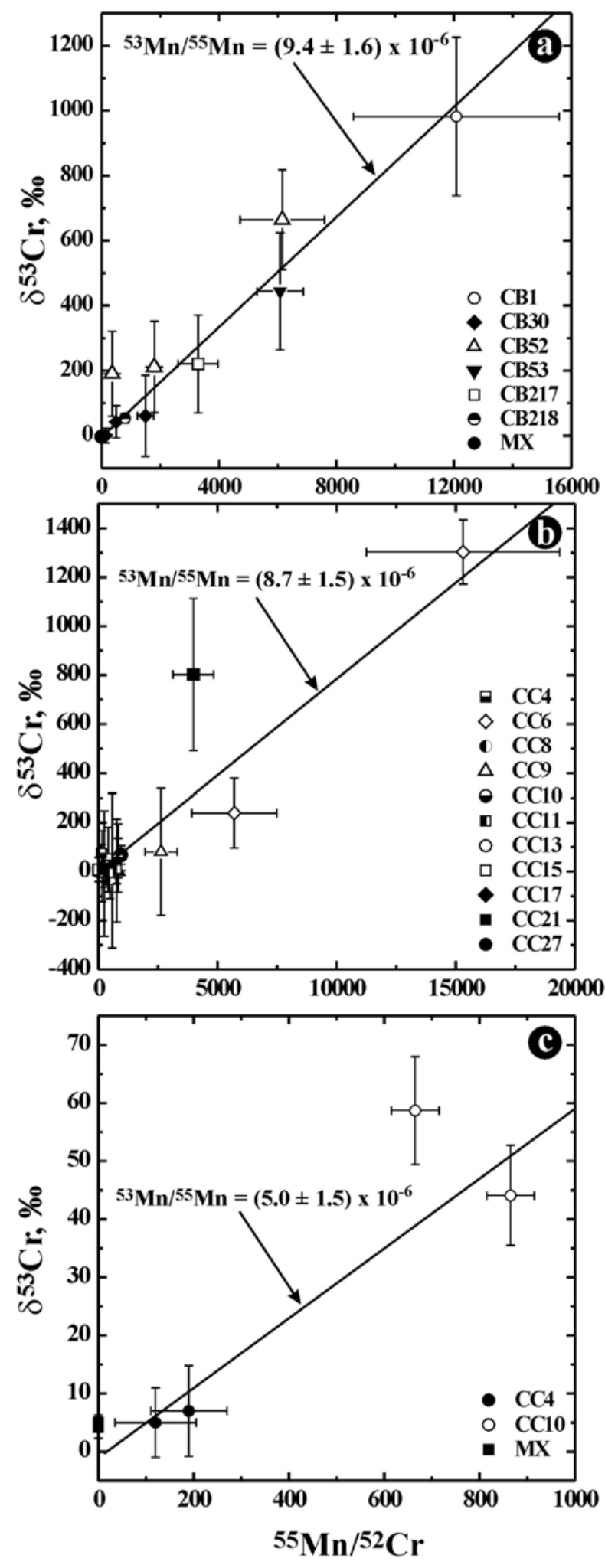
Fig. 5.

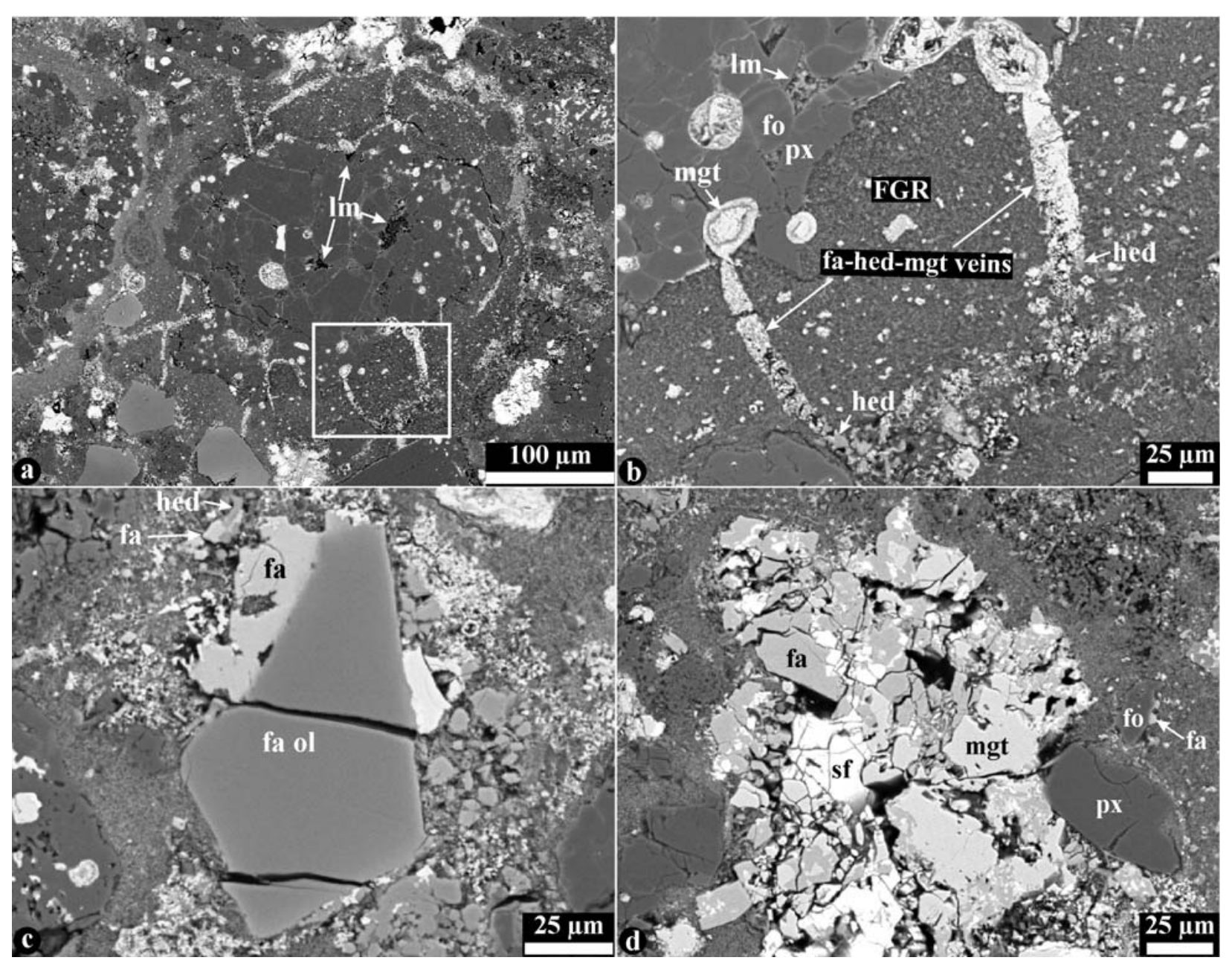


Fig. 6.
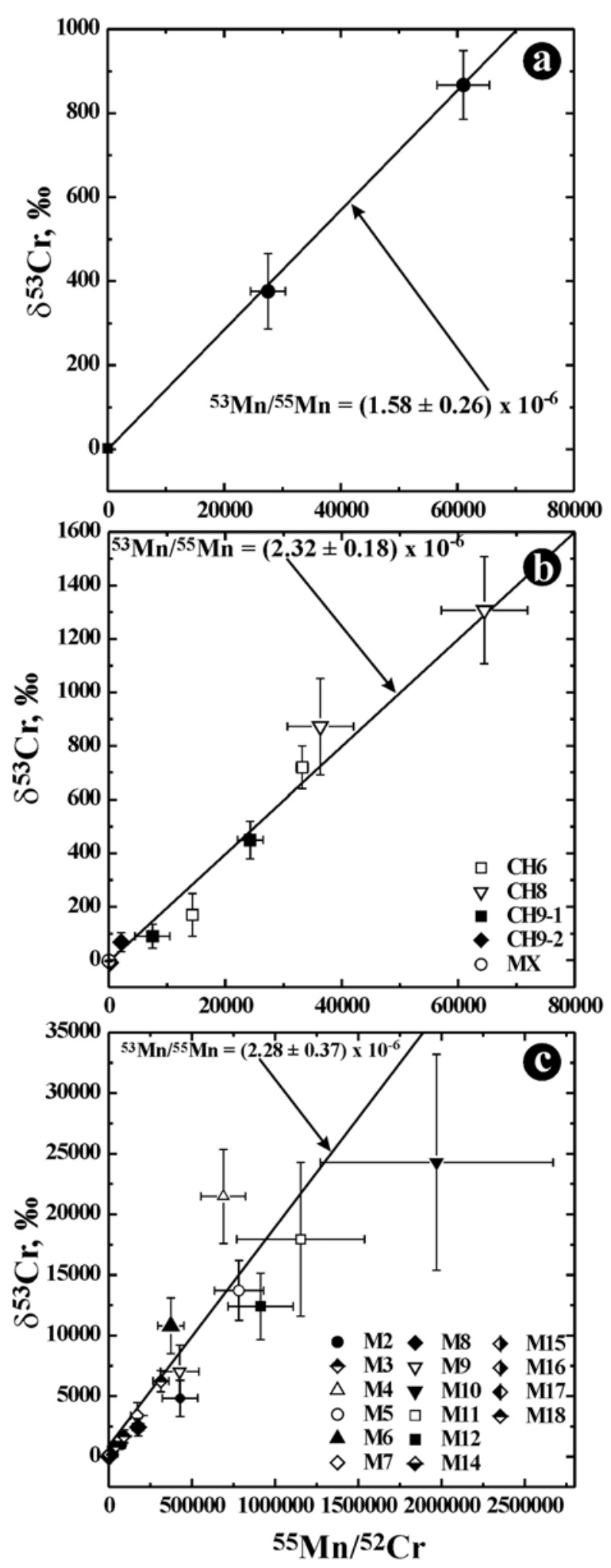
Fig. 7.

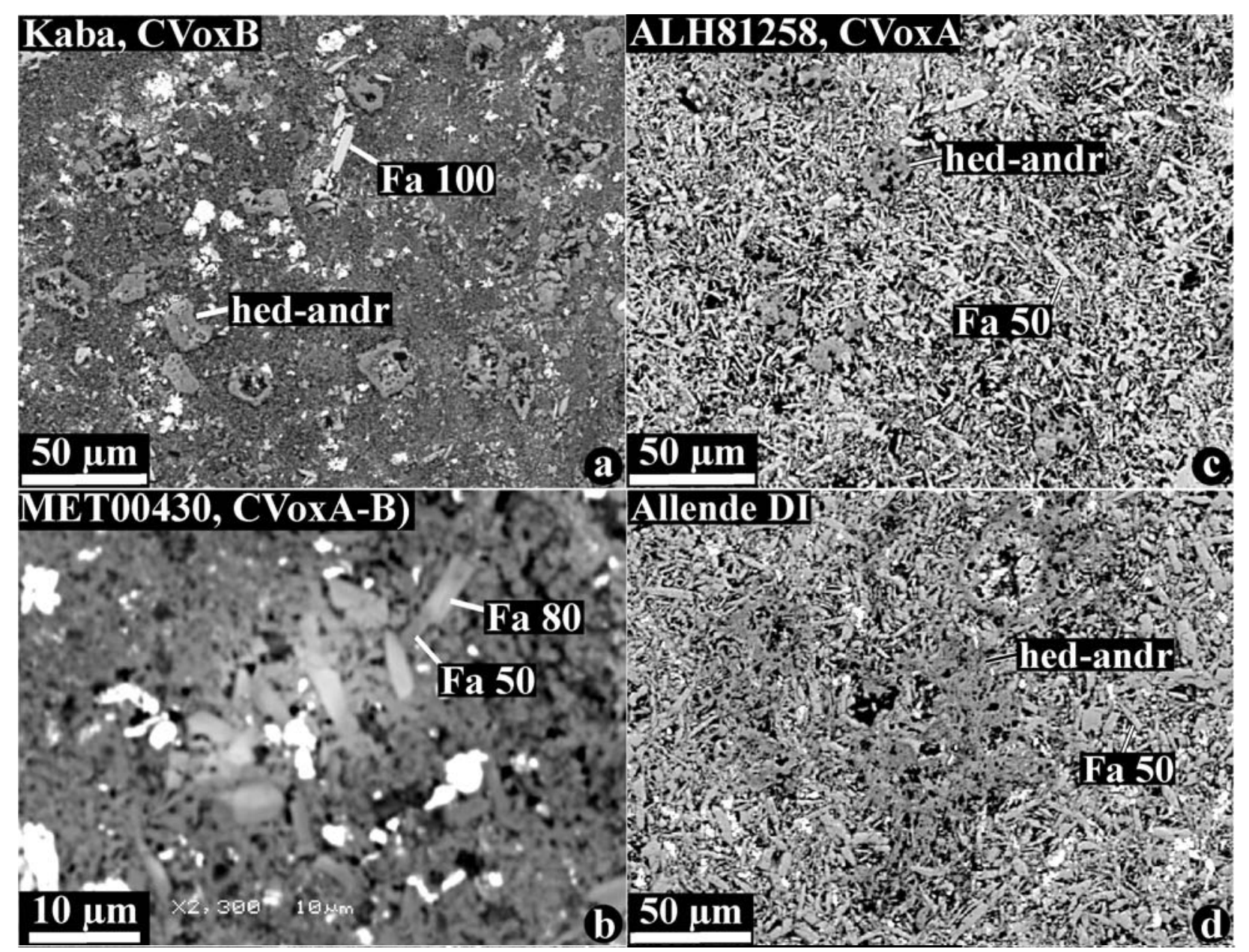


Fig. 8.

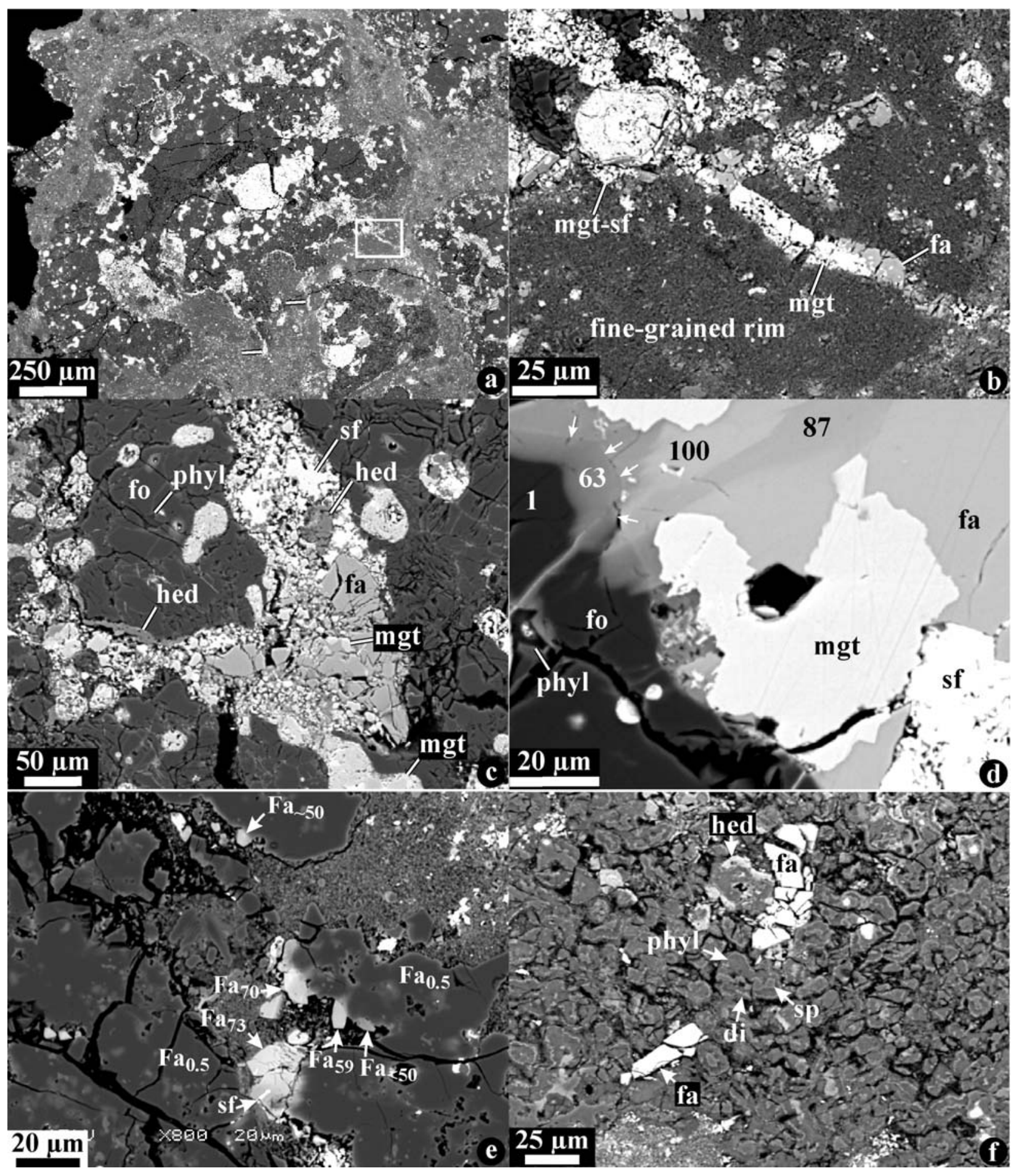


Fig. 9.
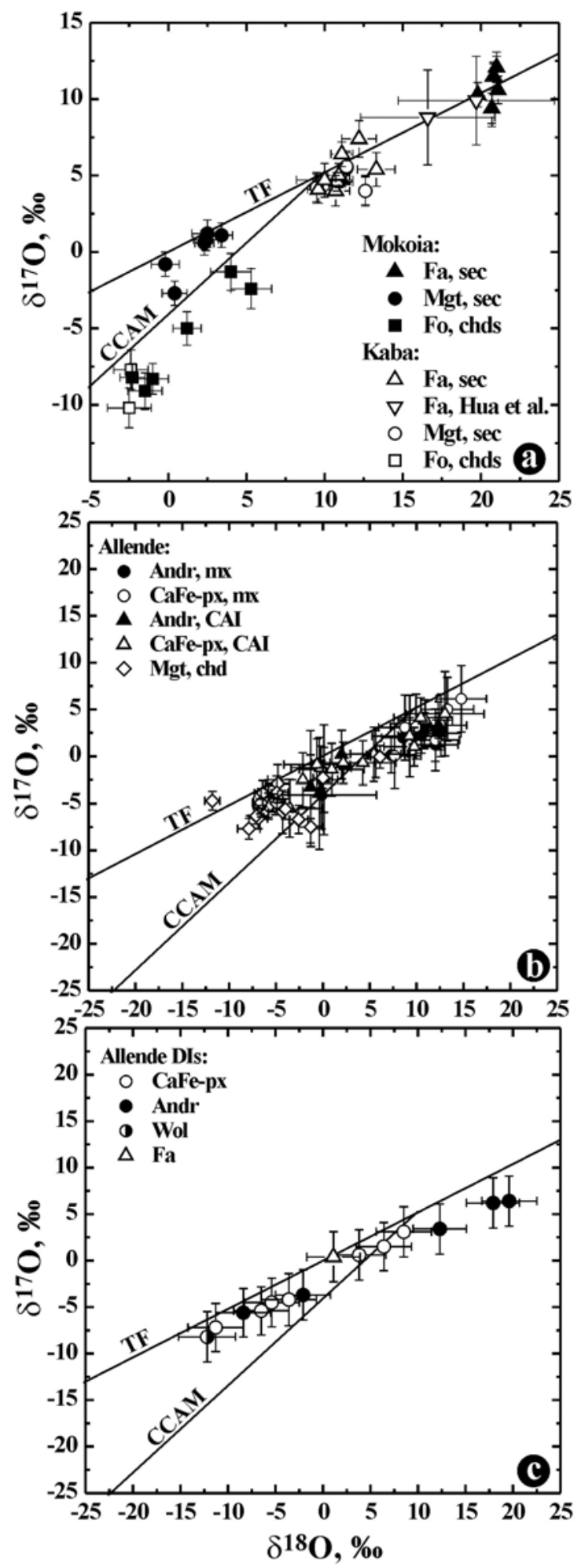
Fig. 10.
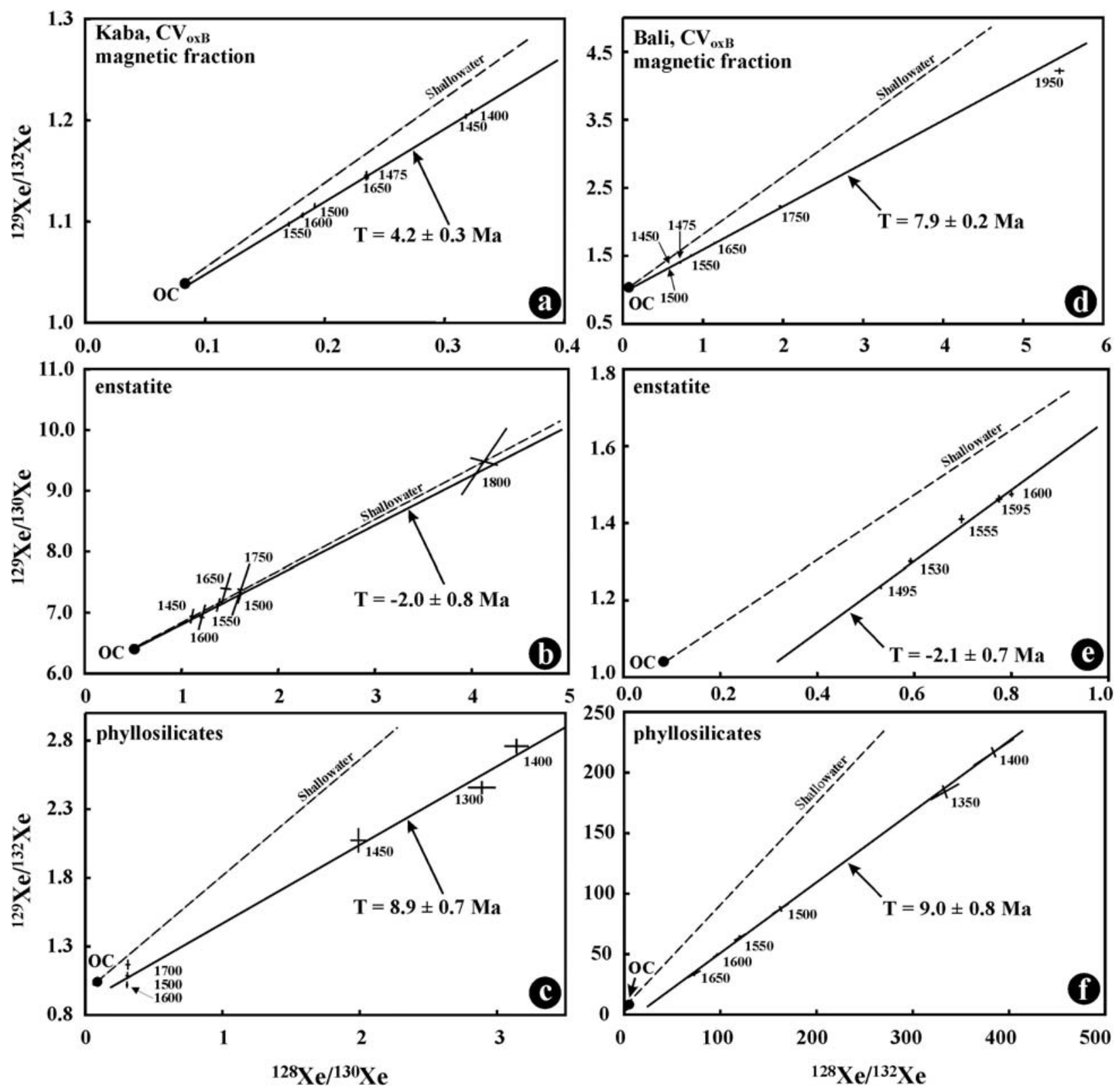
Fig. 11.

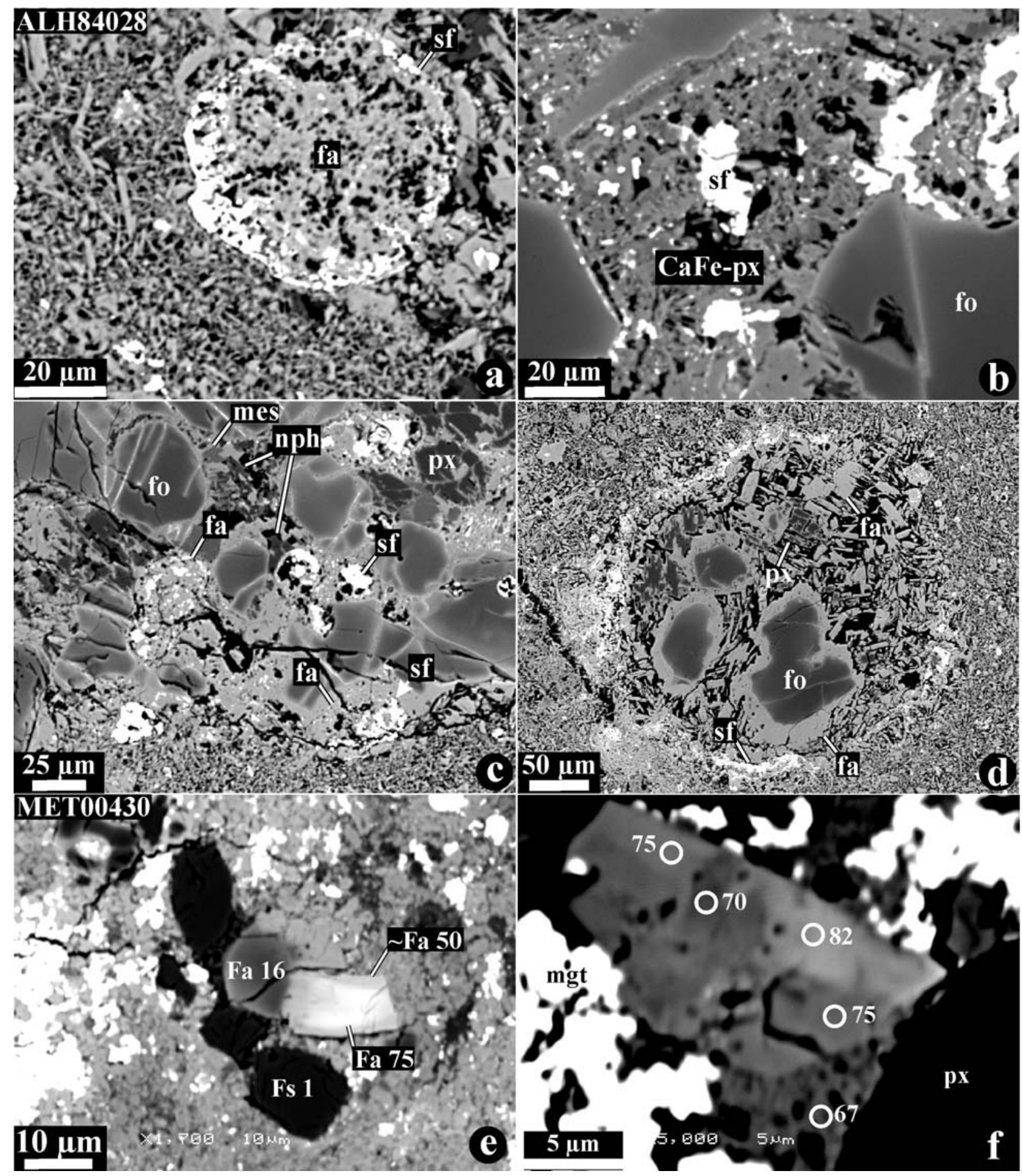


Fig. 12.
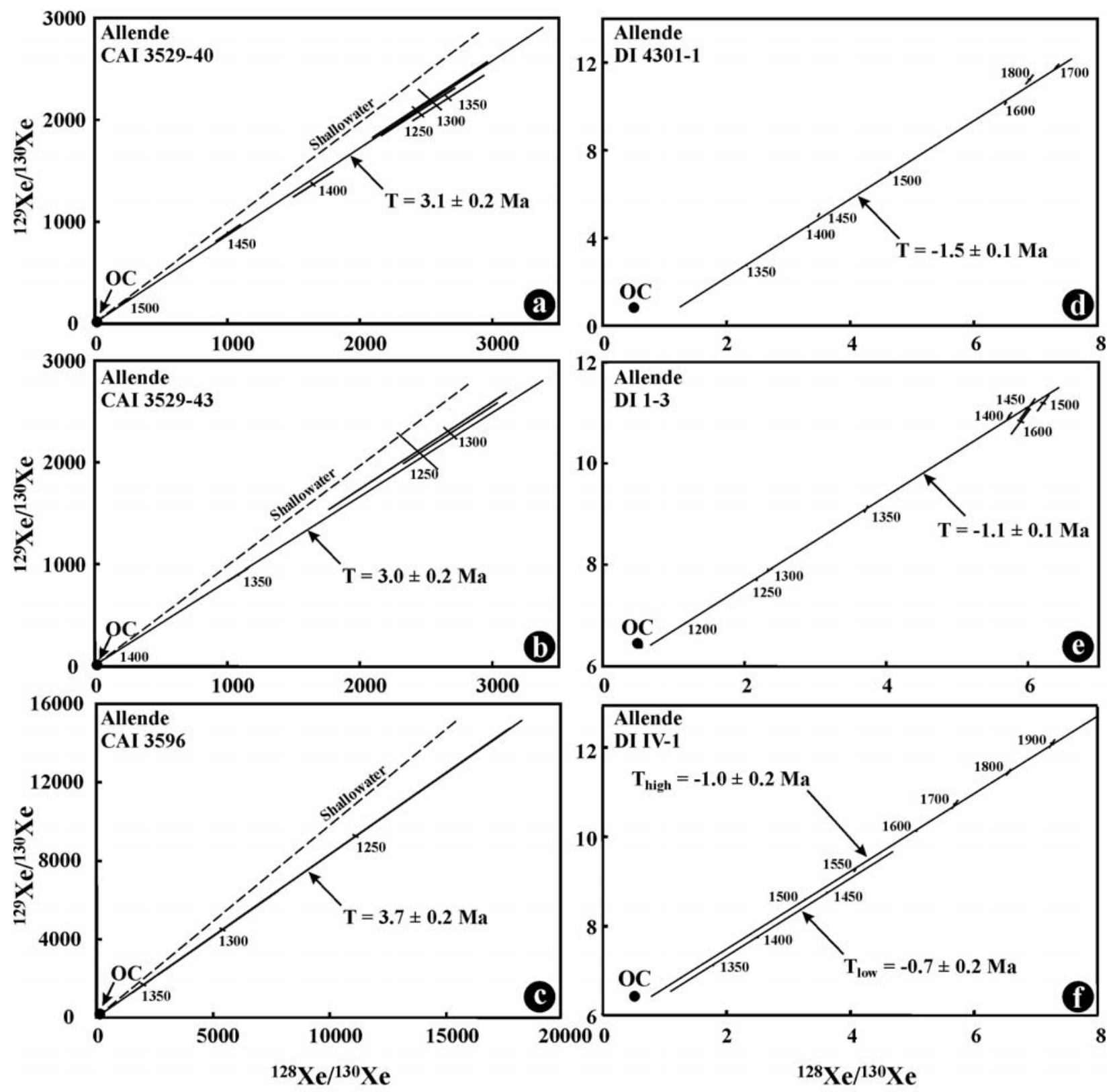
Fig. 13.

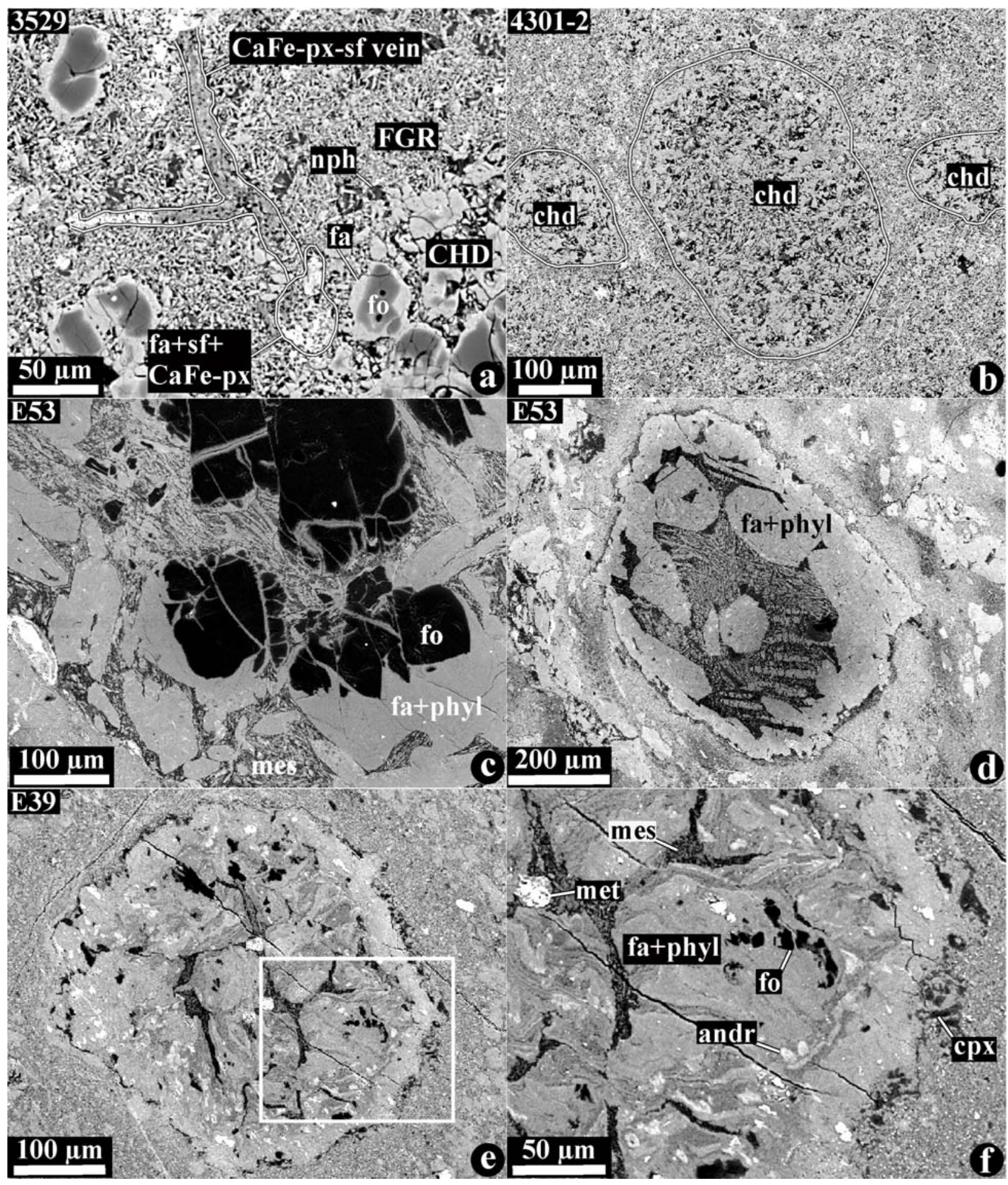


Fig. 14.

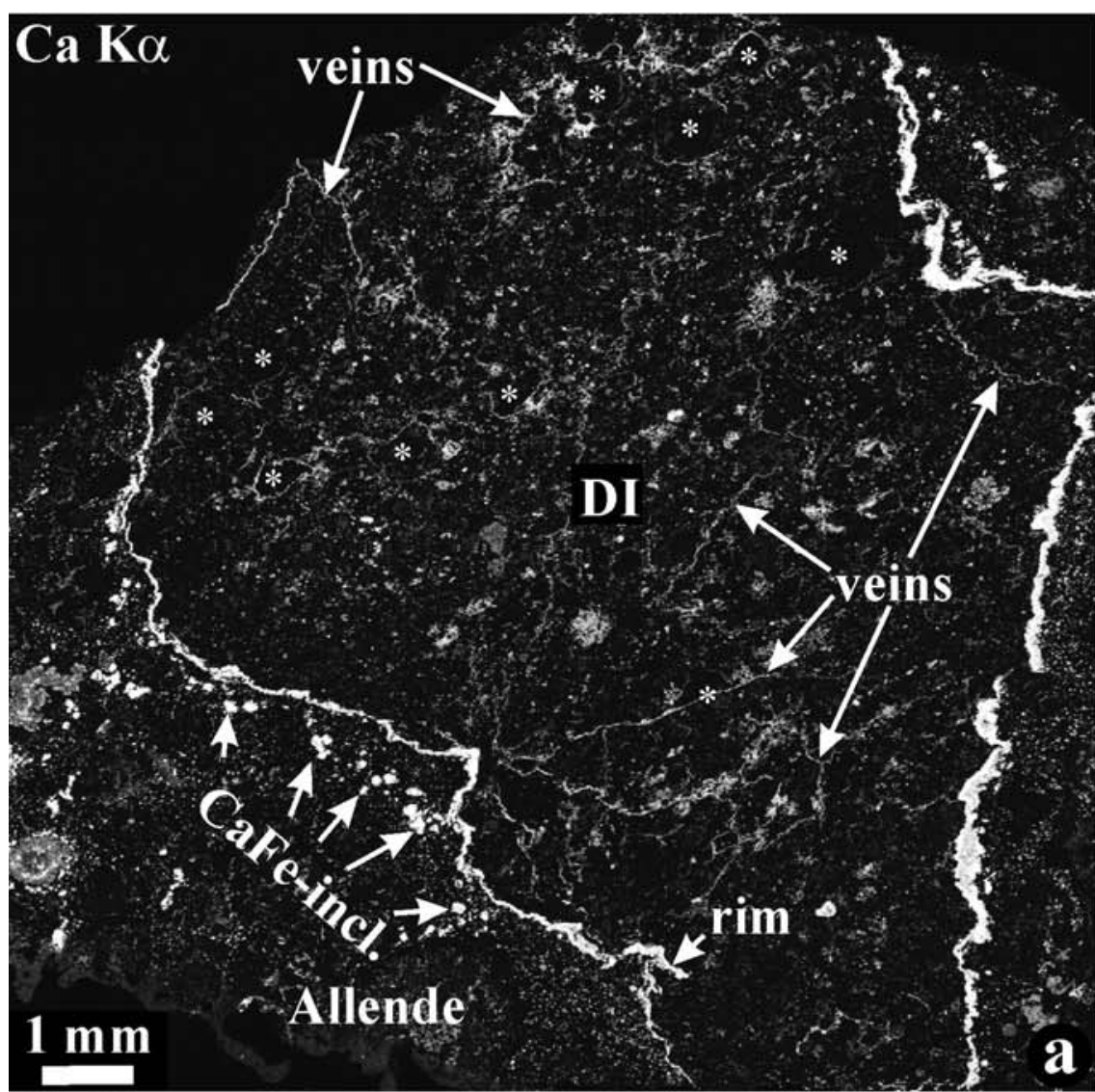

Ca K $\alpha$

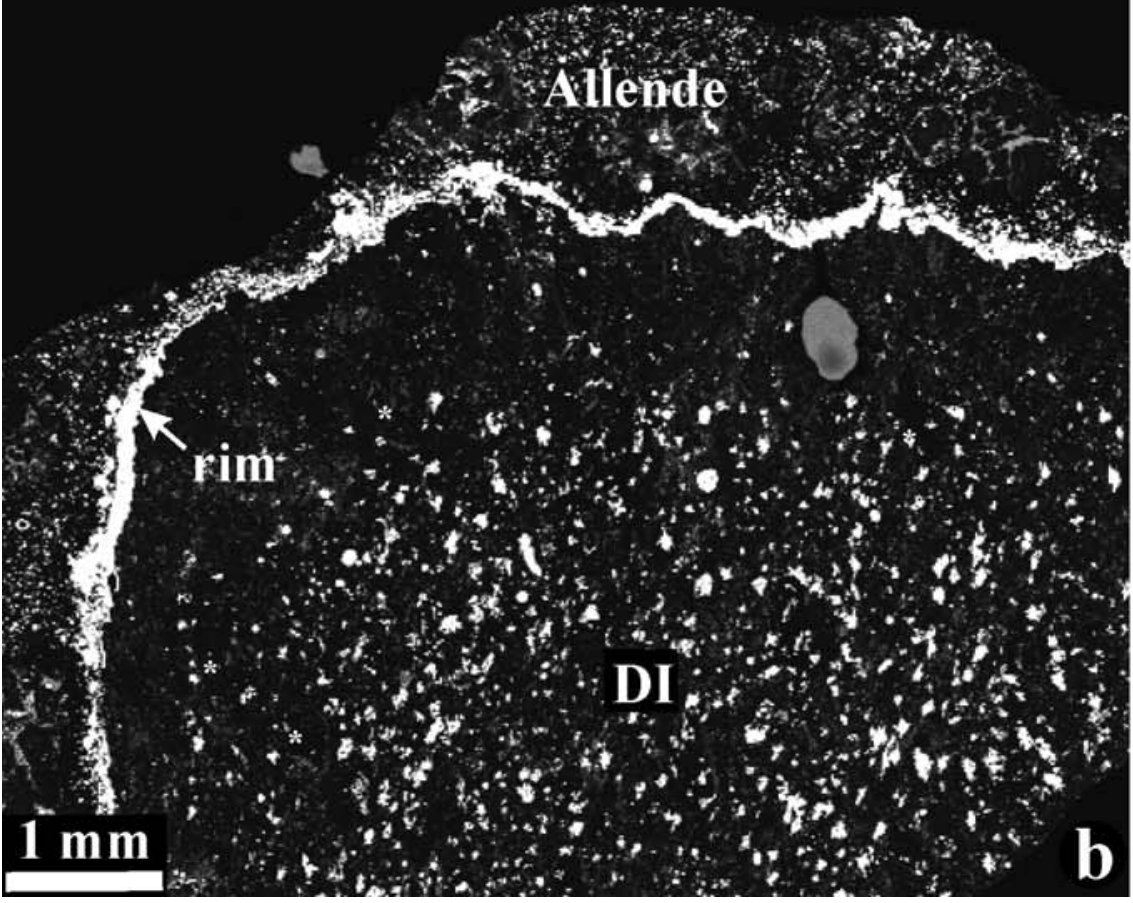


Fig. 15.
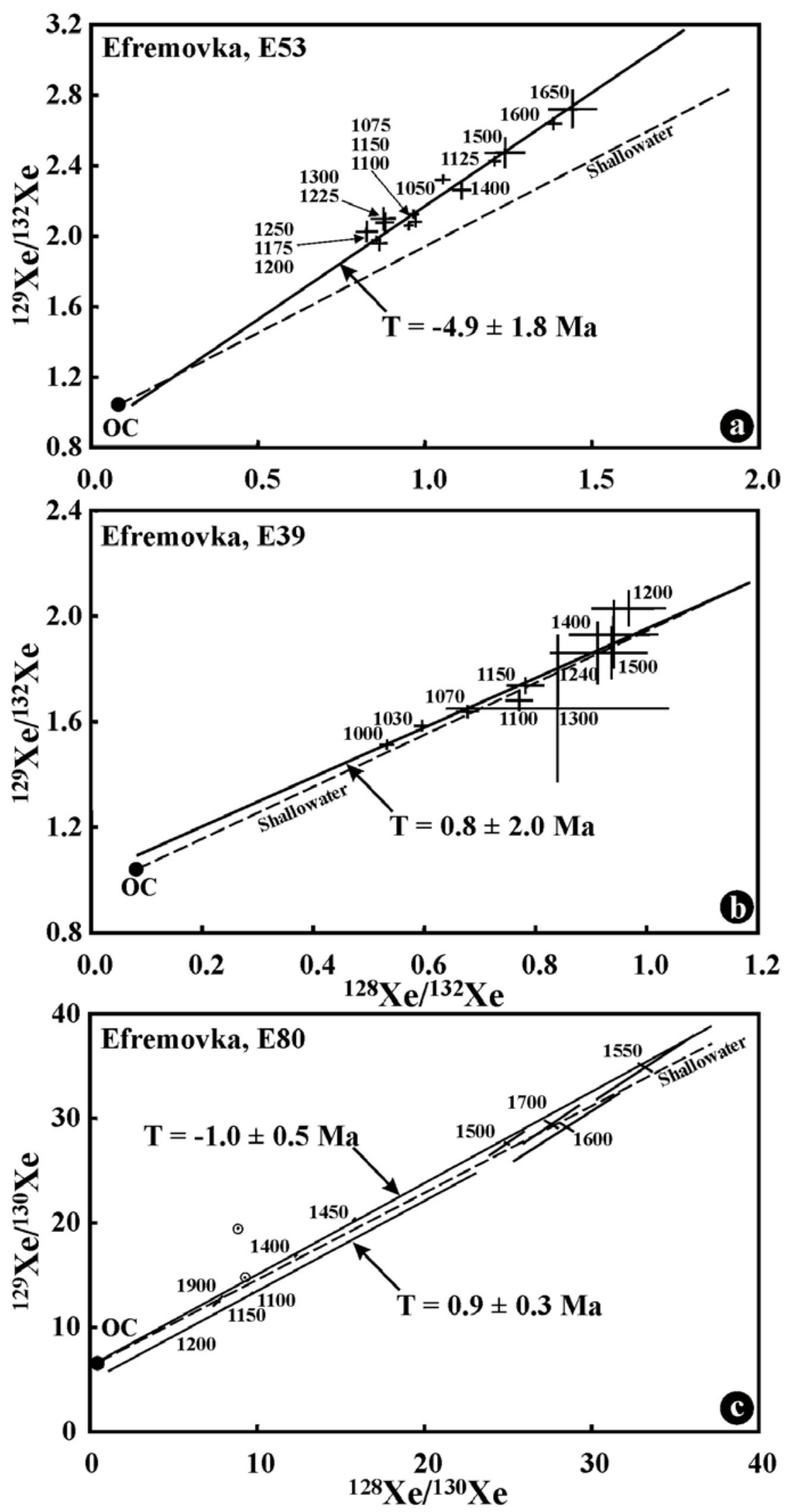
Fig. 16.
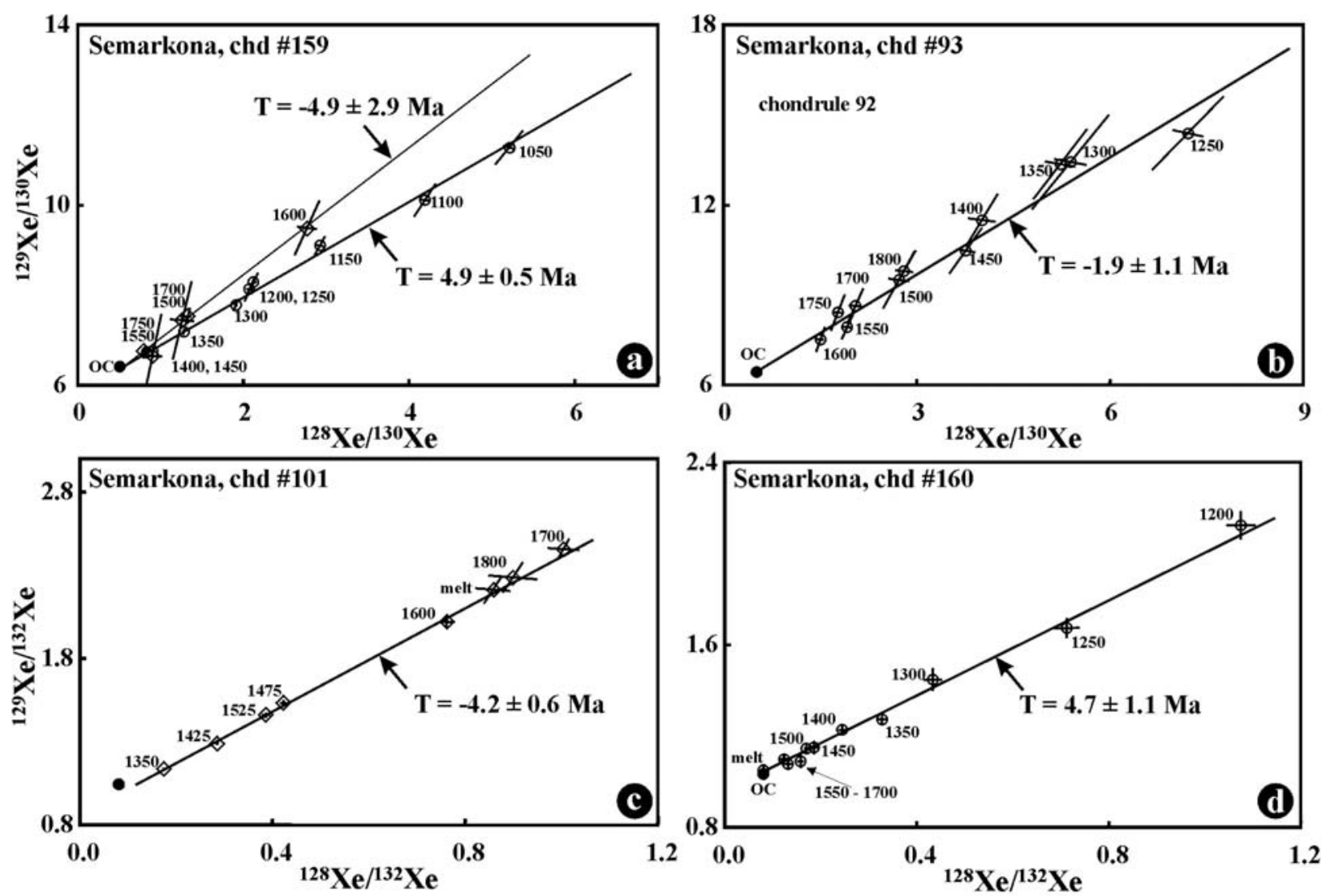
Fig. 17.
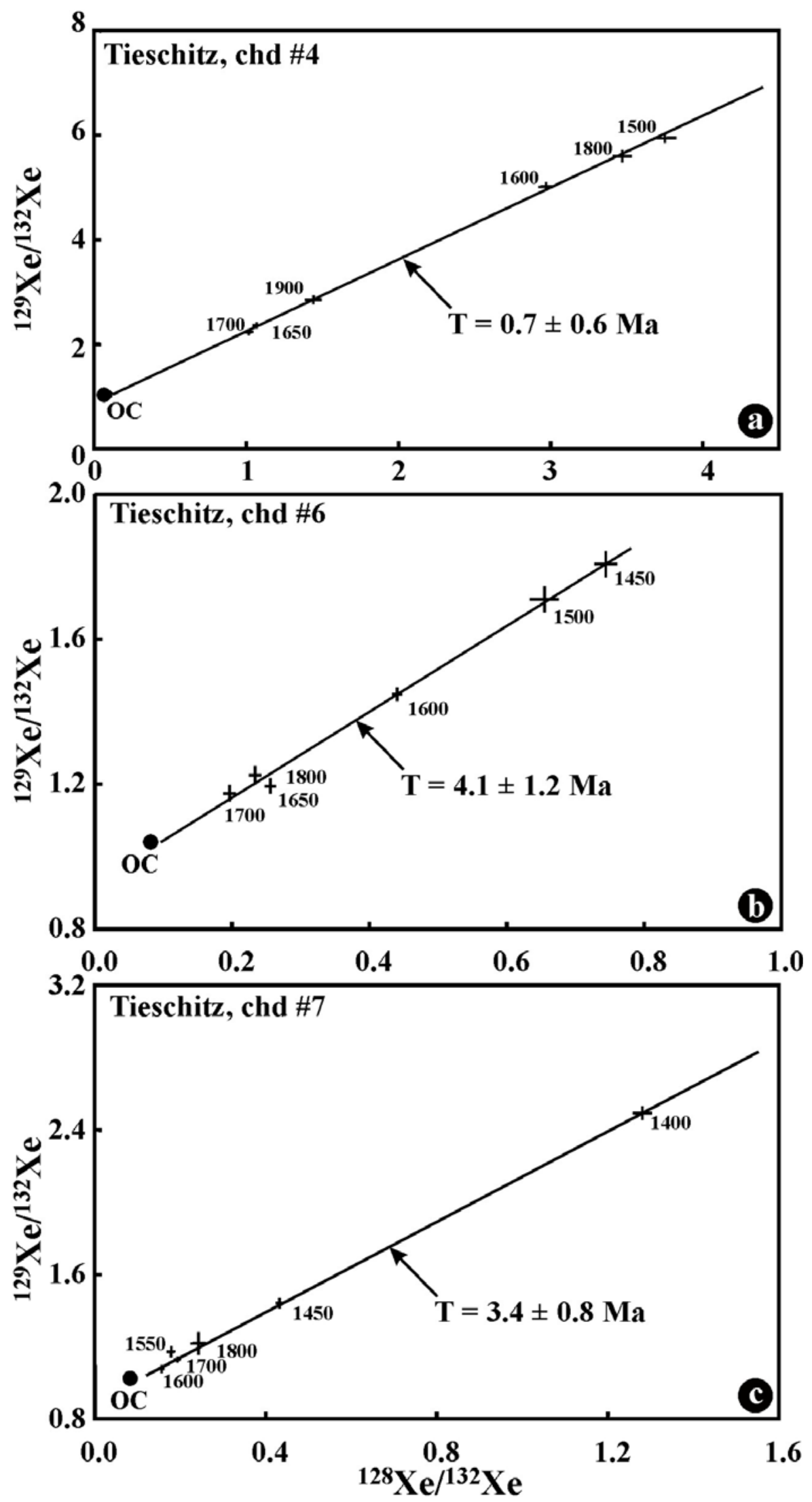
Fig. 18.

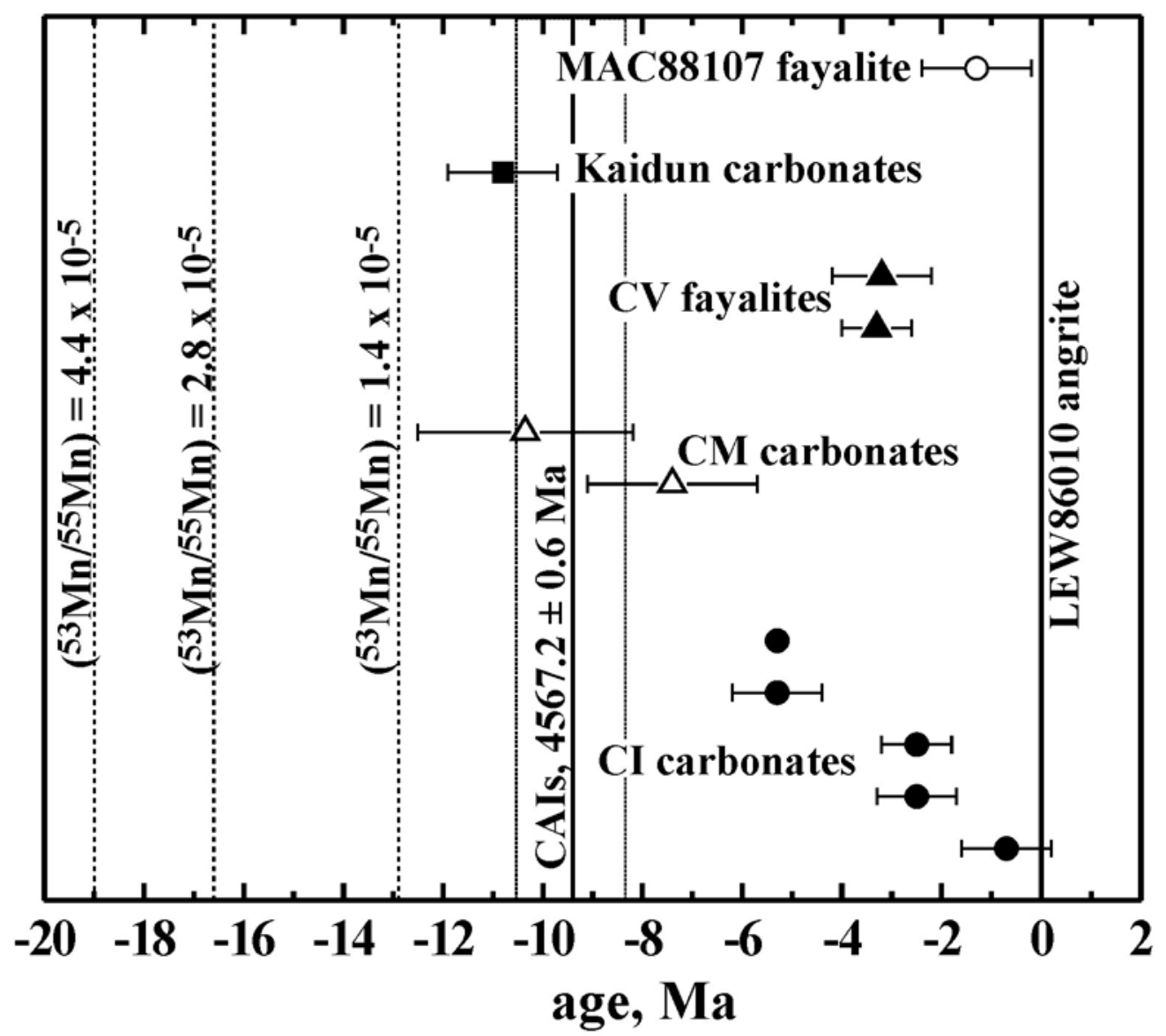


Fig. 19.

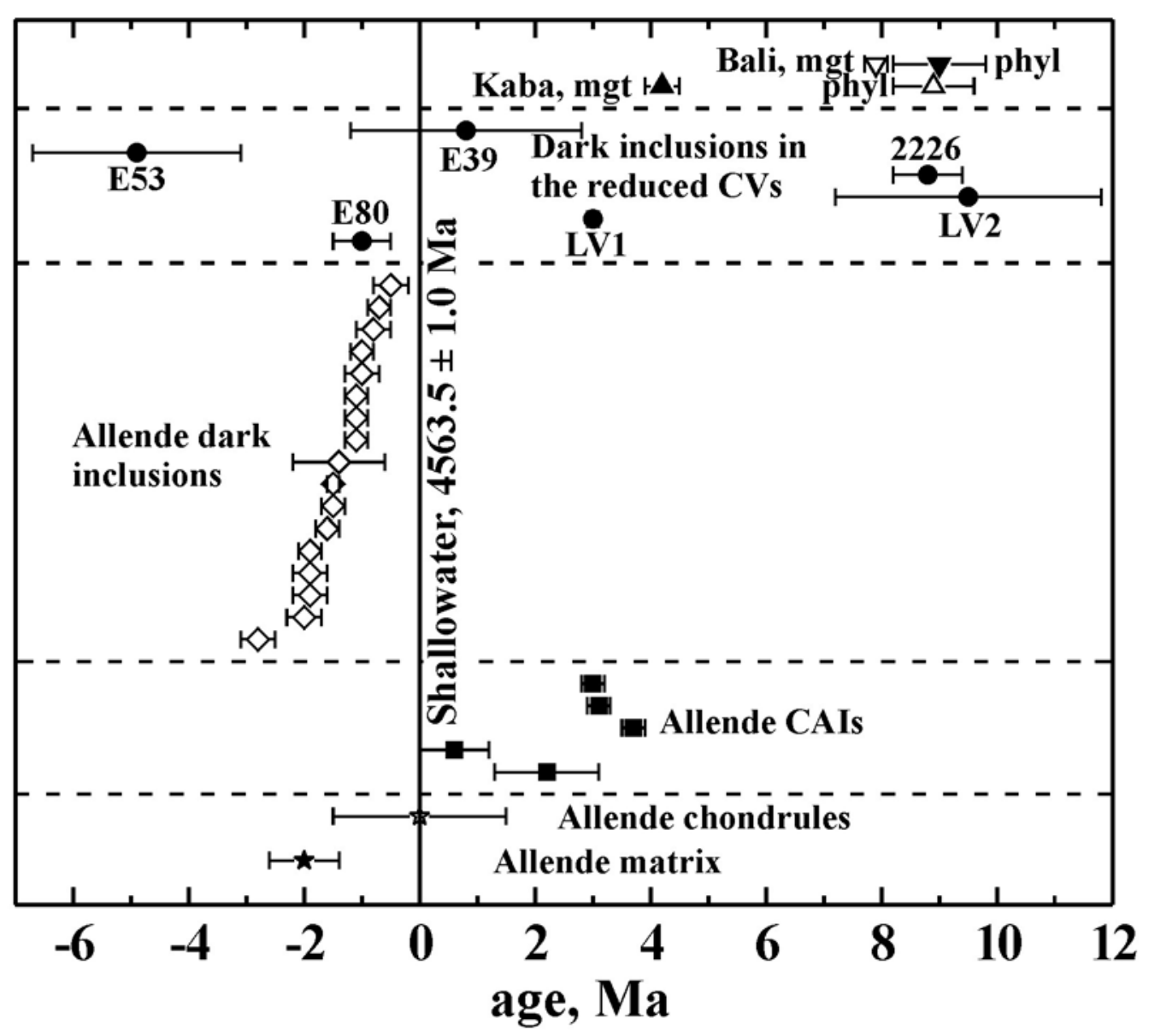

